\title{
Hacia una síntesis biogeográfica de México
}

\section{Toward a synthesis of Mexican biogeography}

\author{
Juan J. Morrone
}

Museo de Zoología “Alfonso L. Herrera”, Departamento de Biología Evolutiva, Facultad de Ciencias, Universidad Nacional Autónoma de México (UNAM), Apartado postal 70-399, 04510 México, D.F. México.

Correspondencia:jjm@hp.fciencias.unam.mx

Resumen. El reconocimiento de componentes bióticos constituye una primera etapa hacia una teoría biogeográfica sintética. En México podemos caracterizar 3 componentes bióticos principales, cada uno con una combinación diferente de elementos bióticos. El componente Neártico (región Neártica) incluye las áreas áridas subtropicales del norte del país, en las provincias biogeográficas de California, Baja California, Sonora, Altiplano Mexicano y Tamaulipas. En este componente predomina el elemento original (Septentrional Antiguo o Paleoamericano), junto con otro de dispersión más reciente (Neártico) y un tercero Neotropical Antiguo. Los eventos vicariantes asociados con la evolución biótica del componente Neártico se relacionan con la formación de la Sierra Madre Occidental, que aisló el desierto de Chihuahua de los desiertos de Sonora y Mohave; y la expansión del Mar de Cortés, que aisló la Península de Baja California del continente. El componente Transicional (Zona de Transición Mexicana) incluye las áreas básicamente montañosas del centro del país, que se asignan a las provincias biogeográficas de la Sierra Madre Oriental, Sierra Madre Occidental, Eje Volcánico Transmexicano, Cuenca del Balsas y Sierra Madre del Sur. En este componente coexisten los elementos Paleoamericano, Neártico, Mesoamericano Tropical y Mesoamericano de Montaña. Los eventos vicariantes asociados con la evolución biótica del componente Transicional se relacionan con el desarrollo de las Sierras Madre y el vulcanismo del Eje Volcánico Transmexicano. El componente Neotropical (región Neotropical) incluye áreas tropicales húmedas y subhúmedas del sur de México, asignadas a las provincias biogeográficas de la Costa Pacífica Mexicana, Golfo de México, Chiapas y Península de Yucatán. En éste predomina el elemento Mesoamericano Tropical, aunque también presenta los elementos Neártico y Antillano. Los eventos vicariantes asociados con la evolución biótica del componente Neotropical se relacionan con el desarrollo de los istmos de Tehuantepec y Panamá y la inundación de las tierras bajas de Nicaragua y de la Península de Yucatán.

Palabras clave: biogeografía, evolución, Neártico, Neotrópico.

Abstract. Recognition of biotic components constitutes the first step toward a synthetic biogeographic theory. In Mexico we can characterize three main biotic components, each one having a particular combination of different biotic elements. The Nearctic component (Nearctic region) includes the arid subtropical areas in the north of the country, in the Californian, Baja Californian, Sonoran, Mexican Plateau and Tamaulipan biogeographic provinces. This component is dominated by the original element (Old Northern or Paleoamerican), together with one of more recent dispersal (Nearctic) and a third of ancient Neotropical origin. Vicariant events associated with the biotic evolution of the Nearctic component are related to the uplift of the Sierra Madre Occidental, which separated the Chihuahuan desert from the Sonoran and Mojave deserts; and the expansion of the Sea of Cortes, separating the Peninsula of Baja California from the continental mainland. The Transitional component (Mexican Transition Zone) includes basically montane areas in central Mexico, which are assigned to the Sierra Madre Oriental, Sierra Madre Occidental, Transmexican Volcanic Belt, Balsas basin and Sierra Madre del Sur biogeographic provinces. In this component, the Paleoamerican, Nearctic, Tropical Mesoamerican and Montane Mesoamerican elements coexist. Vicariant events associated with the biotic evolution of the Transitional component are the development of the Sierras Madre and the volcanism of the Transmexican Volcanic Belt. The Neotropical component (Neotropical region) includes humid and subhumid tropical areas of southern Mexico, assigned to the Mexican Pacific Coast, Mexican Gulf, Chiapas and Yucatan Peninsula biogeographic provinces. In it the Tropical Mesoamerican element predominates, but Nearctic and Antillean elements are also present. Vicariant events associated with the biotic evolution of the Neotropical component are related to the development of the isthmuses of Tehuantepec and Panama, and the inundation of the lowlands of Nicaragua and the Yucatan Peninsula.

Key words: biogeography, evolution, Nearctic, Neotropics.

Recibido: 30 julio 2005; aceptado: 23 septiembre 2005 


\section{Introducción}

Resulta llamativo que las distribuciones geográficas de los seres vivos posean límites y que éstos se repitan para taxones diferentes. Este patrón biogeográfico permite el reconocimiento de componentes bióticos, los que pueden definirse como conjuntos de taxones integrados espaciotemporalmente debido a una historia común, que caracterizan áreas geográficas. Dado que los componentes bióticos son parte de otros componentes mayores y a su vez incluyen otros menores, pueden ser ordenados jerárquicamente en un sistema de reinos, regiones, subregiones, dominios, provincias y distritos (Espinosa-Organista et al., 2001). Esta regionalización biogeográfica, sustentada en la homología biogeográfica primaria (los trazos generalizados reconocidos por la panbiogeografía) y contrastada por la homología biogeográfica secundaria (los cladogramas generales de áreas de la biogeografía cladística), resulta básica para una comprensión adecuada de la evolución biótica de nuestro planeta (Morrone, 2004a). Los componentes bióticos rara vez poseen un origen "único", sino que usualmente son conjuntos de elementos de afinidades diferentes, que se han integrado en el curso de la evolución biótica (Brooks, 2005). Es posible identificar estos elementos bióticos, teniendo en cuenta las relaciones filogenéticas de los taxones involucrados, análisis filogeográficos, relojes moleculares y, cuando existen, fósiles.

Algunos componentes bióticos poseen una composición biótica particularmente compleja, constituyendo zonas de transición (Darlington, 1957; Palestrini y Zunino, 1986; Halffter, 1987; Morrone, 2004c). Éstas se localizan en los límites entre regiones biogeográficas y representan eventos de "hibridación" biótica, promovidos por cambios históricos y ecológicos que permiten la interacción entre elementos bióticos diferentes. Desde una perspectiva evolutiva, las zonas de transición merecen especial atención, pues más que líneas estáticas, los límites entre regiones biogeográficas representan áreas de interacción biótica intensa (Ruggiero y Ezcurra, 2003). En los análisis panbiogeográficos, las zonas de transición se detectan por la presencia de nodos o áreas donde convergen trazos generalizados diferentes (Escalante et al., 2004; Morrone, 2004c; Morrone y Gutiérrez, 2005). En los análisis biogeográficos cladísticos, las posibles zonas de transición poseerán relaciones conflictivas, pues resultarán ser simultáneamente áreas hermanas de áreas o conjuntos de áreas diferentes, tal como les sucede a las especies híbridas en los análisis filogenéticos, resultando así en politomías en los cladogramas generales de áreas.

Algunos autores (Ringuelet, 1961; Reig, 1981; Halffter, 1987) reconocieron, aunque empleando una nomenclatura diferente, componentes y elementos bióticos. Estos conceptos, sin embargo, no han sido empleados por panbiogeógrafos y biogeógrafos cladistas, quizá preocupados por su aparente tono "dispersalista". Aquí reivindico el reconocimiento de componentes y elementos bióticos como parte fundamental de los análisis biogeográficos históricos, los cuales comprenderían los siguientes pasos sucesivos: (1) reconocer componentes bióticos basados en la homología biogeográfica primaria (análisis panbiogeográficos); (2) contrastar dichos componentes a partir del análisis de la homología biogeográfica secundaria (análisis biogeográficos cladísticos); (3) establecer un arreglo jerárquico de los componentes en reinos, dominios, provincias, distritos, etc.; (4) reconocer los elementos bióticos que han contribuido a los componentes; y 5) proponer un escenario geobiótico que explique la integración y evolución de componentes y elementos.

México constituye un área ideal para llevar a cabo análisis biogeográficos. Si bien durante el siglo XIX se realizaron algunas contribuciones importantes a la biogeografía de México (Humboldt, 1820; Martens y Galeotti, 1842; Ramírez, 1899), es en el siglo XX cuando identificamos numerosos trabajos descriptivos $\mathrm{y}$ análisis empleando enfoques dispersalistas, fenéticos, panbiogeográficos y cladísticos. Entre los principales se encuentran: Hoffmann (1922, 1936), Smith (1941), Dice (1943), Goldman y Moore (1945), Barrera (1962), Halffter (1962, 1964a, b, 1965, 1972, 1974, 1976, 1978, 1987, 2003), Ryan (1963), Stuart (1964), Reyes-Castillo (1970, 1978), Cabrera y Willink (1973), Müller (1973), Rzedowski (1973, 1978), Good (1974), Rosen (1976, 1978), Savage (1982), Kohlmann y Sánchez (1984), Kohlmann y Halffter (1988), Samek (1988), FerrusquíaVillafranca (1990), Casas-Andreu y Reyna-Trujillo (1990), Ramírez-Pulido y Castro-Campillo (1990), Rzedowski y Reyna-Trujillo (1990), Liebherr (1991, 1994a), Morón (1991, 1992), Ball (1992), Morafka et al. (1992), Grismer (1994), Álvarez-Castañeda et al. (1995), Dinerstein et al. (1995), Halffter et al. (1995), Hernández-Baños et al. (1995), Crother y Guyer (1996), Llorente-Bousquets (1996), Arriaga et al. (1997), Escalante et al. (1998), Sánchez-Osés y Pérez-Hernández (1998, 2005), Campbell (1999), Luna Vega et al. (1999, 2001), Morrone (1999, 2001a, b, 2002c, 2004a, b), Morrone et al. (1999), Espinosa-Organista et al. (2000), Lobo y Halffter (2000), Marshall y Liebherr (2000), Zink et al. (2000), Contreras-Medina y Eliosa-León (2001), Flores-Villela y Goyenechea (2001), Morrone y Márquez (2001, 2003), Zink (2002), Aguilar-Aguilar et al. (2003, 2005), Garcillán et al. (2003), Márquez y Morrone (2003), Reyes-Castillo (2003), Rojas-Soto et al. (2003), Escalante et al. (2004), Katinas et al. (2004), Brooks (2005), Corona et al. (2005), Morrone y Gutiérrez (2005), Pérez-Ponce de León y Choudhoury (2005), y Rosas-Valdés y Pérez-Ponce de León (2005). Estas contribuciones han proporcionado claves para comprender cómo se estructuran espacialmente y evolucionan los componentes y elementos bióticos del territorio mexicano, pero debido a que los enfoques en que se basan son aparentemente contradictorios, hasta el momento no han sido integradas en una teoría coherente. 
En este ensayo reviso algunas contribuciones biogeográficas, discuto sus aportes principales al reconocimiento de componentes y elementos bióticos, y las integro en un conjunto de hipótesis generales que pretenden explicar la evolución espacial de la biota mexicana.

\section{Antecedentes}

La revisión exhaustiva de todas las contribuciones biogeográficas publicadas hasta la fecha iría más allá del carácter de este ensayo. Para discutir en mayor detalle he seleccionado algunas del siglo XX, a la vez que comento brevemente otras.

Smith (1941). En julio de 1939 se llevó a cabo en México, D.F. el Primer Congreso Nacional de Geografía y Exploraciones Geográficas, organizado por la Secretaría de Educación
Pública. El encargado de la Sección de Biogeografía invitó a diversos especialistas del país y extranjeros a enviar contribuciones. El esquema biogeográfico de $\mathrm{H}$. Smith fue publicado en 1941 en los Anales de la Escuela Nacional de Ciencias Biológicas. Smith (1941) consideró que las especies de lagartijas del género Sceloporus constituían un grupo ideal para analizar la biogeografía de México, debido a su gran diversidad, su intervalo altitudinal (desde el nivel del mar hasta $3800 \mathrm{~m}$ ), su presencia en prácticamente todos los hábitats terrestres y lo poco que su distribución geográfica ha sido afectada por factores ambientales y el hombre.

Smith (1941) reconoció 23 provincias biogeográficas (Fig. 1), las que clasificó en 2 regiones y 3 subregiones:

Región Neártica

Subregión de las Montañas Rocosas

1. Provincia de la Altiplanicie Oaxaqueña $(\mathrm{OH})$ : porción elevada y pequeña, constituida mayoritariamente por planicies con pastizales, que se sitúa en la parte superior del río Balsas

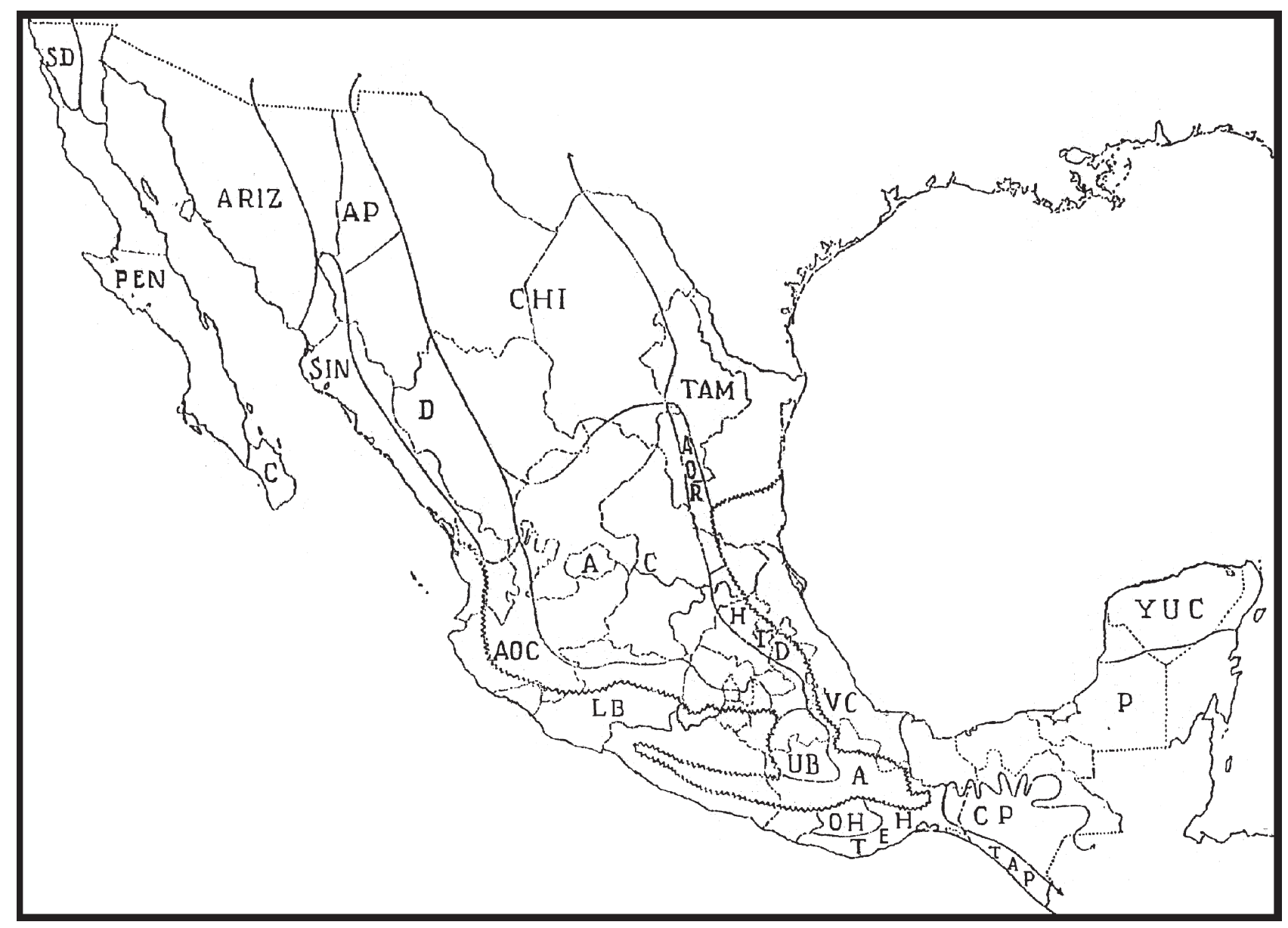

Figura 1. Provincias reconocidas en el esquema biogeográfico de Smith (1941). La línea festoneada indica el límite entre las regiones Neártica y Neotropical. A, Guerrerense; AC, Austro-Central; AOC, Austro-Occidental; AOR, Austro-Oriental; AP, Apachiana; ARIZ, Arizoniana; C, del Cabo de Baja California; CHI, Chihuahuense; CP, de la Altiplanicie Chiapaneca; D, Durangueña; HID, Hidalguense; LB, del Balsas Inferior; OH, de la Altiplanicie Oaxaqueña; P, del Petén; PEN, Peninsular; SD, Sandieguina; SIN, Sinaloense; TAM, Tamaulipeca; TAP, Tapachulteca; TEH, Tehuana; UB, del Balsas Superior; VC, Veracruzana; YUC, Yucateca. 
y se extiende hacia el sur hasta el río Tehuantepec.

2. Provincia Guerrerense (A): porción sur de la altiplanicie al sur del río Balsas, en los estados de Guerrero y Oaxaca, que se extiende hacia el norte por el lado oriental hasta El Mirador (Veracruz) y hacia el sur hasta el Istmo de Tehuantepec. Dentro de ésta se reconocen dos secciones: Oriental y Occidental.

3. Provincia del Balsas Superior (UB): área desértica o semiárida, que limita con el extremo austral de la Altiplanicie Mexicana, ocupando la parte superior de la cuenca del río Balsas. De acuerdo con el autor, esta provincia conecta las regiones Neártica y Neotropical.

4. Provincia Austro-Central (AC): área amplia y uniforme, situada en el centro de la Altiplanicie Mexicana, rodeada por el este, sur y oeste por cadenas montañosas. En el noroeste, esta provincia se fusiona con la provincia Chihuahuense.

5. Provincia Austro-Occidental (AOC): área montañosa situada en el borde suroeste de la Altiplanicie Mexicana, que se extiende desde el norte de Nayarit hasta Jalisco, el sur del Distrito Federal y el norte de Puebla. Dentro de esta provincia se reconocen tres secciones: Occidental, Central y Oriental.

6. Provincia Austro-Oriental (AOR): norte de la región montañosa que forma el ángulo oriental de la Meseta Central.

7. Provincia Hidalguense (HID): sección sur de la región montañosa del borde oriental de la Meseta Central.

8. Provincia Chihuahuense (CHI): área central al norte de la provincia Austro-Central, al este de la Sierra Madre Occidental y al oeste de la provincia Tamaulipeca. Dentro de esta provincia se reconocen tres secciones: Occidental, Central y Oriental.

9. Provincia Sinaloense (SIN): región costera desde el sur de Sonora hasta el sur de Mazatlán.

10. Provincia Tamaulipeca (TAM): región costera ancha que llega hasta el Trópico de Cáncer.

11. Provincia Arizoniana (ARIZ): parte occidental del estado de Sonora y el noroeste de Baja California.

12. Provincia Apachiana (AP): ángulo occidental montañoso de la meseta que se extiende desde el centro de Chihuahua hasta el sureste de Arizona.

13. Provincia Durangueña (D): montañas de la Sierra Madre Occidental desde el centro de Chihuahua hasta el norte de Nayarit.

14. Provincia de Baja California (PEN): la mayor parte de la península de Baja California, con excepción del extremo sur, que corresponde a la provincia del Cabo, y el extremo norte, que corresponde a las provincias Sandieguina y Arizoniana. 15. Provincia del Cabo de Baja California (C): extremo sur de la península de Baja California, al sur y este de la isla de Espíritu Santo.

Subregión Californiana

16. Provincia Sandieguina (SO): centro y norte de Baja California al norte del paralelo de $30^{\circ}$.
Región Neotropical

Subregión Mexicana

17. Provincia de la Altiplanicie Chiapaneca $(\mathrm{CP})$ : región elevada que se extiende al oeste hasta el Istmo de Tehuantepec $\mathrm{y}$ al este hacia el interior de Guatemala.

18. Provincia Tapachulteca (TAP): región costera al sur de la provincia anterior, que se extiende desde la frontera occidental de Chiapas hasta Guatemala. Dentro de esta provincia se reconocen dos secciones: Norte y Sur.

19. Provincia del Petén (P): área septentrional de la Altiplanicie Chiapaneca, incluyendo la vertiente del Golfo de México en el Istmo de Tehuantepec. Hacia el norte se extiende hasta el paralelo de $20^{\circ}$ de latitud norte y al este hasta Guatemala y Belice.

20. Provincia Yucateca (YUC): península de Yucatán al norte del paralelo de $20^{\circ}$ de latitud norte.

21. Provincia Veracruzana (VC): área costera al norte del río Papaloapan hasta el Trópico de Cáncer.

22. Provincia Tehuana (TEH): región semiárida del estado de Oaxaca, que se extiende desde la Altiplanicie Oaxaqueña y la provincia Guerrerense al sur hacia la costa, al este hasta los límites del estado de Chiapas y al oeste aproximadamente hasta el río Verde.

23. Provincia del Balsas Inferior (LB): área extendida a lo largo de las costas del Pacífico desde el río Verde en Oaxaca hasta el sur de Mazatlán en Sinaloa, extendiéndose por el río Balsas hasta el norte de Oaxaca y el suroeste de Puebla.

El esquema biogeográfico de Smith (1941) es bastante detallado, aunque dado que se restringe a México, resulta difícil evaluar cómo el autor clasifica a los componentes bióticos que reconoce como provincias en relación con otros situados fuera del territorio nacional. La asignación de 16 provincias a la región Neártica y siete a la Neotropical plantea la existencia del límite entre ambas regiones dentro del territorio mexicano, tal como posteriormente ha sido reconocido por otros autores (Cabrera y Willink, 1973; Müller, 1973; Rzedowski, 1978; Arriaga et al., 1997; Morrone, 1999, 2001a, b). El esquema de Goldman y Moore (1945), basado en mamíferos, posee ciertas semejanzas con el de Smith (1941). El de Ryan (1963), restringido a Mesoamérica, sólo trata componentes del sur de nuestro país.

Cabrera y Willink(1973). Dos autores argentinos, el botánico A. L. Cabrera y el entomólogo A. Willink, publicaron en 1973 una obra muy importante para la comprensión global de la biogeografía americana. Estos autores presentaron un esquema biogeográfico de regiones, dominios, provincias y, en algunos casos, distritos de América Latina y el Caribe, detallando los taxones animales y vegetales de cada área.

Para México, Cabrera y Willink (1973) reconocieron 4 provincias (Fig. 2), las cuales clasificaron en 2 regiones y 3 dominios:

Región Holártica

Dominio Norteamericano Pacífico 


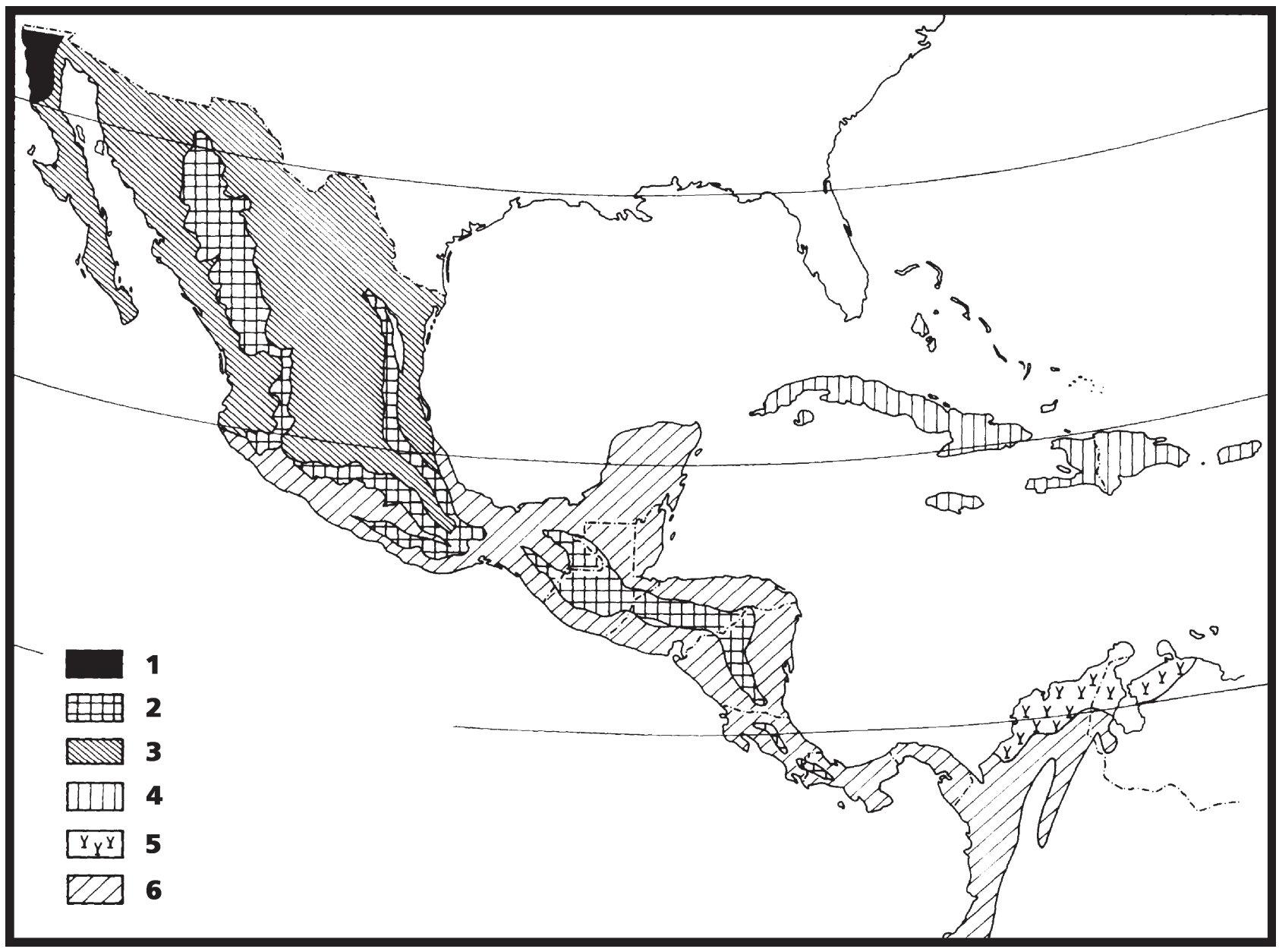

Figura 2. Provincias reconocidas en el esquema biogeográfico de Cabrera y Willink (1973). 1, Bosque Montano; 2, Mesoamericana de Montaña; 3, Xerófila Mexicana; 4, Caribe; 5, Guajira; 6, Pacífica.

1. Provincia del Bosque Montano: abarca desde el suroeste de los Estados Unidos de América, penetrando en México en el norte de la península de Baja California, sobre las montañas de San Pedro Mártir.

Región Neotropical

Dominio Caribe

2. Provincia Mesoamericana de Montaña: ocupa las "tierras frías” de México y América Central, sobre las Sierras Madre Occidental y Oriental y las montañas del sur de México, Guatemala y Panamá. Su altitud varía de acuerdo con la orientación y la latitud, pero usualmente se halla entre 1000 y poco más de $4000 \mathrm{~m}$.

3. Provincia Xerófila Mexicana: ocupa la mayor parte del territorio mexicano, abarcando áreas xéricas con lluvias inferiores a $750 \mathrm{~mm}$ anuales. Dentro de esta provincia, Cabrera y Willink (1973) reconocieron 3 distritos: el Sonoriano, que abarca el estado de Sonora, el norte de Sinaloa y la península de Baja California; el Chihuahuano, que ocupa el Altiplano Mexicano, entre 1000 y 2000 m de altitud; y el Árido del Sur de México, que se encuentra en la porción austral de la provincia.

\section{Dominio Amazónico}

4. Provincia Pacífica: abarca desde las laderas occidentales bajas de los Andes ecuatorianos y colombianos hasta las regiones bajas y las costas de América Central y el sur de México.

En relación con otros esquemas biogeográficos, el tratamiento de México parece demasiado simplificado, pues Cabrera y Willink (1973) sólo reconocen 4 provincias. Sin embargo, estos componentes bióticos se asignan a 2 regiones y 3 dominios diferentes, destacando así la naturaleza compleja de la biota mexicana. El esquema de Müller (1973), basado en vertebrados terrestres, también abarca el territorio latinoamericano, pero lamentablemente, para México sólo incluye la porción austral, dado que se restringe a la región Neotropical en sentido estricto.

Rzedowski (1973). Este autor llevó a cabo un análisis biogeográfico fenético de las áreas áridas del norte de México y el suroeste de los Estados Unidos de América. Las áreas 
mexicanas analizadas (Fig. 3) fueron la costa del Golfo de California, en los estados de Sonora, Baja California y Baja California Sur; la porción norte del estado de Chihuahua; el Valle de San Luis Potosí, situado en la mitad suroeste del estado homónimo; y el Valle del Mezquital, en el estado de Hidalgo. El autor incluyó dos áreas de los Estados Unidos, la Gran Cuenca y el desierto del Mohave.

De acuerdo con los resultados del análisis, las áreas de Chihuahua, el Valle del Mezquital y el Valle de San Luis Potosí resultaron muy semejantes, teniendo varias especies en común. Rzedowski (1973) halló una similitud menor entre las áreas áridas de Sonora y las de Chihuahua e Hidalgo, y más que al aislamiento geográfico, especuló que sus diferencias se deberían a causas ecológicas, debido a que el área de Sonora es más cálida. El autor también comparó estas zonas áridas con otras áreas semejantes de América del Norte (Gran Cuenca), América del Sur (costa peruana y Monte), África (Sahara) y Australia, y halló que la similitud mayor se encontraba entre el desierto de Chihuahua y el Monte de la Argentina. Al comparar las zonas áridas mexicanas con otras áreas no áridas, Rzedowski (1973) encontró una similitud mayor entre los desiertos de Chihuahua, Baja California y Sonora con los bosques tropicales deciduos del sur de Sonora, siendo fundamentalmente taxones neotropicales los que

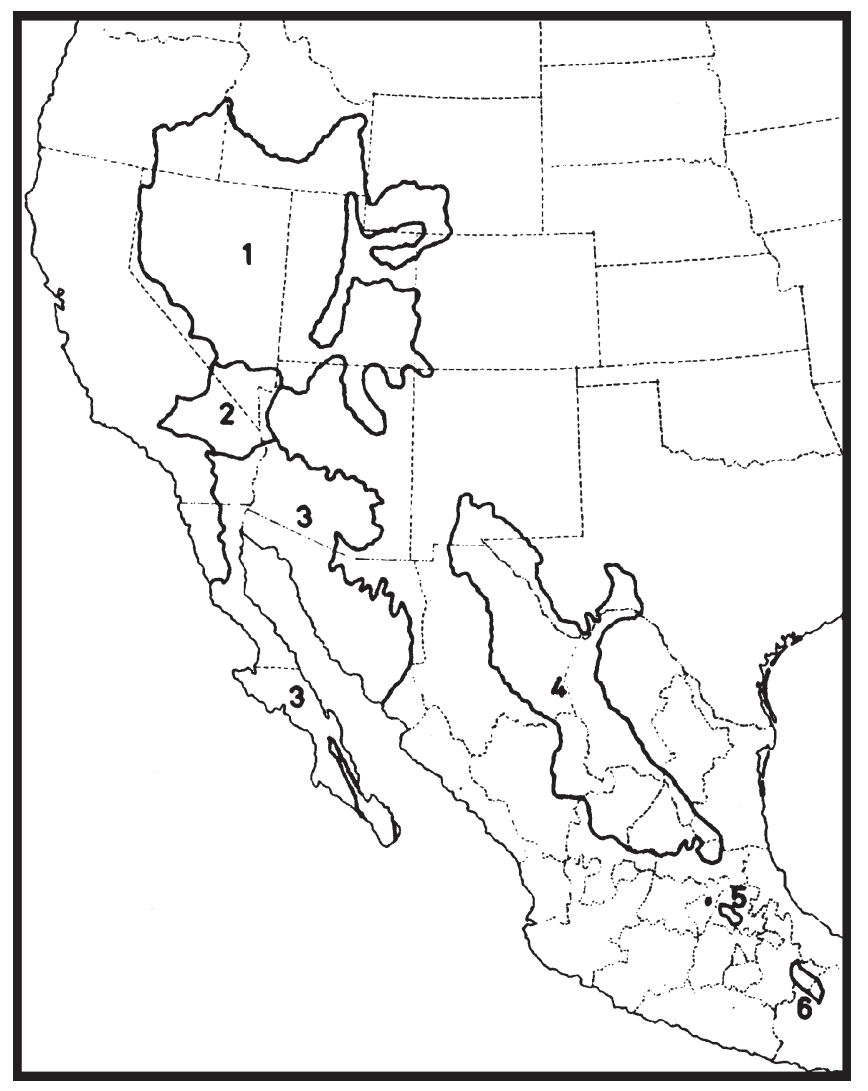

Figura 3. Áreas áridas analizadas por Rzedowski (1973). 1, Gran Cuenca; 2, Mohave; 3, Sonora; 4, Chihuahua; 5, Valle del Mezquital; 6, Valle de Tehuacán-Cuicatlán. determinan esta similitud. El autor determinó la existencia de dos elementos: uno neotropical y otro restringido a México y áreas aledañas.

Pese a las limitaciones que poseen los análisis fenéticos, considero valioso el intento por cuantificar las similitudes entre diferentes áreas biogeográficas y por descubrir sus afinidades. En el análisis de Rzedowski (1973) resulta destacable la afinidad mayor del elemento florístico de zonas áridas con el que habita áreas neotropicales.

Rosen (1976). Este autor llevó a cabo un análisis panbiogeográfico basado en taxones animales, con el objeto de dilucidar la historia biogeográfica de las Antillas. Para la biota terrestre encontró 2 trazos generalizados transcontinentales y 2 transoceánicos (Fig. 4), los cuales pueden considerarse componentes bióticos mayores:

1. Trazo Sudamericano-Caribeño: abarca América del Sur, las Antillas Mayores y Menores, las Bahamas, América Central y las tierras bajas de México. Los taxones antillanos y centroamericanos usualmente tienen sus taxones hermanos en América del Sur, siendo mucho menos numerosos los presentes sólo en las Antillas y América del Sur que los exclusivos de América Central y del Sur.

2. Trazo Norteamericano-Caribeño: abarca América del Norte, las tierras bajas del Golfo de México, América Central, las Antillas Mayores y las Bahamas. Aparentemente comprende un elemento más antiguo, laurásico o pangeico, y otro más moderno, gondwánico.

3. Trazo Pacífico Oriental-Caribeño: abarca el Pacífico Oriental hasta las islas Galápagos, porciones de la costa pacífica de América Central y del Sur, y toda la costa caribeña, en el Golfo de México.

4. Trazo Atlántico-Caribeño: abarca las costas de África y el Caribe.

Los cuatro trazos generalizados se superponen en el Mar Caribe, el cual está limitado al oeste por América Central, al norte por las Antillas Mayores, al este por las Antillas Menores, y al sur por América del Sur.

Al compararlos con las teorías geofísicas disponibles en ese momento, Rosen (1976) concluyó que las Antillas originalmente integraron un archipiélago en América Central, el cual fue desplazado en el terciario inferior por lo que actualmente es América Central. Aunado con este desplazamiento, una porción del piso oceánico del Pacífico Oriental se desplazó hacia el Atlántico Occidental tropical, constituyendo el Mar Caribe actual. El establecimiento del Istmo de Panamá en el plioceno permitió la dispersión biótica entre América Central y del Sur. Este análisis permite sustentar la relación entre el sur de México y las Antillas, y a la vez comprender cómo pudieron llegar elementos bióticos neotropicales de América del Sur a México.

Rzedowski (1978). "Vegetación de México", publicada por J. Rzedowski en 1978, constituye un hito en la biogeografía de 


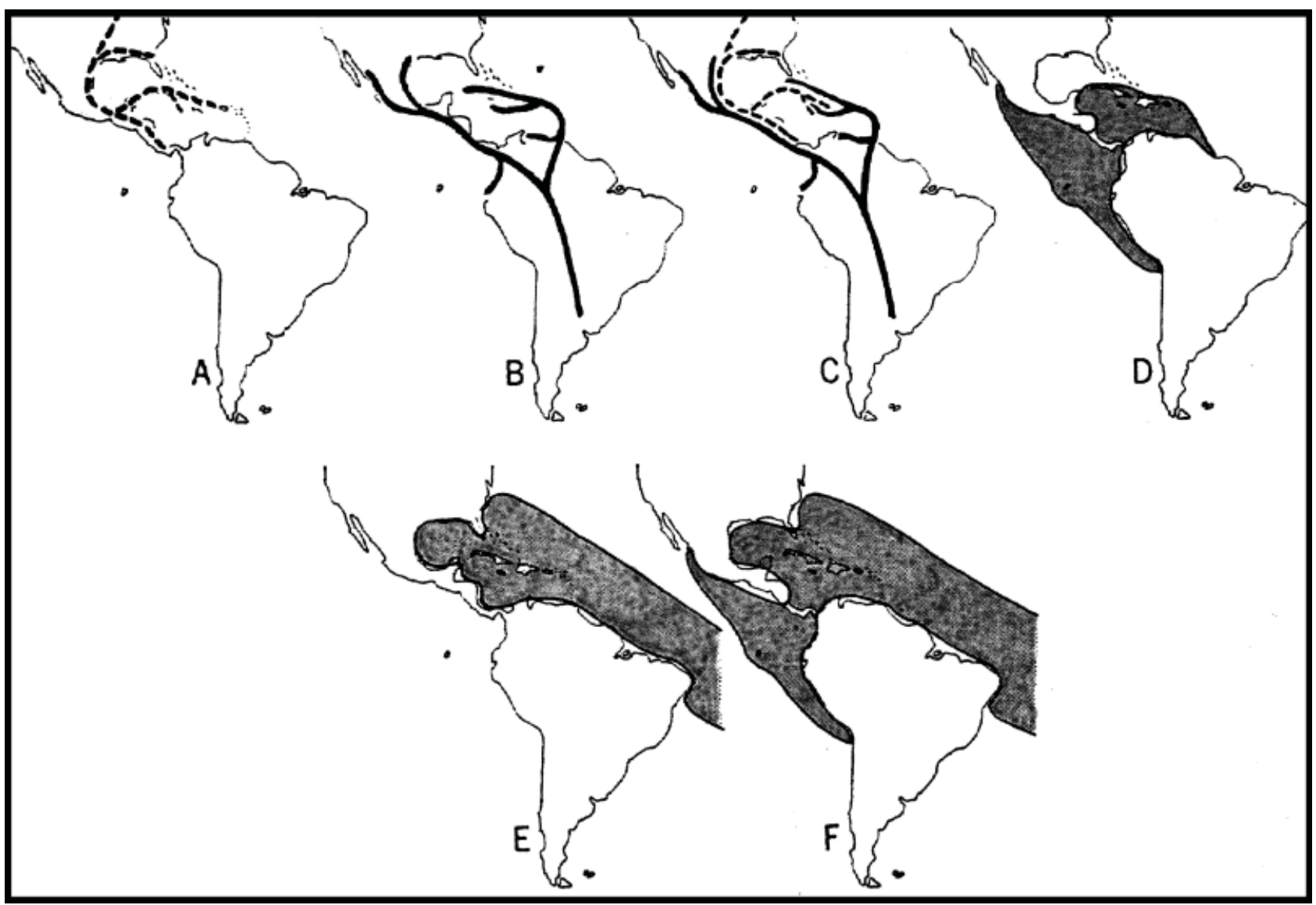

Figura 4. Trazos generalizados hallados por Rosen (1976). A, Norteamericano-Caribeño; B, Sudamericano-Caribeño; C, superposición de los trazos Norteamericano-Caribeño y Sudamericano-Caribeño en el Caribe; D, Pacífico Oriental-Caribeño; E, Atlántico Oriental-Atlántico Occidental; F, Pacífico Oriental-Atlántico Oriental.

México. En esta obra, el autor discute las bases fisiográficas y climáticas, la influencia del hombre, las relaciones geográficas y posibles orígenes de la flora mexicana, las formas y espectros biológicos, y los tipos de vegetación de nuestro país.

En el capítulo referido a las relaciones geográficas y posibles orígenes de la flora, Rzedowski (1978) reconoce la existencia de 6 elementos florísticos principales en el territorio mexicano. El elemento con afinidades meridionales incluye taxones neotropicales, relacionados con formas centroamericanas y sudamericanas, que constituyen el mayor porcentaje de la flora del país. El elemento con afinidades boreales incluye taxones neárticos, relacionados con formas de regiones templadas y frías de los Estados Unidos y Canadá. El elemento con afinidades antillanas comprende taxones neotropicales con formas emparentadas en las Antillas; su influencia mayor se da en la península de Yucatán. El elemento con afinidades con el este de Asia es más evidente en la flora de las partes más húmedas del país. El elemento con afinidades africanas, poco frecuente, se da en plantas de clima cálido. Finalmente, el elemento endémico, aunque no tan abundante como en Australia o
Sudáfrica, es significativo y le confiere un sello particular a la flora del país.

En el capítulo dedicado a las provincias florísticas de México, Rzedowski (1978) presenta un esquema de 17 provincias (Fig. 5), las cuales clasifica en 2 reinos y 4 regiones:

Reino Holártico

Región Pacífica Norteamericana

1. Provincia de California: abarca la mayor parte del estado de California, extendiéndose a algunas partes vecinas, como el sector septentrional de la península de Baja California, que incluye las sierras de Juárez y San Pedro Mártir y la planicie costera adyacente del lado del Océano Pacífico.

2. Provincia de la Isla Guadalupe: isla situada a $200 \mathrm{~km}$ de la costa de Baja California.

Región Mesoamericana de Montaña (intermedia entre los dos reinos)

3. Provincia de la Sierra Madre Occidental: se extiende desde Sonora y Chihuahua en el norte hasta Nayarit, Zacatecas y norte de Jalisco en el sur.

4. Provincia de la Sierra Madre Oriental: incluye partes de Coahuila, Nuevo León, Tamaulipas, San Luis Potosí, 


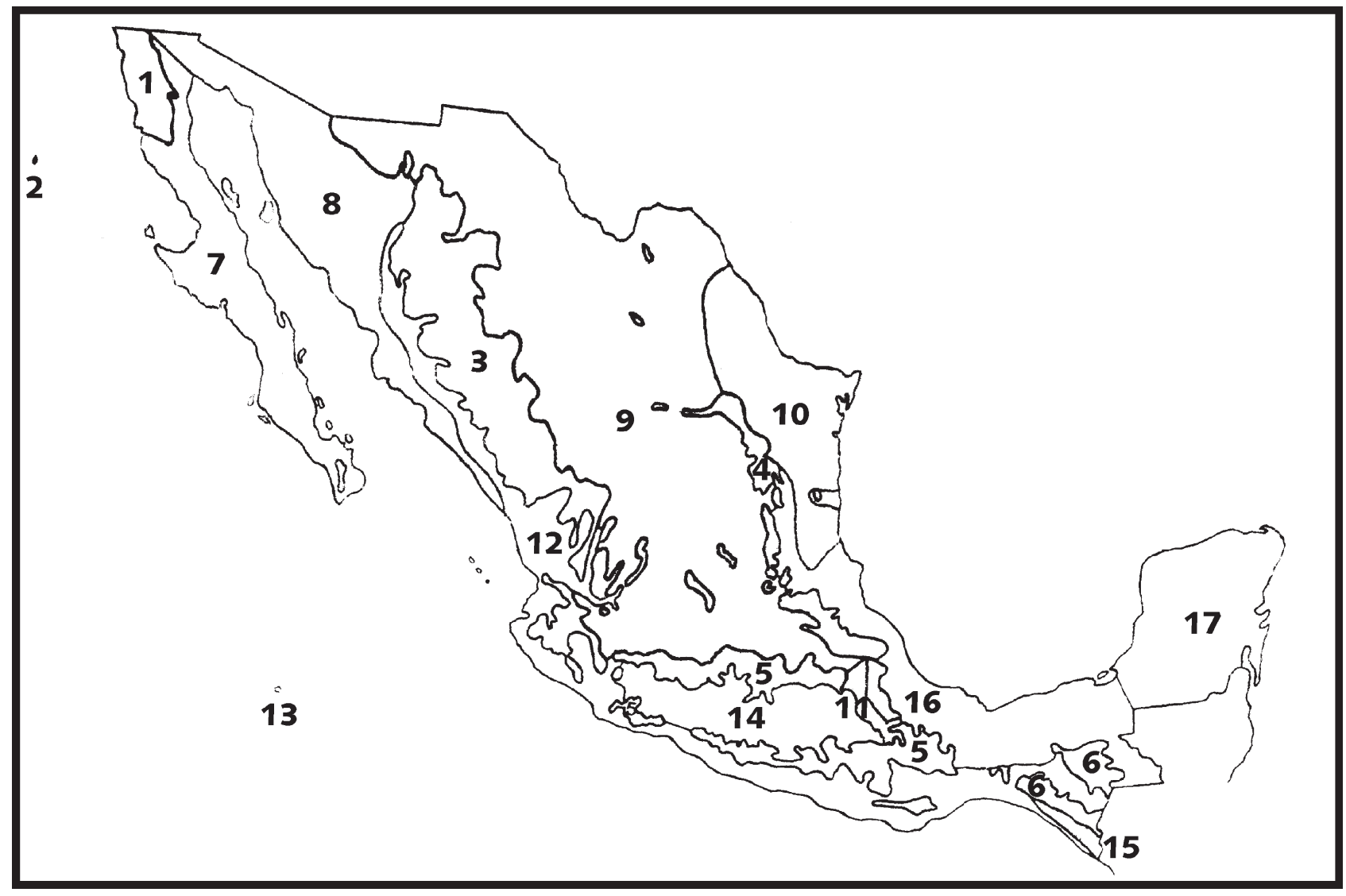

Figura 5. Provincias reconocidas en el esquema biogeográfico de Rzedowski (1978). 1, California; 2, Isla Guadalupe; 3, Sierra madre occidental; 4, Sierra Madre Oriental; 5, Serranías Meridionales; 6, Serranías Transísmicas; 7, Baja California; 8, Planicie Costera del Noroeste; 9, Altiplanicie; 10, Planicie Costera del Noreste; 11, Valle de tehuacán-Cuicatlán; 12, Costa Pacífica; 13, Islas Revillagigedo; 14, Depresión del Balsas; 15, Soconusco; 16, Costa del Golfo de México; 17, Península de Yucatán.

Querétaro, Hidalgo, Veracruz y Puebla. Su límite austral es difícil de delimitar, pues se une sin solución de continuidad con el Eje Volcánico Transmexicano.

5. Provincia de las Serranías Meridionales: incluye el Eje Volcánico Transmexicano, la Sierra Madre del Sur y el complejo montañoso del norte de Oaxaca.

6. Provincia de las Serranías Transístmicas: abarca las montañas de Chiapas, continuando más allá de las fronteras de México hacia América Central.

Reino Neotropical

Región Xerofítica Mexicana

7. Provincia de Baja California: abarca el área peninsular de Baja California.

8. Provincia de la Planicie Costera del Noroeste: ocupa la mayor parte del estado de Sonora y se extiende por la costa de Sinaloa en forma de franja angosta.

9. Provincia de la Altiplanicie: se extiende desde Chihuahua y Coahuila en el norte hasta Michoacán, Estado de México, Tlaxcala y Puebla en el sur, siendo la provincia más extensa del país.

10. Provincia de la Planicie Costera del Noreste: comprende la zona fisiográfica homónima, en los estados de Tamaulipas, Nuevo León, Coahuila, San Luis Potosí y el norte de Veracruz, e incluye también una porción adyacente del estado de Texas en los Estados Unidos.

11. Provincia del Valle de Tehuacán y Cuicatlán: corresponde a un área pequeña del sureste del estado de Puebla y porciones adyacentes de Oaxaca y Veracruz.

Región Caribea

12. Provincia de la Costa Pacífica: se extiende en forma de franja angosta e ininterrumpida desde el este de Sonora y suroeste de Chihuahua en el norte hasta Chiapas en el sur, prolongándose a lo largo de la misma vertiente hasta América Central.

13. Provincia de las Islas Revillagigedo: incluye las islas Socorro, San Benedicto y Clarión, situadas en el Océano Pacífico, a más de $350 \mathrm{~km}$ del continente.

14. Provincia de la Depresión del Balsas: se intercala entre el Eje Volcánico Transmexicano y la Sierra Madre del Sur, incluyendo partes de los estados de Jalisco, Michoacán, Estado de México, Guerrero, Morelos, Puebla y Oaxaca. 15. Provincia del Soconusco: corresponde a una franja 
estrecha en las estribaciones inferiores de la Sierra Madre de Chiapas, prolongándose hacia Guatemala.

16. Provincia de la Costa del Golfo de México: se extiende en forma de franja continua a lo largo de las partes bajas de los estados de Veracruz y Tabasco, además de algunas porciones adyacentes de Tamaulipas, San Luis Potosí, Hidalgo, Puebla, Oaxaca, Chiapas y probablemente de Campeche.

17. Provincia de la Península de Yucatán: comprende la península de Yucatán, una parte de Belice y el departamento de El Petén en Guatemala.

El sistema de Rzedowski (1978) ha sido el más empleado en los análisis biogeográficos llevados a cabo especialmente por botánicos.

Savage (1982). El trabajo de J. Savage (1982) constituye una propuesta original que intenta combinar los procesos de vicarianza y dispersión para explicar la biogeografía de los anfibios y reptiles de Mesoamérica, a la cual reconoce como un área biogeográfica.

Savage (1982) consideró que en Mesoamérica era posible reconocer 6 elementos herpetofaunísticos (Fig. 6), de los cuales 3 se hallan en México. La herpetofauna de las tierras bajas orientales y occidentales posee una extensión amplia, es la más diversa y rica en especies, y se distribuye en las tierras bajas desde Tamaulipas en el norte hasta Panamá en el sur. La herpetofauna de las tierras bajas occidentales se asocia con condiciones climáticas semiáridas a subhúmedas, distribuida a lo largo de la costa Pacífica desde el norte de Sinaloa hasta el Golfo de Nicoya y la Meseta Central de Costa Rica, incluyendo también partes de Chiapas y Guatemala, así como tierras altas de Honduras y Nicaragua. La herpetofauna de las tierras altas de Guatemala se restringe a hábitats húmedos templados de las tierras altas de Chiapas y Guatemala.

En una contribución anterior, Savage (1966) había distinguido 4 elementos que habrían contribuido a la herpetofauna mesoamericana:

El elemento Mesoamericano incluye géneros mesoamericanos tropicales, cuyos taxones emparentados se distribuyen en el área o en América del Sur, pero que son básicamente endémicos de América Central y México. La evidencia indica que estos taxones o sus ancestros deben haber tenido una distribución más amplia en América del Norte durante el terciario inferior, cuando las condiciones cálidas llegaban por el norte hasta los estados de Montana, Wyoming, Utah, Colorado, Dakota del Norte y Dakota del Sur.

El elemento Septentrional Antiguo incluye géneros

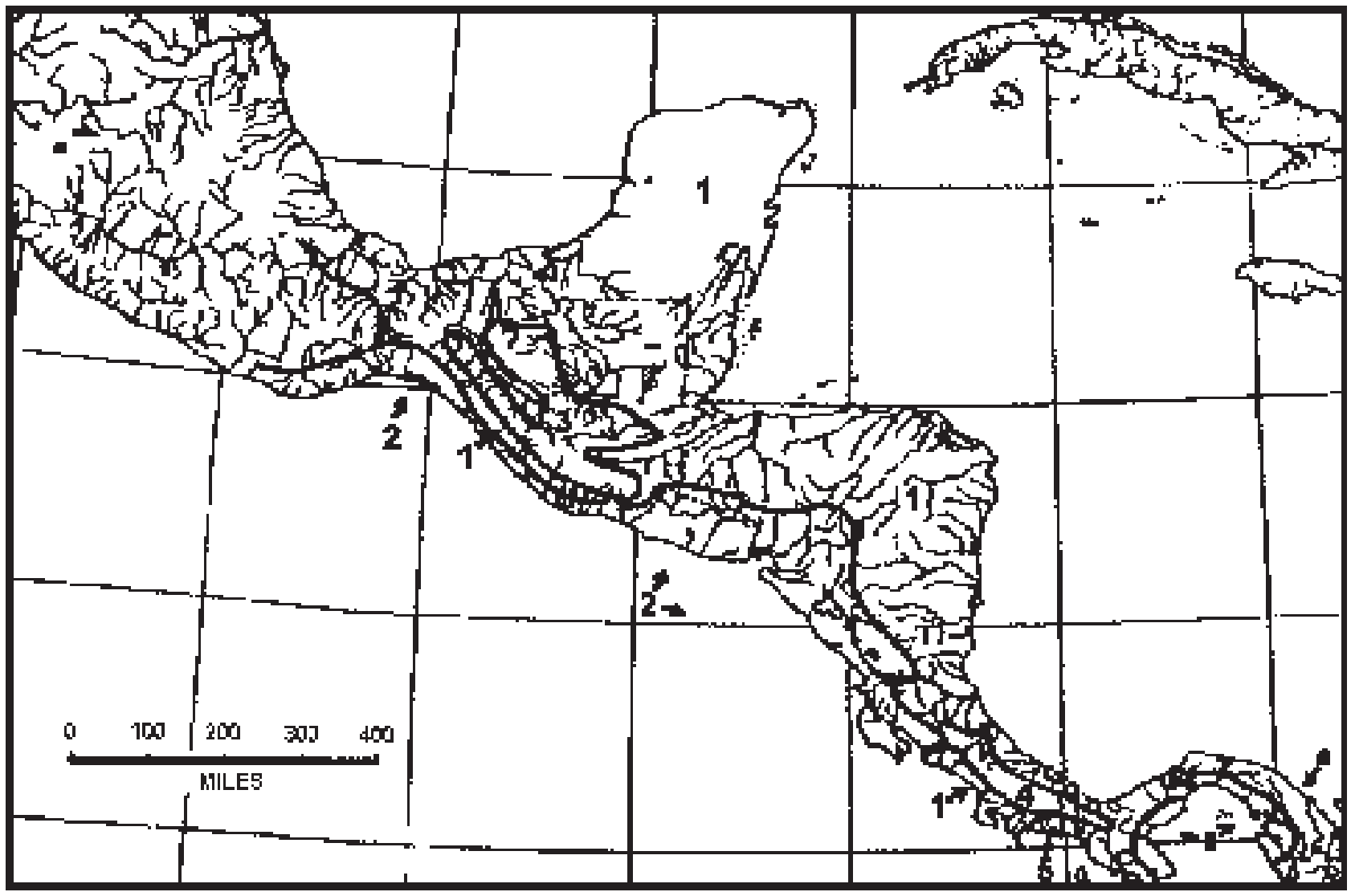

Figura 6. Elementos herpetofaunísticos reconocidos para Mesoamérica por Savage (1982). 1, Tierras bajas orientales y occidentales; 2 , tierras bajas occidentales; 3, tierras altas de Guatemala; 4, Talamanca; 5, Panamá; 6, Chocó. 
primariamente extratropicales en Eurasia o América del Norte, pero que están representados en las Américas por varios taxones tropicales. Estos taxones o sus ancestros deben haber tenido una distribución circumpolar más o menos continua en el terciario, y luego se dispersaron hacia el sur y sus distribuciones se fragmentaron debido a las condiciones más frías del cenozoico.

El elemento Sudamericano incluye géneros con distribución básicamente sudamericana, que arribaron recientemente a Mesoamérica.

El elemento Septentrional Reciente está representado por pocos géneros, primariamente extratropicales, distribuidos en regiones áridas y semiáridas del suroeste de los Estados Unidos y áreas adyacentes de México. Aparentemente evolucionaron in situ en respuesta a las condiciones de aridez y temperaturas más bajas de la última parte del cenozoico.

Si bien Savage (1982) continuó considerando válidos estos elementos, los reinterpretó a partir de nueva evidencia geológica, datos de otros taxones y consideraciones basadas, principalmente, en los trazos generalizados de Rosen (1976). Como parte de esta reinterpretación, Savage (1982) propuso un modelo con 5 eventos básicos, 3 de dispersión y 2 de vicarianza, los que se presentan a continuación en orden cronológico:

1. Dispersión "antigua" de grupos neotropicales desde América del Sur hacia América Central, entre el cretácico tardío y el paleoceno, asociada con eventos geológicos aún no esclarecidos.

2. Vicarianza que fragmentó las biotas centroamericana y sudamericana en el paleoceno, antes del desarrollo del Istmo de Panamá, con lo que éstas evolucionaron en aislamiento.

3. Dispersión de grupos neárticos desde América del Norte hacia América Central, antes del eoceno.

4. Vicarianza que fragmentó las biotas centroamericana y norteamericana, en el oligoceno, asociada con el surgimiento de los sistemas montañosos y el enfriamiento y desecamiento asociados.

5. Dispersión "reciente" de grupos neotropicales desde América del Sur hacia América Central, en el plioceno, asociada con el establecimiento del Istmo de Panamá.

A modo de síntesis, Savage (1982) comparó esquemáticamente (Figs. 7-8) su hipótesis con la de Rosen (1976). El autor señaló que su modelo explica la razón por la que los taxones del elemento Septentrional Antiguo no llegaron a América del Sur en el terciario, la presencia de este elemento en las Antillas Mayores, las diferencias entre las biotas de las Antillas Mayores y Menores, y la gran semejanza entre las biotas de Cuba y América Central Nuclear.

Halffter (1987). En una serie de publicaciones referidas fundamentalmente a la entomofauna de zonas montañosas, Halffter (1962, 1964a, b, 1965, 1972, 1974, 1976, 1978, 1987, 2003; ver también Liebherr, 1994a; Halffter et al., 1995; Llorente-Bousquets, 1996; Morrone y Márquez, 2001;
Reyes-Castillo, 2003; Corona et al., 2005) definió la Zona de Transición Mexicana como "un área compleja y variada donde se superponen las faunas neotropical y neártica" (Halffter, 1987: 95). La publicación de 1987, seguramente por estar en inglés, ha sido la más citada, sin embargo, recomiendo una lectura exhaustiva de las publicaciones de 1962, 1964a, 1974 y 1978 para una comprensión adecuada del desarrollo de esta teoría. De acuerdo con Halffter (1987), la Zona de Transición Mexicana abarca el suroeste de los Estados Unidos, todo México y América Central hasta las tierras bajas de Nicaragua. Su fisiografía es compleja (Fig. 9), como resultado de eventos ocurridos desde el cenozoico medio. La comunicación de esta zona de transición con América del Norte ha sido posible desde el mesozoico, mientras que su comunicación con América del Sur ha variado a lo largo del tiempo.

Halffter (1976, 1987, 2003) analizó la distribución de varios taxones de escarabajos (Coleoptera: Scarabaeidae) de la Zona de Transición Mexicana, teniendo en cuenta dónde se hallaban distribuidos sus taxones emparentados, la riqueza de especies, su grado de simpatría, la historia geológica del área y la diversidad de hábitats ocupada por las especies. Como resultado, reconoció 3 elementos bióticos, a los que denominó patrones de dispersión y, posteriormente, patrones de distribución: Neártico, Mesoamericano y Paleoamericano.

El patrón Neártico (Fig. 10) incluye taxones holárticos y neárticos que se diversificaron en las montañas de México durante el plioceno y pleistoceno. Su límite austral se encuentra en el Istmo de Tehuantepec, pero puede poseer algunas especies centroamericanas. Los taxones asignados a este patrón usualmente se encuentran en bosques de coníferas y pastizales de altura, situados por encima de 1700 $\mathrm{m}$ de altitud. Sus taxones emparentados se encuentran al norte, en los Estados Unidos de América y Canadá. Dentro de este patrón, Halffter reconoció la existencia de taxones exclusivamente neárticos y taxones holárticos, teniendo los segundos una mayor antigüedad.

El patrón Mesoamericano (Fig. 11) incluye taxones que evolucionaron en hábitats montañosos húmedos de México y América Central, en especial bosques mesófilos. Tienen su mayor diversidad específica en América Central, y más al norte y al oeste, a lo largo de las vertientes de los océanos Atlántico y Pacífico. Sus taxones emparentados se encuentran en América Central y del Sur, y se habrían diversificado en la Zona de Transición Mexicana durante el oligoceno.

El patrón Paleoamericano (Fig. 12) incluye taxones que llegaron más tempranamente que los otros 2 , y se diversificaron en la Zona de Transición Mexicana antes del cierre del Istmo de Tehuantepec durante el plioceno. Se restringen a áreas montañosas, con preferencias ecológicas por desiertos, pastizales o selvas lluviosas. Pueden poseer especies en América Central. Sus taxones emparentados se distribuyen en áreas templadas y tropicales del Viejo 

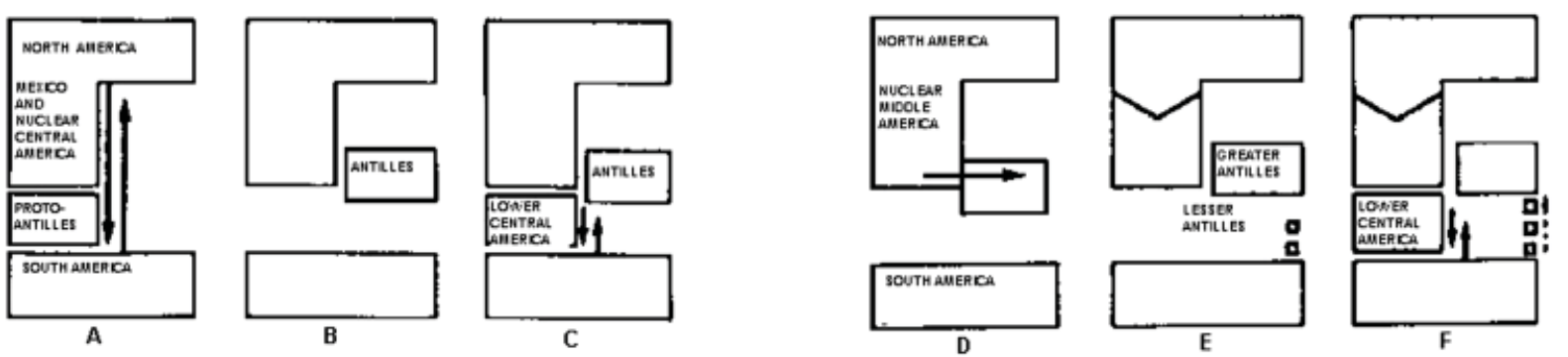

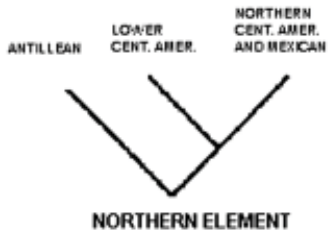

7

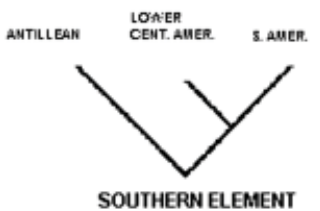

SOUTHERN ELEMENT

Figuras 7-8. Comparación de hipótesis, con indicación de los cladogramas predichos por cada una de ellas. 7, Rosen (1976); 8, Savage (1982). Las flechas indican eventos de dispersión.

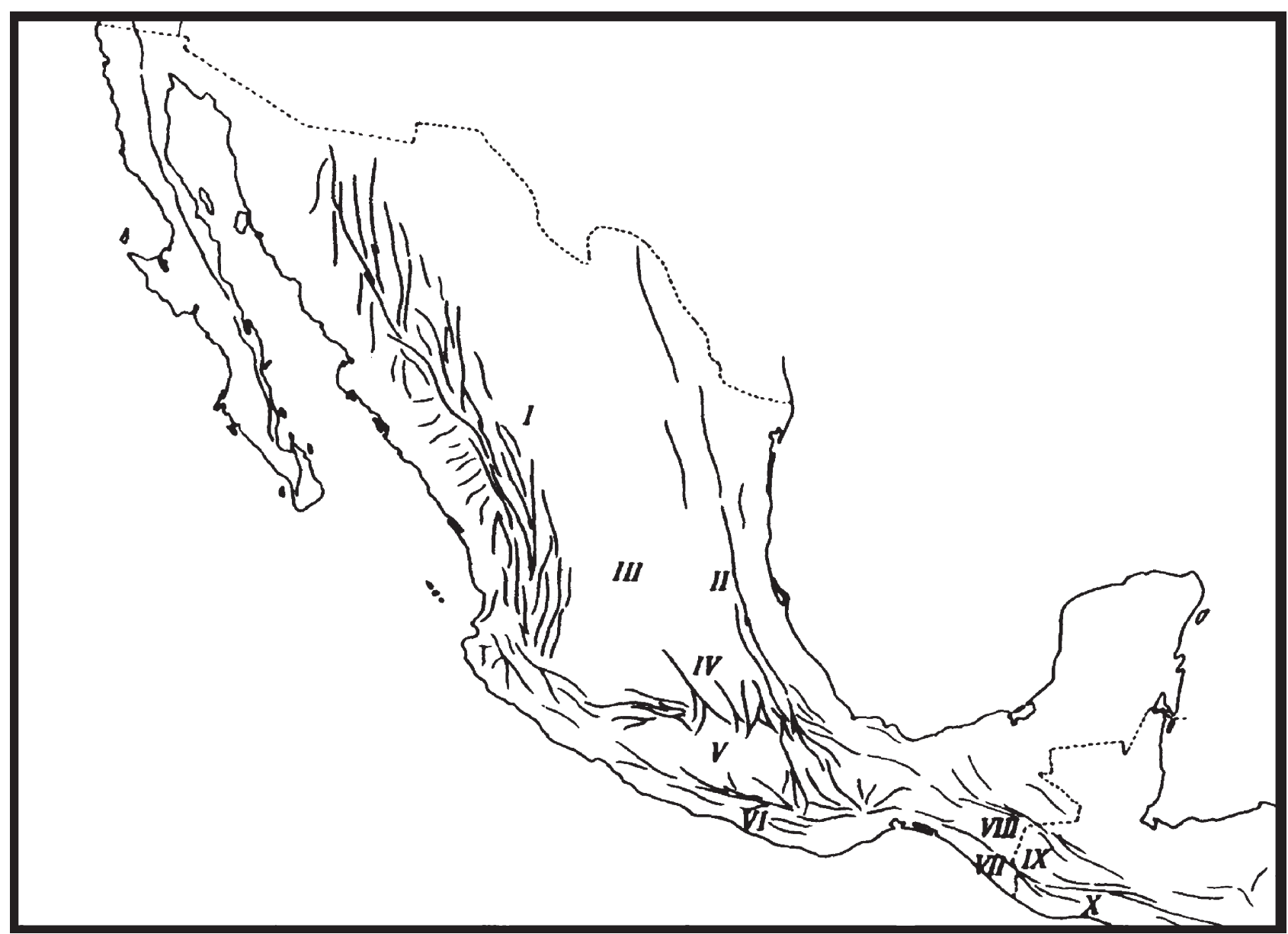

Figura 9. Sistemas orográficos de la Zona de Transición Mexicana, de acuerdo con Halffter (1987). I, Sierra Madre Occidental; II, Sierra Madre Oriental; III, Altiplano Mexicano; IV, Eje Volcánico Transmexicano; V, Cuenca del Balsas; VI, Sierra Madre del Sur; VII, Sierra Madre de Chiapas; VIII, Macizo Central de Chiapas; IX y X, Núcleo Centroamericano. 


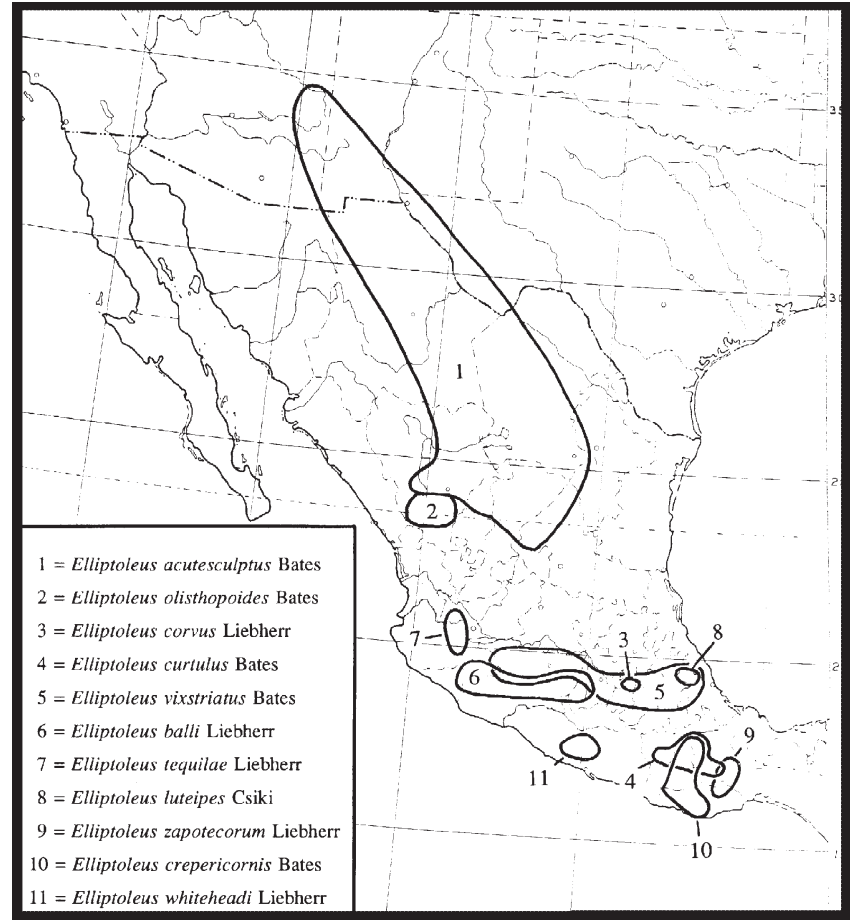

Figura 10. Distribución del género Elliptoleus (Coleoptera: Carabidae), que ilustra el patrón Neártico (tomado de Liebherr, 1994a).
Mundo, y habrían llegado a la zona desde el norte, luego de atravesar el estrecho de Bering. Halffter et al. (1995) distinguieron 4 variedades de este patrón: Paleoamericano Relictual (especies endémicas de distribución restringida, pertenecientes a géneros del Viejo Mundo), Paleoamericano de Montaña (linajes que colonizaron las montañas de la Zona de Transición Mexicana y, en menor medida, las de América Central), Mesoamericano de Montaña (taxones de filiación paleoamericana, pero distribuidos junto con el patrón mesoamericano de montaña) y Paleoamericano Tropical (taxones que se distribuyen en áreas de altitud baja y moderada, asociados con condiciones tropicales).

Halffter (1964a, b) reconoció un cuarto patrón, el del Altiplano, cuya diversidad mayor se encuentra en el Altiplano Mexicano o en las tierras altas de Chiapas y Guatemala. Las afinidades de este elemento se encontrarían en América del Sur. Se trataría de líneas que se dispersaron hacia México en el mioceno y se diversificaron en el Altiplano Mexicano durante el eoceno-plioceno, a la vez que se extinguieron en otras áreas (Halffter, 1964a, b, 1976; Lanteri, 1990). A ellos se sumaron otros taxones holárticos durante el pliocenopleistoceno (Halffter, 1964a, b).

Al norte del Istmo de Tehuantepec, los 3 patrones principales exhiben una zonación marcada (Halffter, 1987;

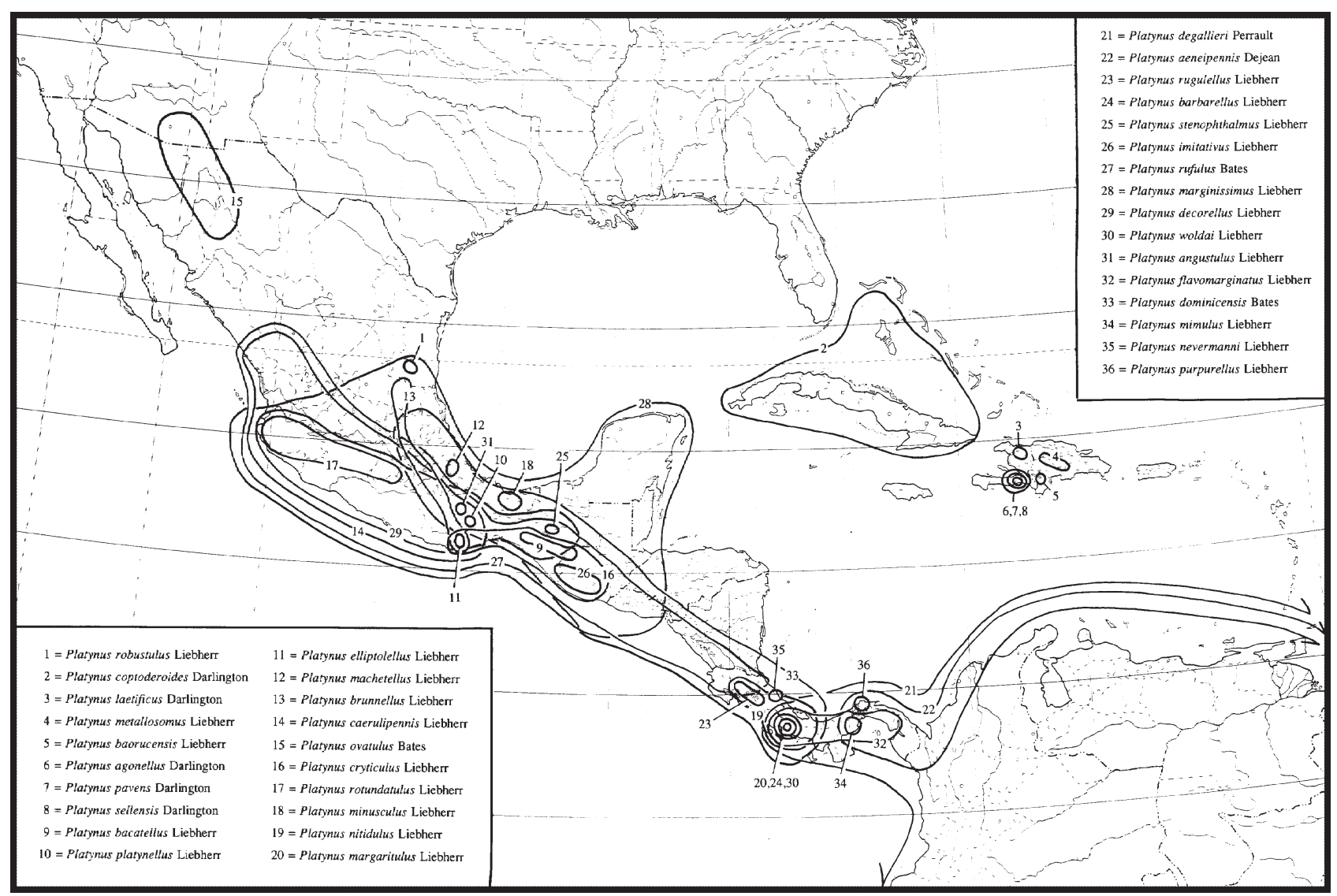

Figura 11. Distribución del grupo de especies de Platynus degallieri (Coleoptera: Carabidae), que ilustra el patrón Mesoamericano (tomado de Liebherr, 1994a). 


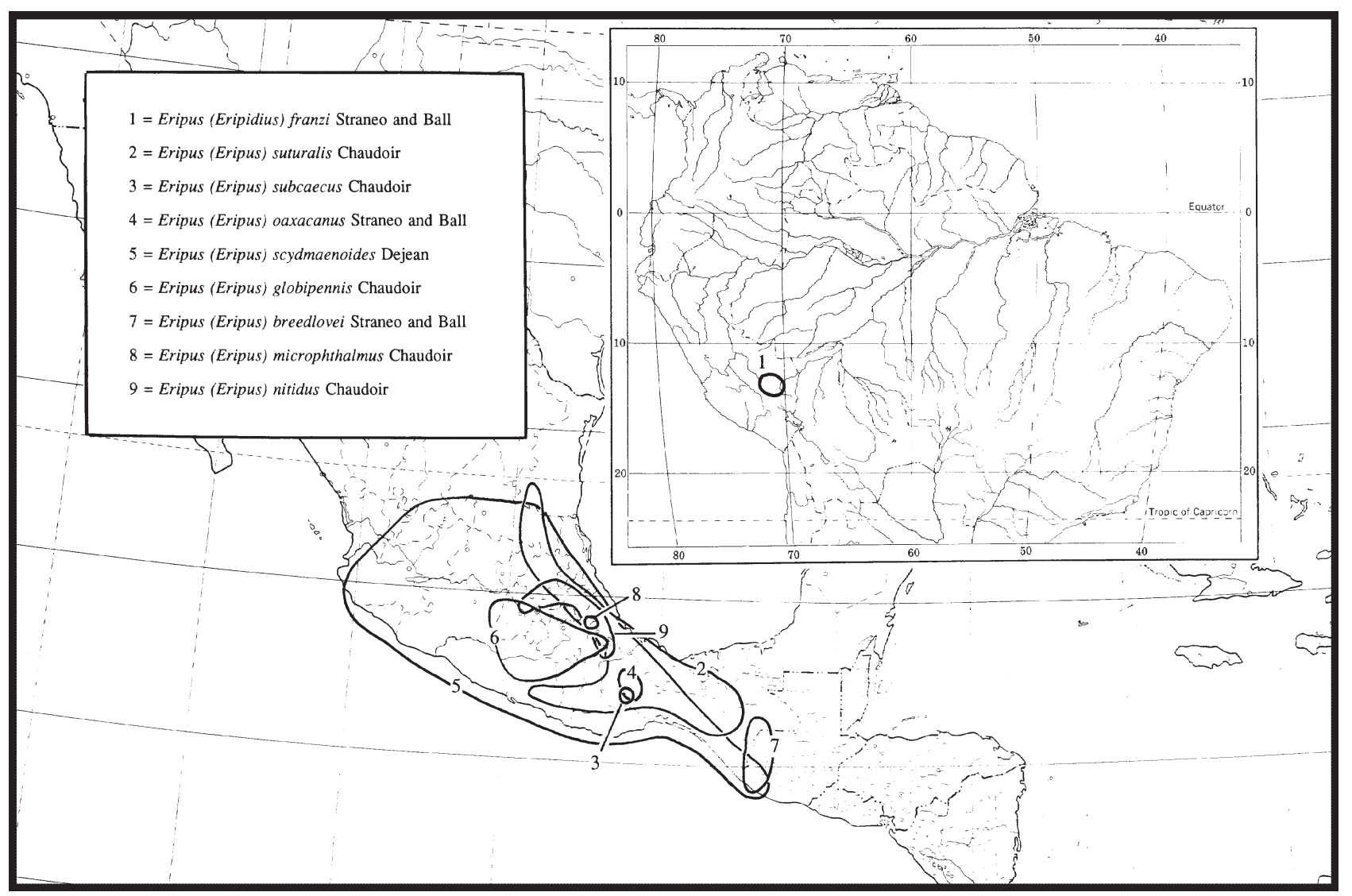

Figura 12. Distribución del género Eripus (Coleoptera: Carabidae), que ilustra el patrón Paleoamericano (tomado de Liebherr, 1994a).

Halffter et al., 1995). Los elementos mesoamericanos se encuentran a altitudes menores que $2000 \mathrm{~m}$; entre 2000 y 3000 $\mathrm{m}$ la fauna combina elementos neárticos y paleoamericanos; y por encima de $3000 \mathrm{~m}$ los insectos son casi exclusivamente neárticos. Las tierras bajas también poseen una entomofauna de origen sudamericano, pero de origen más reciente.

Al sur del Istmo de Tehuantepec la situación es diferente. En las montañas de Chiapas y América Central predomina el elementoMesoamericano, siendolostaxonespaleoamericanos menos frecuentes y los neárticos muy escasos. De acuerdo con Halffter (1987), la Zona de Transición Mexicana finaliza en los lagos de Nicaragua, pudiendo hallarse escasos ejemplos de taxones mesoamericanos y neárticos en la sierra de Talamanca, donde predomina la fauna neotropical.

$\mathrm{Si}$ bien se han señalado algunas imprecisiones o anomalías (Llorente-Bousquets, 1996), el concepto de la Zona de Transición Mexicana de Halffter posee un valor heurístico innegable. No solo ha sido utilizado por numerosos autores, en especial zoólogos, sino que ha inspirado el trabajo de numerosos biogeógrafos (Reyes-Castillo, 1970, 1978; Kohlmann y Halffter, 1988; Morón, 1991, 1992; Schuster, 1992; Liebherr, 1994a; Lobo y Halffter, 2000; Marshall y Liebherr, 2000; Morrone y Márquez, 2001, 2003; Escalante et al., 2004; Morrone, 2004a, b; Morrone y Gutiérrez, 2005).
Samek (1988). Este autor propuso una regionalización fitogeográfica del Caribe (Fig. 13), donde reconoce 3 subregiones: Centroamericana, Antillana, y de Colombia y Venezuela Septentrional. La subregión Centroamericana incluye parte de México. El esquema de Samek (1988) para nuestro país es el siguiente:

Región del Caribe

Subregión Centroamericana

1. Provincia de las Islas Revillagigedo: islas Socorro, San Benedicto y Clarión.

2. Provincia de la Costa Pacífica de América Central: franja estrecha que se extiende por la costa pacífica desde Sonora hasta Panamá.

3. Provincia del Golfo de México: franja que ocupa las tierras bajas desde Tamaulipas hasta Honduras, ocupando también la península de Yucatán.

Este esquema resulta interesante, pues integra en un componente único, la región del Caribe, áreas situadas en el sur de México, las Antillas y en el noroeste de América del Sur. En este aspecto, los esquemas biogeográficos de Good (1974) y Morrone (2001a, b, 2004a, b) son similares.

Morafka et al. (1992). Durante el siglo XX, se llevaron a cabo numerosos análisis para explicar la historia biogeográfica de los desiertos de América del Norte. El modelo de Mohavia 


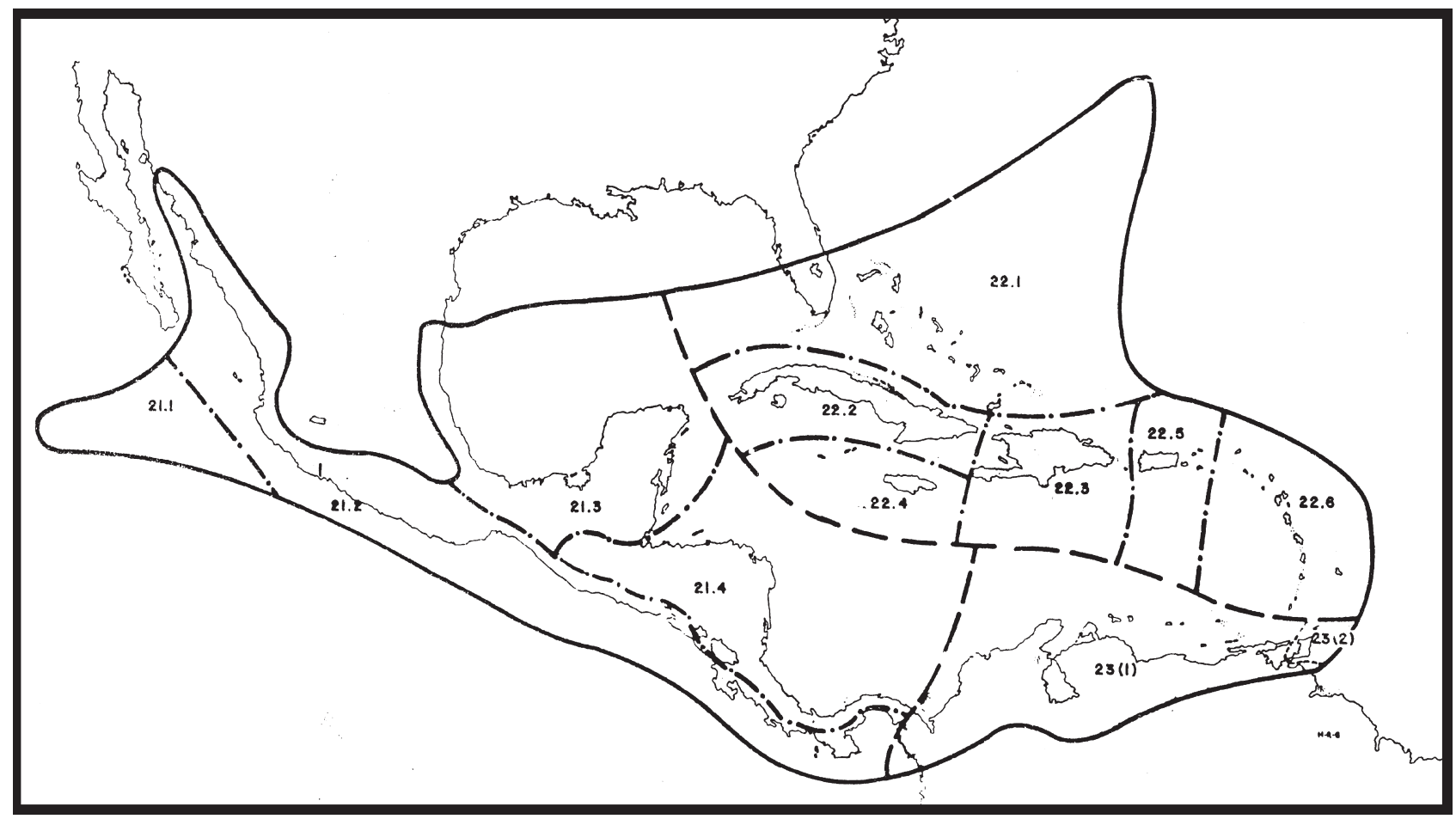

Figura 13. Provincias biogeográficas de la región del Caribe reconocidas por Samek (1988). 21.1, Islas Revillagigedo; 21.2, Costa Pacífica de América Central; 21.3, Golfo de México; 21.4, Guatemala-Panamá; 22.1, Bermudas, Bahamas y Florida; 22.2, Cuba; 22.3, La Española; 22.4, Jamaica; 22.5, Puerto Rico; 22.6, Colombia y Venezuela Septentrional.

(Fig. 14), propuesto originalmente por Axelrod (1958), fue evaluado para la herpetofauna por Morafka et al. (1992). De acuerdo con la hipótesis inicial, los taxones que habitan los matorrales espinosos divergieron antes que los que habitan el chaparral y los pastizales y, a su vez, éstos fueron seguidos por disyunciones más o menos simultáneas con los taxones que habitan los desiertos de Chihuahua, Sonora y la península de Baja California. Los episodios finales de aislamiento separaron los taxones del desierto de Mohave. La fragmentación sucesiva implícita en este modelo, que debería reflejarse en vicarianza, lo hace adecuado para contrastar mediante un análisis biogeográfico cladístico.

Morafka et al. (1992) comenzaron su análisis detallando la información existente acerca de la evolución de los desiertos norteamericanos. A partir de esta información, construyeron un cladograma (Fig. 15), que ilustra los resultados esperados de la narrativa construida por los autores. Las unidades ecológicas que constituyen las terminales del cladograma pueden traducirse a áreas: el matorral espinoso equivale a las tierras bajas del sur de Sonora y Sinaloa; el chaparral equivale a la costa del sur de California hasta El Rosario, Baja California; los pastizales equivalen al sur de las grandes planicies de los Estados Unidos; y el relictual equivale al desierto del Mohave. La secuencia de disyunciones va de unos 40 millones de años (disyunción del matorral espinoso) hasta 5-6 millones de años atrás (disyunción del desierto de Mohave).
A partir de una matriz de datos con todos los taxones de reptiles analizados, el análisis de parsimonia proporcionó un cladograma general de áreas (Fig. 16), que resultó semejante al modelo propuesto. Un segundo análisis incluyendo solamente 3 taxones para los cuales existían cladogramas produjo otro cladograma general de áreas (Fig. 17). Éste resulta un poco diferente del modelo, aunque coincide en que la disyunción de Baja California precede a la disyunción entre Sonora y Chihuahua, indicando que su biota se diferenció antes de la de los otros desiertos.

Grismer (1994) llevó a cabo un análisis biogeográfico cladístico de la herpetofauna de Baja California, concluyendo que ésta se originó por vicarianza, cuando el Golfo de California se formó y extendió hacia el norte, aislando a la península. Por otra parte, propuso que el desarrollo de los desiertos de Sonora, Mojave y la Gran Cuenca coadyuvó a la fragmentación de las especies de la península de Baja California de las del suroeste de los Estados Unidos de América y el noroeste de México.

Liebherr (1994a). Este autor llevó a cabo un análisis biogeográfico cladístico, basado en 14 taxones de Carabidae (Coleoptera) que habitan la Zona de Transición Mexicana, de los cuales 6 pueden asignarse al patrón Neártico, 4 al Mesoamericano de Montaña y 4 al Paleoamericano. Las áreas analizadas (Fig. 18) fueron la Sierra Madre Occidental unida al Altiplano Mexicano, la Sierra Madre Oriental, las 

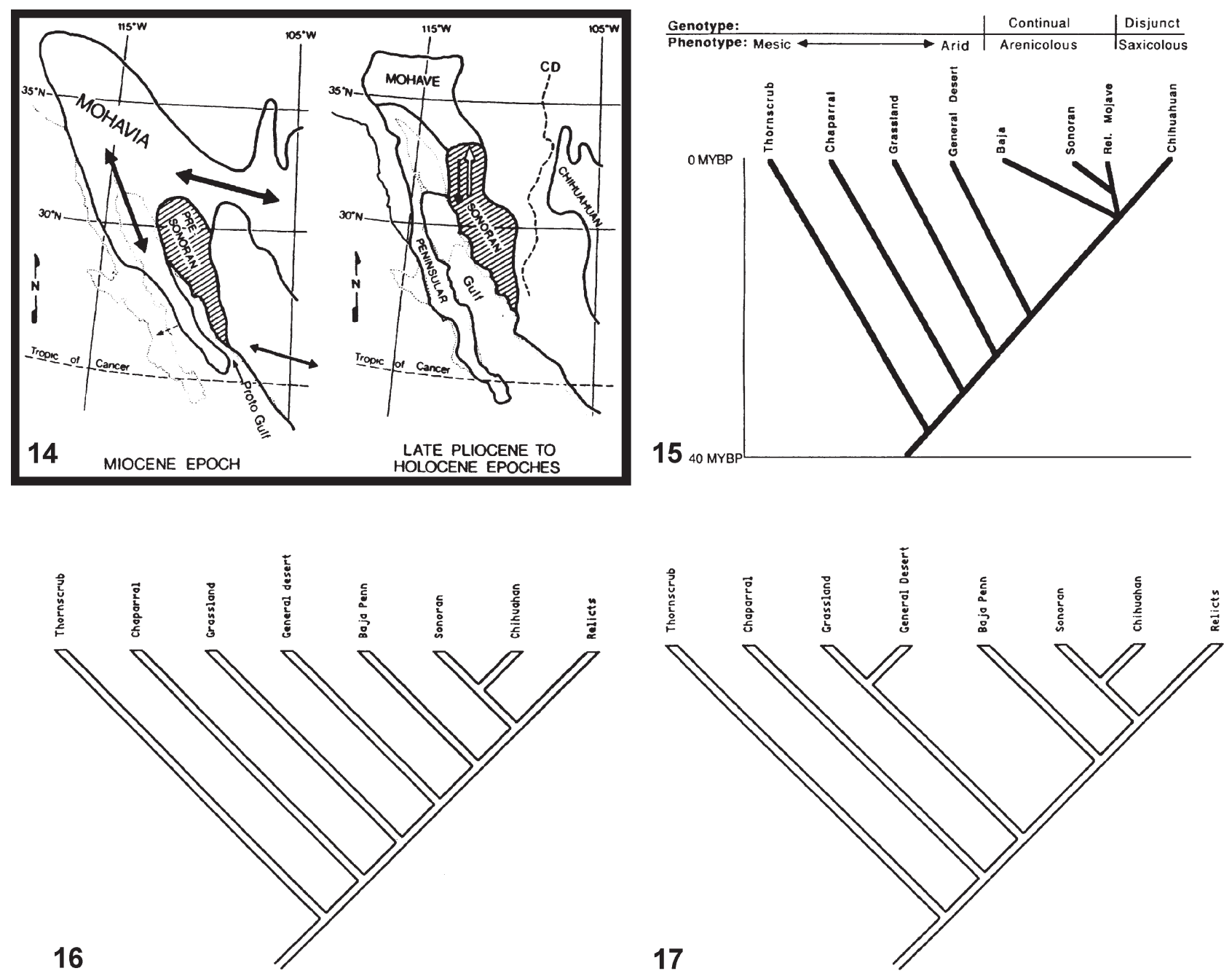

Figuras 14-17. Análisis de Morafka et al. (1992). 14, Modelo que indica la disrupción de Mohavia, detallando las disyunciones; 15, modelo cladístico derivado de la información analizada; 16, cladograma general de áreas obtenido del análisis de todos los taxones estudiados; 17 , cladograma general de áreas obtenido del análisis de los taxones con relaciones filogenéticas conocidas.

montañas de Arizona, la porción sur de la Sierra Madre Occidental, el Eje Volcánico Transmexicano, la Sierra Madre del Sur, las montañas de Chiapas y Guatemala, el desierto de Sonora, y la cordillera de Talamanca.

Liebherr (1994a) obtuvo una cladograma general de áreas (Fig. 19), en el cual la Sierra Madre Oriental resultó ser el área hermana de las restantes áreas estudiadas. Éstas constituyen una tricotomía entre el sur de la Sierra Madre Occidental; la Sierra Madre Occidental unida al Altiplano Mexicano, el desierto de Sonora y las montañas de Arizona; y el Eje Volcánico Transmexicano junto con la Sierra Madre del Sur, la cordillera de Talamanca y la Sierra Madre de Chiapas.

Liebherr (1994a) consideró que los resultados de su análisis coincidían con los de Rosen (1978) y Ball (1992), al separar a la Sierra Madre Oriental del resto de las áreas. Por otra parte, consideró que la relación entre el Eje
Volcánico Transmexicano y la Sierra Madre del Sur estaba sustentada fuertemente por el análisis. En relación con la relevancia otorgada previamente al Istmo de Tehuantepec como evento vicariante, este autor consideró que éste solo sería relevante para los taxones del elemento Neártico, pero no sería significativo para taxones paleoamericanos o mesoamericanos, debido a que éstos, por ser más antiguos, habrían tenido más tiempo para diferenciarse en la Zona de Transición Mexicana.

Hernández-Baños et al. (1995). Estos autores llevaron a cabo un análisis biogeográfico fenético de 335 especies de aves distribuidas en 33 islas de bosque húmedo de montaña de México y América Central (Fig. 20).

El análisis de similitud entre las avifaunas estudiadas permitió obtener un fenograma (Fig. 21), del cual se deducen patrones geográficos claros, distinguiéndose los siguientes 

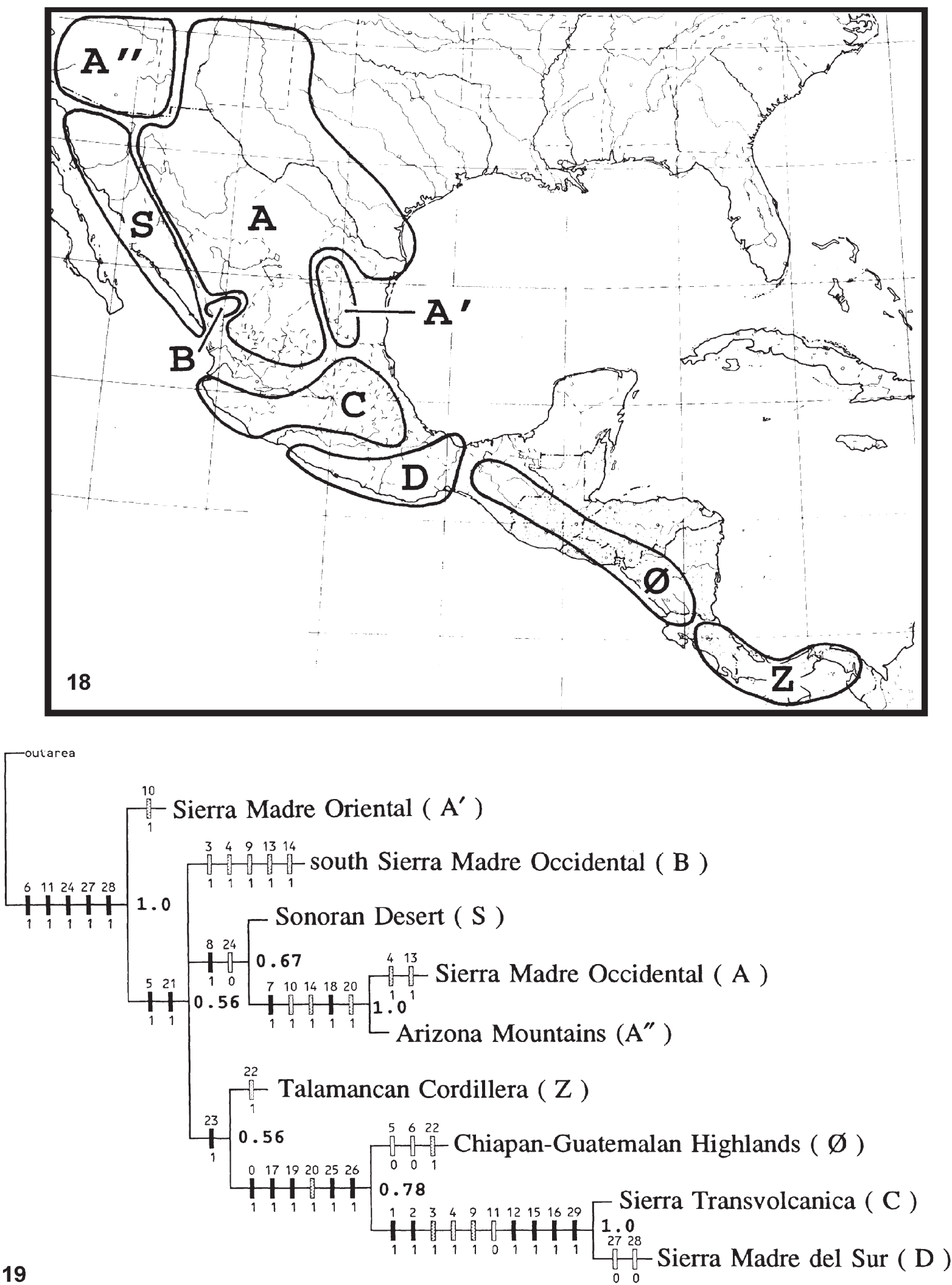

Figuras 18-19. Análisis biogeográfico cladístico de Liebherr (1994a). 18, Áreas analizadas; 19, cladograma general de áreas obtenido. A, Sierra Madre Occidental-Altiplano Mexicano; A', Sierra Madre Oriental; A', montañas de Arizona; B, porción sur de la Sierra Madre Occidental; C, Eje Volcánico Transmexicano; D, Sierra Madre del Sur; 0, montañas de Chiapas y Guatemala; S, desierto de Sonora; Z, cordillera de Talamanca. 


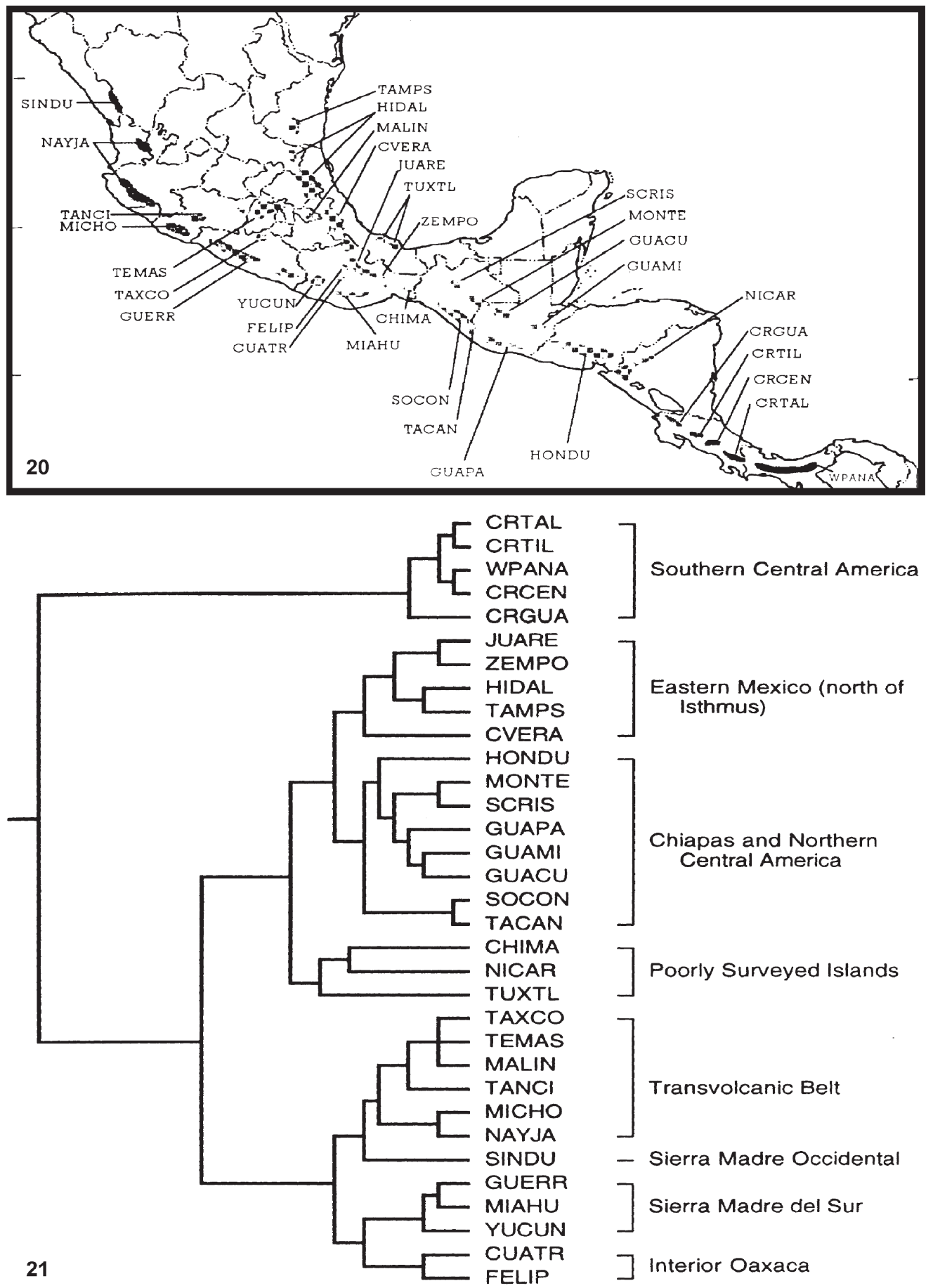

Figuras 20-21. Análisis biogeográfico fenético de Hernández-Baños et al. (1995). 20, Áreas analizadas; 21, fenograma obtenido. CHIMA, Los Chimalapas (Oaxaca); CRGUA, cordillera de Guanacaste (Costa Rica); CRCEN, cordillera Central (Costa Rica); CRTAL, cordillera de Talamanca; CRTIL, cordillera de Tilarán (Costa Rica); CUATR, Sierra de los Cuatro Venados (Oaxaca); CVER, centro de Veracruz; FELIP, cerro San Felipe (Oaxaca); GUACU, sierra de los Chuchumatanes (Guatemala); GUAMI, sierra de las Minas (Guatemala); GUAPA, costa Pacífica de Guatemala; GUERR, sierra de Atoyac (Guerrero); HIDAL, Hidalgo y norte de Veracruz; HONDU, Honduras y El Salvador; JUARE, sierra de Juárez (Oaxaca); MIAHU, sierra de Miahuatlán (Oaxaca); MICHO, costa de Michoacán; MONTE, lagunas de Montebello (Chiapas); NAYJA: Nayarit y Jalisco; NICAR, Nicaragua; SCRIS, San Cristóbal de las Casas (Chiapas); SINDU, Sinaloa y Durango; SOCON, sierra de Soconusco (Chiapas); TACAN, volcán de Tacaná; TAMPS, Tamaulipas y Nuevo León; TANCI, cerro de Tancítaro (Michoacán); TAXCO, sierra de Taxco (Guerrero); TEMAS, Temascaltepec (Estado de México); TUXTL, Los Tuxtlas (Veracruz); WPANA, oeste de Panamá; YUCUÑ, sierra de Yucuñacua (Oaxaca); ZEMPO, cerro de Zempoaltépetl (Oaxaca). 
componentes: sur de América Central (Costa Rica y oeste de Panamá), este de México al norte del Istmo de Tehuantepec, sur de Chiapas y norte de América Central, Eje Volcánico Transmexicano, Sierra Madre Occidental, Sierra Madre del Sur y centro de Oaxaca.

Pese a los problemas asociados con los análisis fenéticos, resulta interesante cómo se evidencian relaciones del elemento bióticos de bosque húmedo, ya reconocidas por estudios previos. Un análisis panbiogeográfico más reciente (Luna Vega et al., 2001) se llevó a cabo en bosques montañosos mesoamericanos y sudamericanos, llevando a reconocer relaciones complejas para los bosques de México y América Central.

Arriaga et al. (1997). En noviembre de 1997 se llevó a cabo un Taller sobre Regionalización en la Comisión para el Conocimiento y Uso de la Biodiversidad (Conabio), en el que participaron 20 expertos mexicanos y extranjeros, para generar un esquema biogeográfico de consenso. Inicialmente, los participantes del Taller analizaron 5 mapas temáticos, con características de relieve, clima, temperatura media anual, régimen de lluvias y vegetación potencial, y los compararon con los 4 sistemas biogeográficos que se resumen a continuación.

El sistema de Ferrusquía-Villafranca (1990), basado en rasgos morfotectónicos, posee 32 provincias, clasificadas en 2 dominios, 2 regiones y zonas de transición. El dominio Holártico (región Neártica) comprende las provincias Baja Californiense, Californiense, Sonorense, Sierra Madre Occidentalense, Chihuahuense, Coahuilense, Tamaulipense, Sierra Madre Orientalense, Altiplanense, Neovolcanense y 8 zonas de extensión regional y áreas adyacentes con asociaciones bióticas complejas. Son transicionales las provincias San Lucasense, Sinaloense y Veracruzense. El dominio Neotropical (región Mesoamericana) comprende las provincias Nayaritense, Jalisqueño-Guerrerense, Oaxaquense, Pacifiquense, Campechano-Petenense, Yucatense, Chiapasense y cuatro zonas de extensión regional y áreas adyacentes con asociaciones bióticas complejas.

El sistema de Rzedowski y Reyna-Trujillo (1990) incluye 16 provincias florísticas, clasificadas en dos reinos y cuatro regiones. El reino Holártico (región Pacífica Norteamericana) comprende las provincias de California y la Isla Guadalupe. El reino Neotropical comprende tres regiones: la región Mesoamericana de Montaña, con las provincias de la Sierra Madre Occidental, Sierra Madre Oriental, Serranías Meridionales y Serranías Transístmicas; la región Xerofítica Mexicana con las provincias de Baja California, Planicie Costera del Noroeste, Altiplanicie, Planicie Costera del Noreste y del Valle de TehuacánCuicatlán; y la región Caribea comprende las provincias de la Costa Pacífica, Depresión del Balsas, Soconusco, Costa del Golfo de México y Península de Yucatán.

El sistema de Casas-Andreu y Reyna-Trujillo (1990) incluye 15 provincias herpetofaunísticas: Californiana, Desierto Colorado-Sonorense, Peninsular, del Cabo, Sierra Madre Occidental, Desierto Chihuahuense, Tamaulipeca, Eje Neovolcánico, Sierra Madre Oriental, Sierra Madre del Sur, Veracruzana, del Petén, Mexicana del Oeste, Sierra Madre de Chiapas y Yucateca.

El sistema de Ramírez-Pulido y Castro-Campillo (1990) incluye 20 provincias mastofaunísticas clasificadas en 2 regiones. La región Neártica comprende las provincias de Baja California, Californiana, Sonorense, Sierra Madre Occidental, Chihuahuense, Sierra Madre Oriental, Tamaulipeca, Zacatecana y Volcánico-Transversa. La región Neotropical comprende las provincias de la Sierra Madre del Sur, Oaxaca-Tehuacanense, del Cabo, Sinaloense, Nayarita, del Balsas, Guerrerense, Chiapaneca, Yucateca y del Golfo.

Los 4 mapas correspondientes se digitalizaron y superpusieron con el objeto de determinar cuáles provincias eran compatibles. Las provincias resultantes se superpusieron con los temas de caracterización para ajustar sus límites. El sistema de consenso obtenido incluye 19 provincias (Fig. 22), clasificadas en 3 medios. El medio árido subtropical incluye las provincias de California, Baja California, del Cabo, Sonorense, Tamaulipeca, Altiplano Norte (Chihuahuense) y Altiplano Sur (Zacatecano-Potosino). El medio tropical húmedo y subhúmedo incluye las provincias de la Costa del Pacífico, Depresión del Balsas, Golfo de México, Yucatán y Petén. El medio montano incluye las provincias de la Sierra Madre Occidental, Sierra Madre Oriental, Eje Volcánico Transversal, Sierra Madre del Sur, Oaxaqueña, Altos de Chiapas y Soconusco.

El esquema biogeográfico de Arriaga et al. (1997) resulta interesante, pues consensa diferentes sistemas. Por ello, los componentes bióticos reconocidos como provincias resultan generalmente muy bien sustentados, aunque algunos de ellos deberían poseer estatus de distrito (Morrone et al., 2002).

Marshall y Liebherr (2000). Estos autores llevaron a cabo un análisis biogeográfico cladístico que incluyó 30 géneros o grupos de especies de insectos, peces, saurios y plantas. Las áreas estudiadas (Fig. 23) fueron Arizona, las tierras altas de Chiapas y Guatemala, Sierra Madre OccidentalAltiplano, Sierra Madre Oriental, Desierto de Sonora, sur de la Sierra Madre Occidental, Sierra Madre del Sur, cordillera de Talamanca y Eje Volcánico Transmexicano.

A partir de la aplicación de un análisis de parsimonia de Brooks (BPA), Marshall y Liebherr (2000) obtuvieron un cladograma general de áreas (Fig. 24). Éste posee una dicotomía básica entre un área septentrional, que reúne las Sierras Madre Occidental y Oriental, junto con los desiertos de Sonora y Arizona (Estados Unidos de América); y un área meridional que reúne al Eje Volcánico Transmexicano, la Sierra Madre del Sur, el sur de la Sierra Madre Occidental, la Sierra Madre de Chiapas y la cordillera de Talamanca en América Central. 


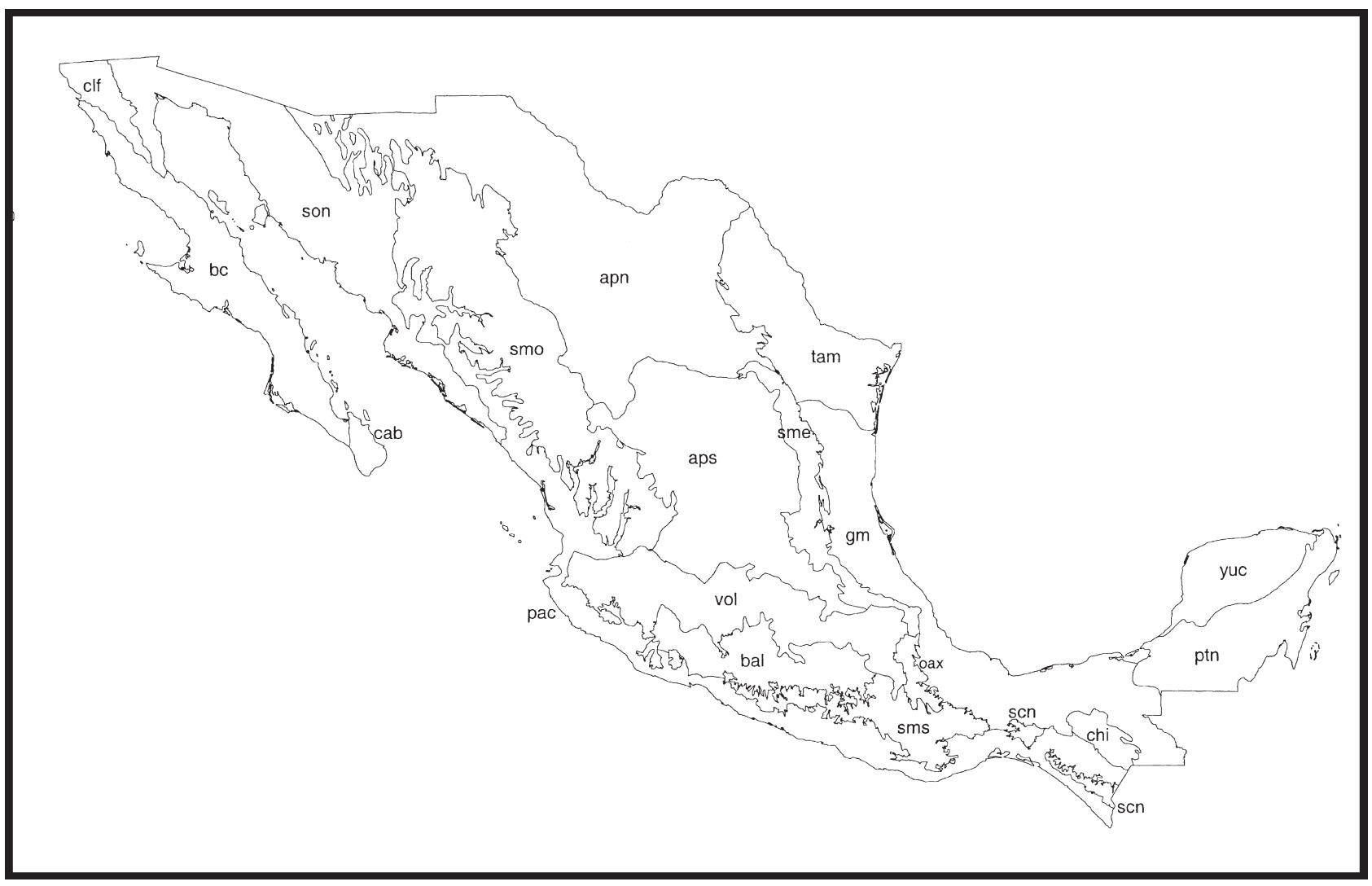

Figura 22. Provincias biogeográficas de México reconocidas por Arriaga et al. (1997). apn, Altiplano Norte; aps, Altiplano Sur; bal, depresión del Balsas; bc, Baja California; cab, del Cabo; chi, Los Altos de Chiapas; clf: California; gm, Golfo de México; oax, Oaxaca; pac, Costa del Pacífico; ptn, El Petén; scn, Soconusco; sme, Sierra Madre Oriental; smo, Sierra Madre Occidental; sms, Sierra Madre del Sur; son, Sonora; tam, Tamaulipeca; vol, Eje Volcánico; yuc, Yucatán.

El cladograma general de áreas obtenido por Marshall y Liebherr (2000) permite inferir la presencia de 2 componentes bióticos principales en México y América Central: uno situado al norte y otro al sur del Eje Volcánico Transmexicano. El límite en el Eje Volcánico Transmexicano difiere de análisis anteriores, que lo situaban en el Istmo de Tehuantepec. De acuerdo con los autores, el componente biótico situado al norte estaría caracterizado por un aislamiento reciente, probablemente pleistocénico, y la prevalencia de especies de distribución amplia. El componente del sur habría divergido después del cierre del Istmo de Tehuantepec, en el plioceno.

Otro análisis biogeográfico cladístico (Flores-Villela y Goyenechea, 2001), basado en taxones animales, permitió obtener dos cladogramas generales de áreas. Estos permiten inferir relaciones entre el desierto de Sonora y el desierto de Chihuahua; entre las tierras bajas del Pacífico del oeste de América Central, del Pacífico mexicano y la Cuenca del Balsas; entre las tierras semiáridas de Tamaulipas y sur de Texas y la Sierra Madre Occidental; y entre la Sierra Madre del Sur y el Eje Volcánico Transmexicano.

Zink et al. (2000). Estos autores analizaron los cladogramas de áreas de 6 grupos de aves que habitan básicamente tierras áridas de América del Norte, basados en secuencias de DNA mitocondrial (Fig. 25), mediante el programa DIVA, con el objeto de estimar la contribución relativa de la vicarianza y la dispersión a su historia biogeográfica.

Zink et al. (2000) obtuvieron 4 cladogramas generales de áreas diferentes, según el modo en que codificaron los taxones distribuidos ampliamente y las áreas ausentes. A partir del cladograma de consenso es posible reconocer 2 grupos de áreas: California y Baja California junto con el Desierto de Sonora; y el Desierto de Chihuahua, el matorral de Sinaloa y el sur de México. La disyunción entre éstos se debería a vicarianza. Este análisis es semejante al de Morafka et al. (1992).

Morrone (2001a). En un esquema biogeográfico de América Latina y el Caribe (Morrone, 2001a; véase también Morrone, 2001b, 2002c; Morrone et al., 2002), basado en análisis panbiogeográficos y biogeográficos cladísticos de distintos taxones animales y vegetales, reconocí para México 14 provincias biogeográficas, clasificadas en dos regiones. La región Neártica comprende las provincias de California, Baja California, Sonora, Altiplano Mexicano y Tamaulipas. La región Neotropical comprende las provincias de la Sierra 


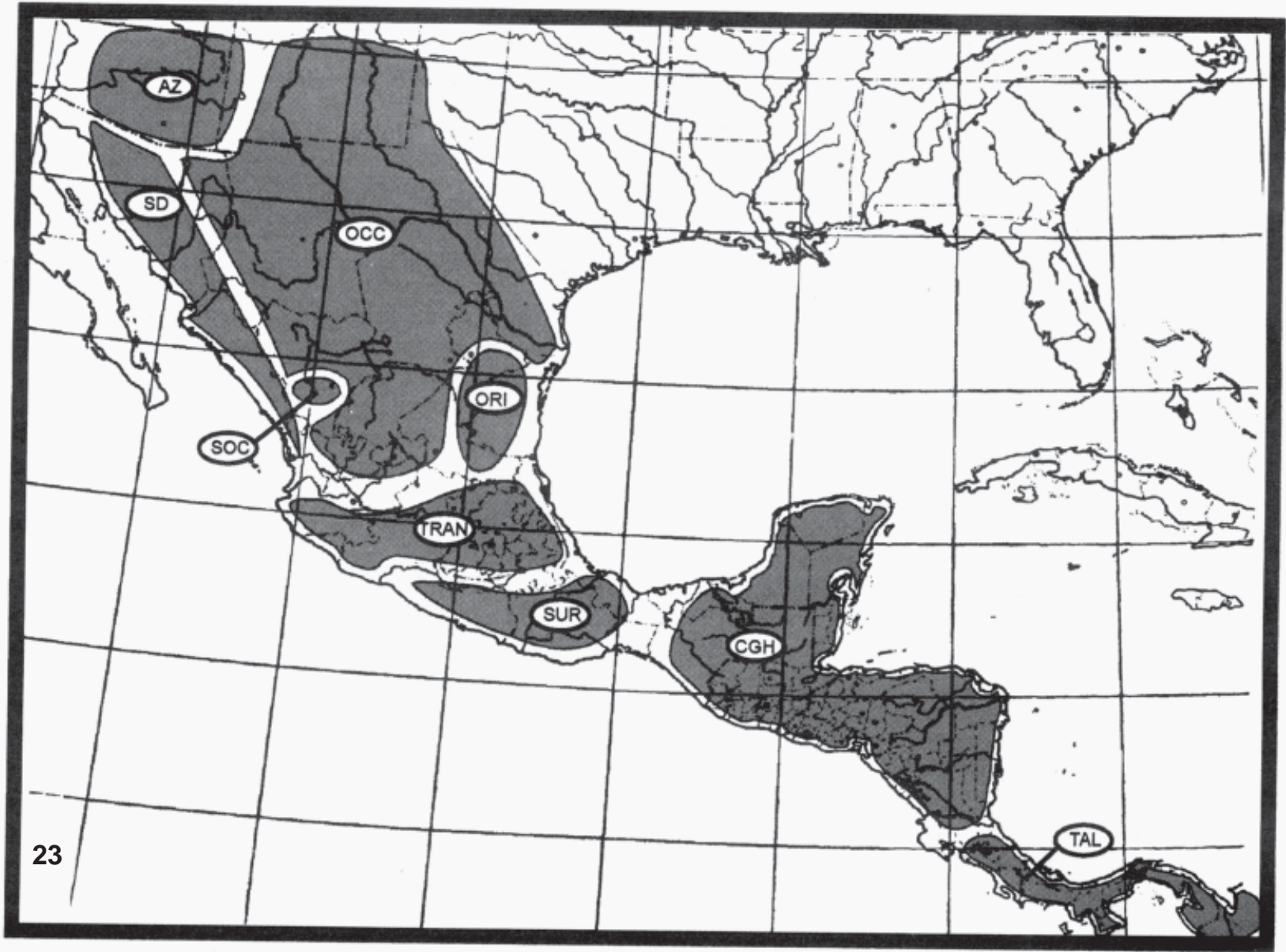

\section{4}
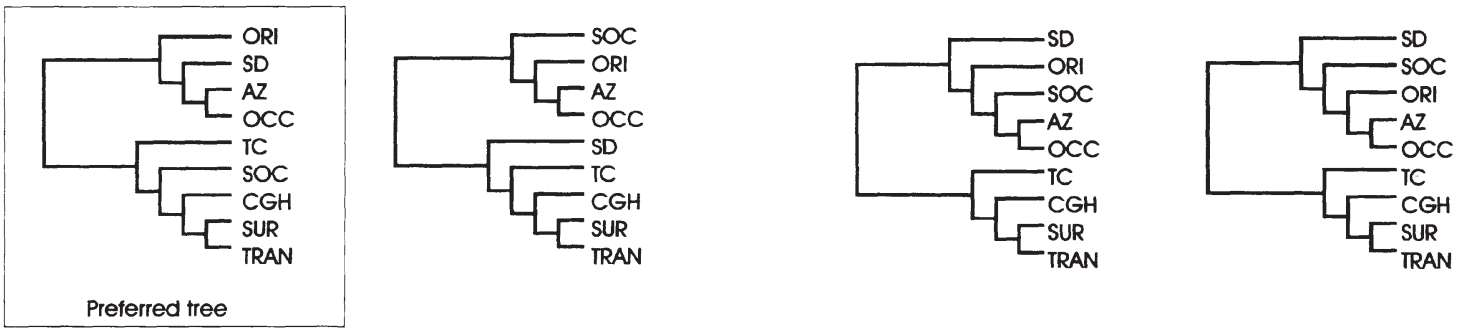

Figuras 23-24. Análisis biogeográfico cladístico de Marshall y Liebherr (2000). 23, Áreas analizadas; 24, cladogramas generales de áreas obtenidos (el recuadro señala el preferido por los autores). AZ, Arizona; CGH, tierras altas de Chiapas y Guatemala; OCG, Sierra Madre Occidental-Altiplano; ORI, Sierra Madre Oriental; SD, Desierto de Sonora; SOC, sur de la Sierra Madre Occidental; SUR, Sierra Madre del Sur; TAL, cordillera de Talamanca; TRAN, Eje Volcánico Transmexicano

Madre Occidental, Sierra Madre Oriental, Eje Volcánico Transmexicano, Cuenca del Balsas, Sierra Madre del Sur, Costa Pacífica Mexicana, Golfo de México, Península de Yucatán y Chiapas.

Este esquema es similar al de Arriaga et al. (1997), aunque considera 5 provincias como sinónimas de otras: del Cabo (= Baja California), El Petén (= Península de Yucatán), Oaxaqueña (= Sierra Madre del Sur), Soconusco (= Chiapas) y Altiplano Norte y Sur (= Altiplano Mexicano).
Con posterioridad (Morrone, 2004a, b), reconocí una Zona de Transición Mexicana en sentido estricto que reúne las provincias de la Sierra Madre Occidental, Sierra Madre Oriental, Eje Volcánico Transmexicano, Cuenca del Balsas y Sierra Madre del Sur. El análisis de Ortega y Arita (1998) llegó a una zona de transición semejante. Los análisis panbiogeográficos de Ochoa et al. (2003), Escalante et al. (2004) y Morrone y Gutiérrez (2005) corroboraron la naturaleza transicional de estas provincias. 

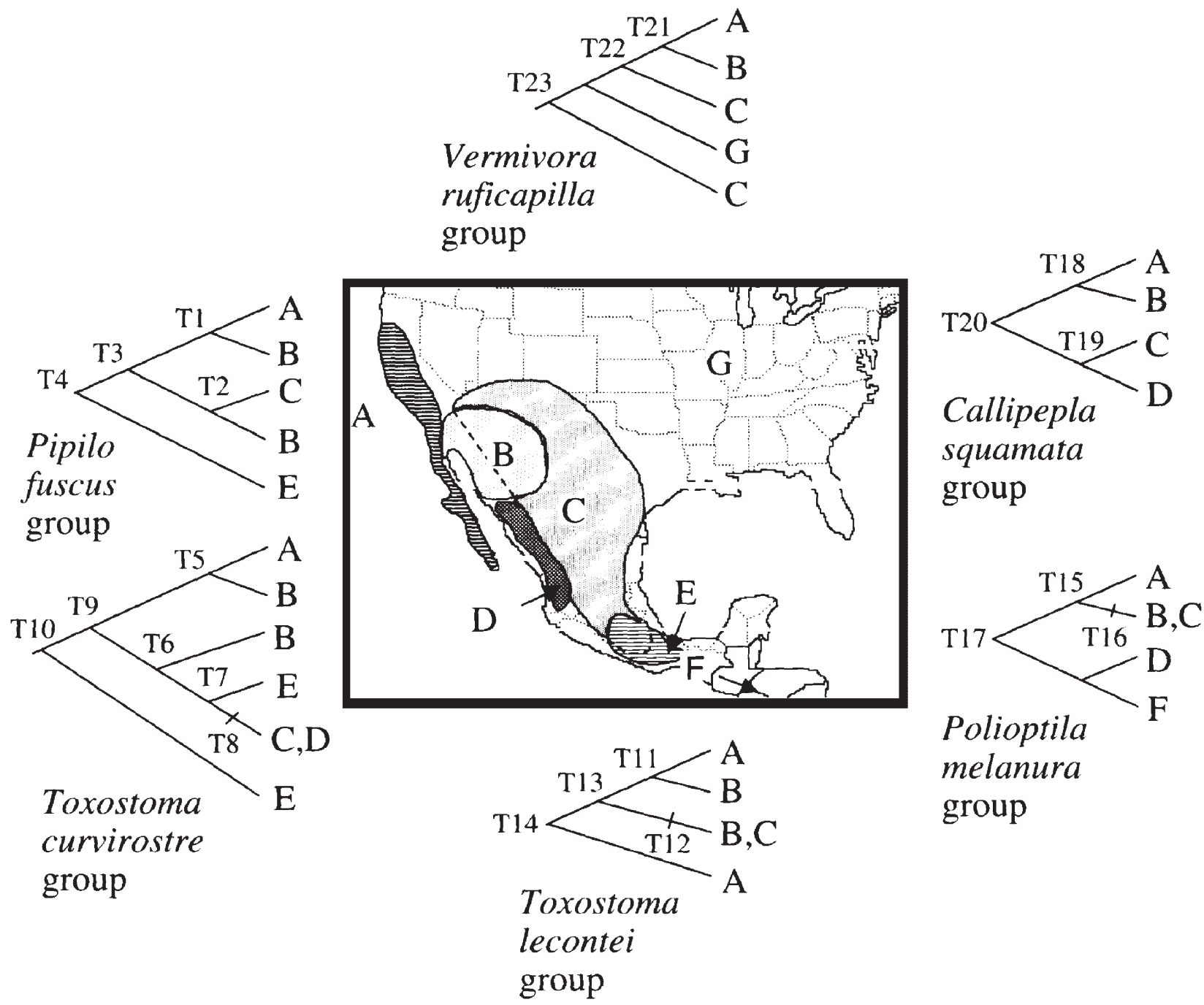

Figura 25. Análisis biogeográfico cladístico de Zink et al. (2000). Mapa con las áreas analizadas y cladogramas de los taxones. A, California y Baja California; B, Desierto de Sonora; C, Desierto de Chihuahua; D, matorral de Sinaloa; E, sur de México; F, América Central; G, este de América del Norte.

Contreras-Medina y Eliosa-León (2001). Estos autores llevaron a cabo un análisis panbiogeográfico de México basado en taxones animales y vegetales. A partir de la comparación de 73 trazos individuales, hallaron 3 trazos generalizados y 2 nodos (Fig. 26). El trazo Sudamericano abarca el sur de México, América Central y América del Sur; en México se bifurca en el área del Istmo de Tehuantepec, dirigiéndose una rama hacia el Golfo de México y la otra hacia el Pacífico. El trazo Norteamericano Occidental se extiende desde Alaska hasta la península de Baja California y el noroeste de México. El trazo Norteamericano Oriental se extiende desde el este de Canadá hasta el Golfo de México.

Las 2 ramas de la bifurcación del trazo generalizado Sudamericano se superponen con los extremos australes de los trazos generalizados Norteamericano Occidental y Oriental, respectivamente, delimitando 2 nodos. Uno se sitúa en las tierras bajas del Pacífico y el otro en las tierras bajas del Golfo de México.

Morrone y Márquez (2001). Estos autores llevaron a cabo un análisis panbiogeográfico de varios taxones del orden Coleoptera, distribuidos en México, América Central y las Antillas. Las áreas analizadas (Fig. 27) fueron las Sierras Madre Occidental, Oriental y del Sur, el Eje Volcánico Transmexicano, la Cuenca del Balsas, la Costa del Pacífico Mexicano, el Golfo de México, la península de Yucatán, Cuba, Chiapas, el este y centro de América Central, y el oeste del Istmo de Panamá.

El análisis de parsimonia de endemismos aplicado produjo un cladograma (Fig. 28) cuyos 2 clados principales fueron convertidos en trazos generalizados (Fig. 29). El trazo generalizado Septentrional abarca las Sierras 


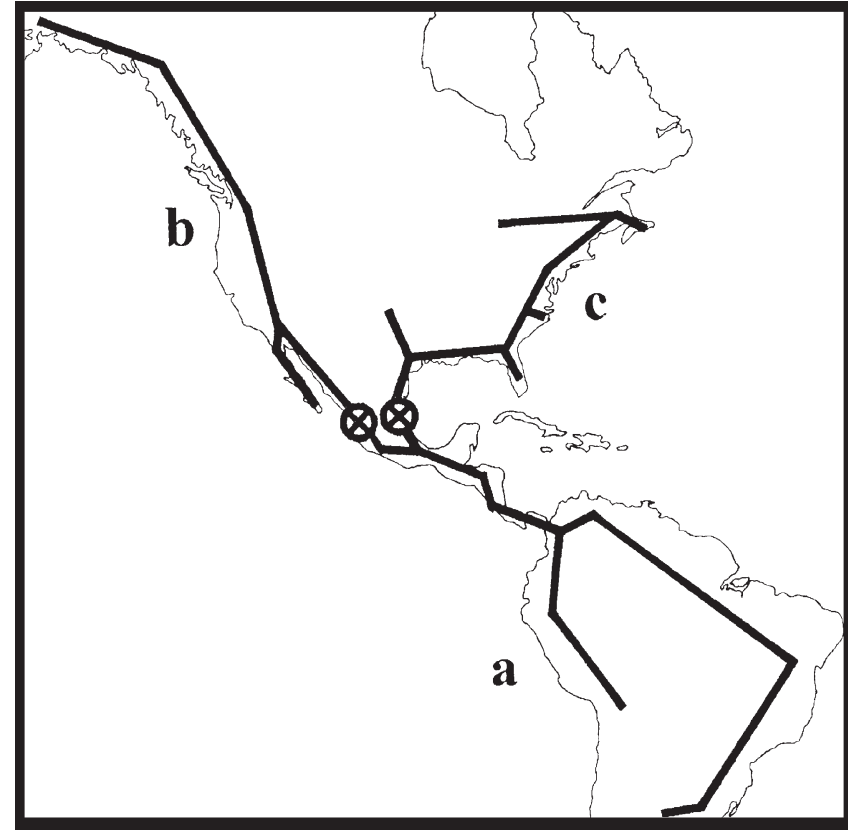

Figura 26. Análisis panbiogeográfico de Contreras-Medina y Eliosa-León (2001). a, Trazo generalizado Sudamericano; b, trazo Norteamericano Occidental; c, trazo Norteamericano Oriental.

Madre Occidental, Oriental y del Sur, el Eje Volcánico Transmexicano y la Cuenca del Balsas. El trazo generalizado Meridional comprende América Central, Chiapas y las costas del Pacífico y del Golfo de México. Este último es semejante al trazo Sudamericano de Contreras-Medina y Eliosa-León (2001).

Morrone y Márquez (2003) agregaron a éstos otros 3 trazos generalizados, con base en análisis previos: Neártico Californiano, Neártico Continental y Antillano (Fig. 30).

\section{Regionalización}

A continuación presento el esquema biogeográfico de México (Morrone, 2001a, b, 2002c, 2004a, b; Morrone et al., 2002), que comprende 14 provincias (Fig. 31), agrupadas en 2 regiones y una zona de transición.

Región Neártica. Comprende básicamente áreas templadofrías y áridas subtropicales de América del Norte, en Canadá, los Estados Unidos de América (excluyendo el sur de la península de Florida) y el norte de México. La región Neártica pertenece al reino Holártico, el cual corresponde al paleocontinente de Laurasia, incluyendo también a la región Paleártica (Europa, Asia al norte del Himalaya, África al norte del Sahara y Groenlandia). Existen numerosos trazos generalizados que conectan ambas regiones (Craw et al., 1999). Sanmartín et al. (2001) llevaron a cabo un análisis biogeográfico cladístico basado en 57 taxones animales, hallando una separación básica entre las regiones Neártica y
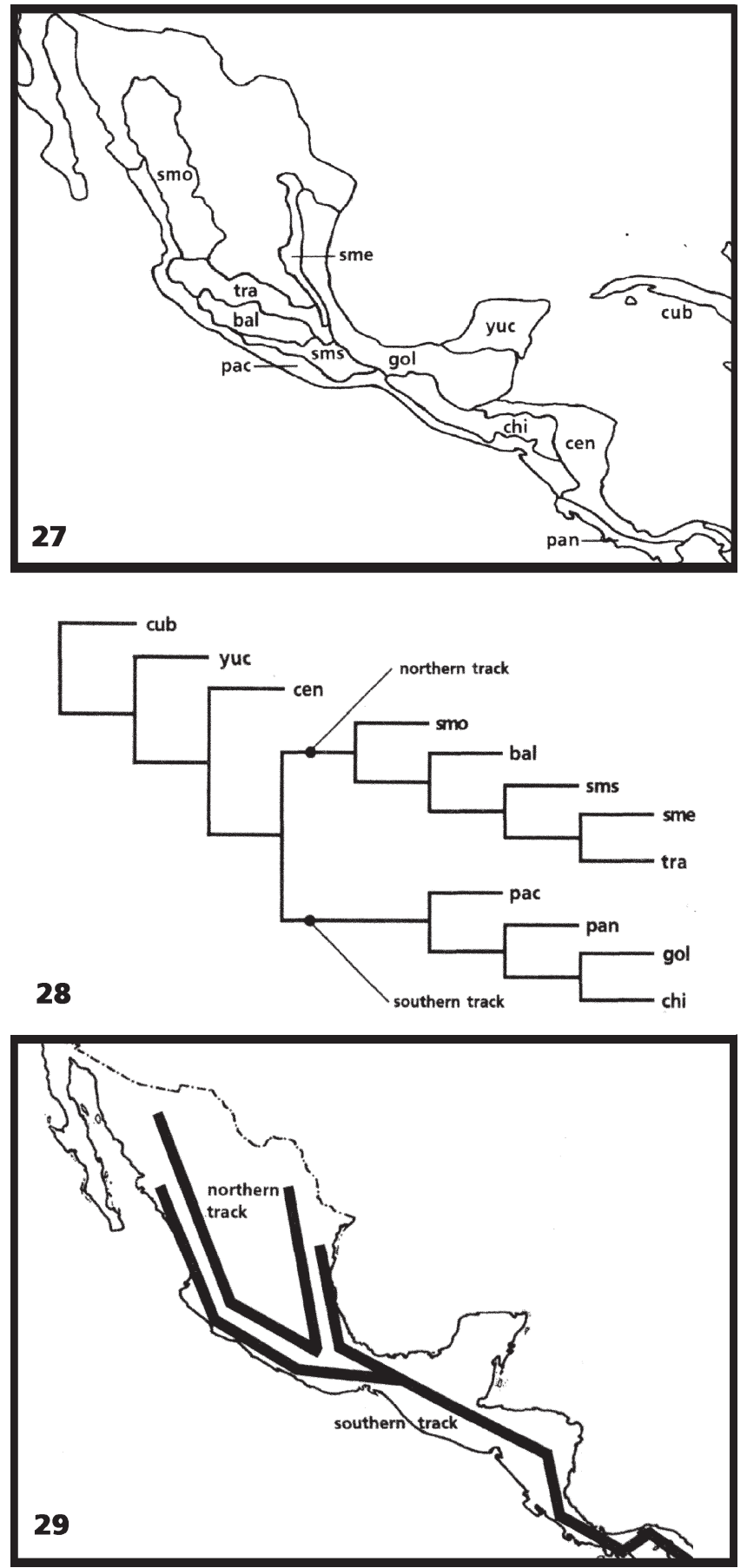

Figuras 27-29. Análisis panbiogeográfico de Morrone y Márquez (2001). 27, Áreas analizadas; 28, cladograma obtenido del análisis de parsimonia de endemismos; 29, trazos generalizados. bal, Cuenca del Balsas; cen, este y centro de América Central; chi, Chiapas; cub, Cuba; gul, Golfo de México; pac, Costa del Pacífico Mexicano; pan, oeste del Istmo de Panamá; sme, Sierra Madre Oriental; smo, Sierra Madre Occidental; sms, Sierra Madre del Sur; tra, Eje Volcánico Transmexicano; yuc, península de Yucatán.

Paleártica, debida a vicarianza.

Las 5 provincias de la región Neártica que corresponden a México, con excepción de la provincia de Baja California, se 


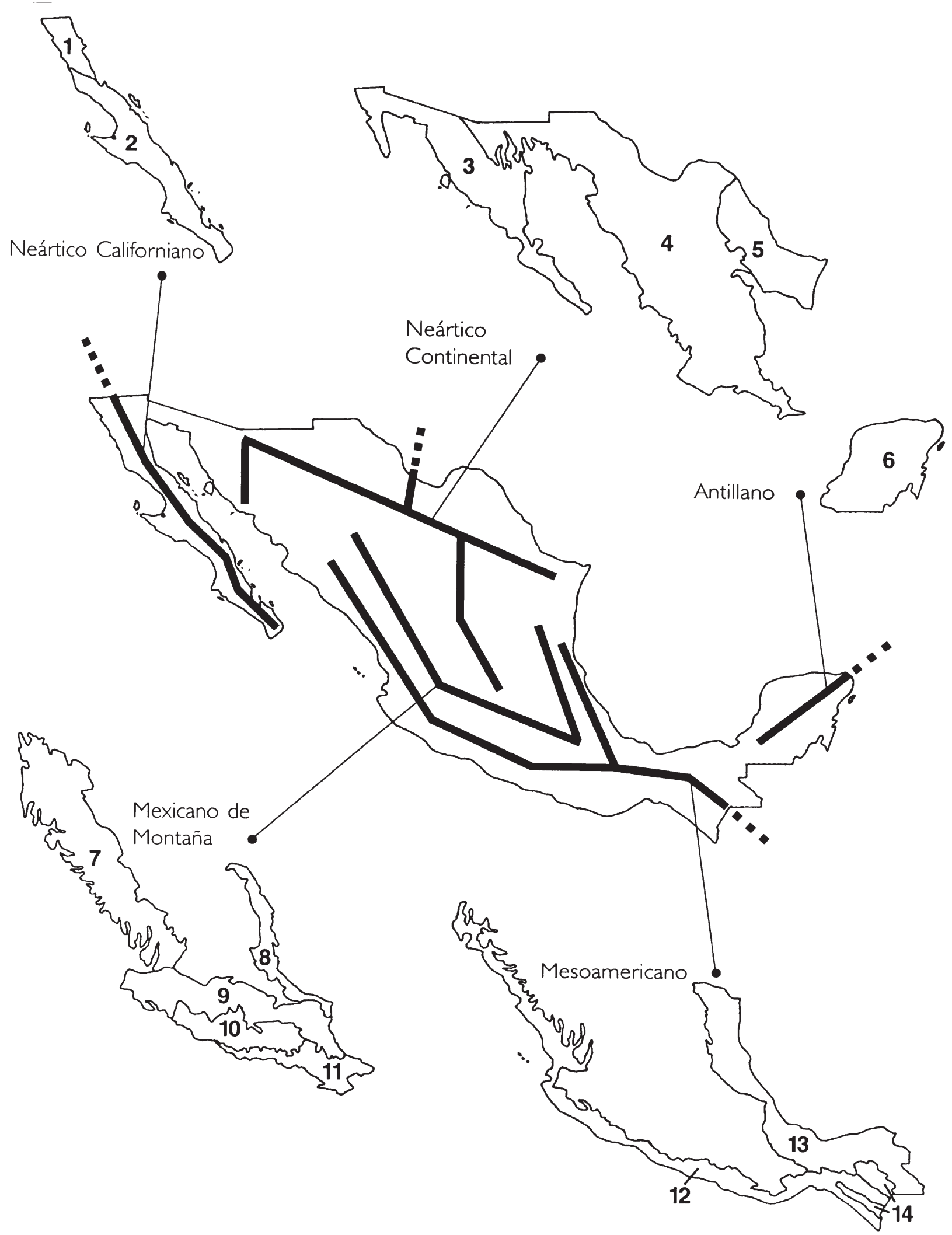

Figura 30. Trazos generalizados reconocidos por Morrone y Márquez (2003), junto con las provincias que los integran. 1, California; 2 , Baja California; 3, Sonora; 4, Altiplano Mexicano; 5, Tamaulipas; 6, Península de Yucatán; 7, Sierra Madre Occidental; 8, Sierra Madre Oriental; 9, Eje Volcánico Transmexicano; 10, Cuenca del Balsas; 11, Sierra Madre del Sur; 12, Costa Pacífica Mexicana; 13, Golfo de México; 14, Chiapas. 


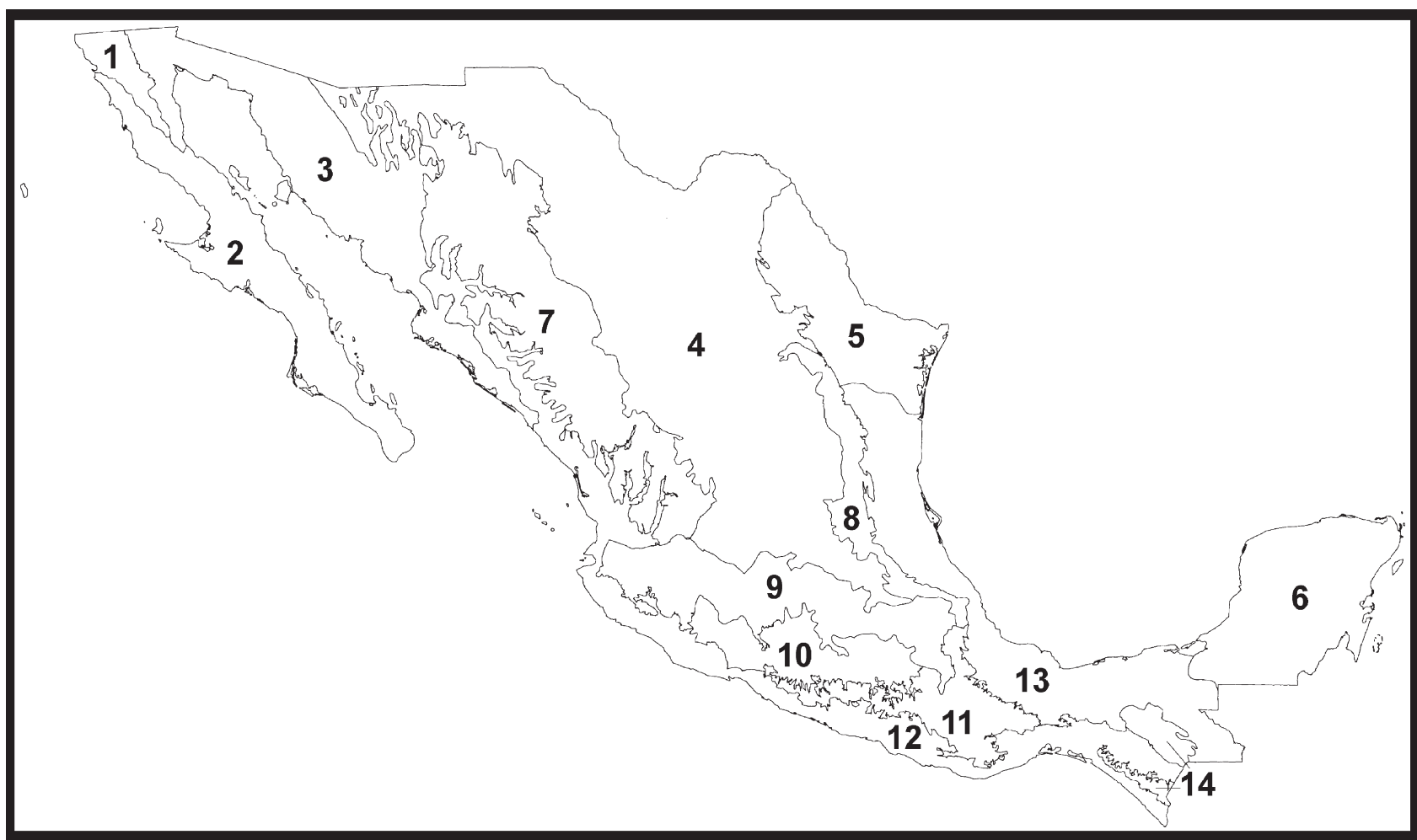

Figura 31. Provincias biogeográficas de México (Morrone, 2001a, b, 2004a, b). 1, California; 2, Baja California; 3, Sonora; 4, Altiplano Mexicano; 5, Tamaulipas; 6, Península de Yucatán; 7, Sierra Madre Occidental; 8, Sierra Madre Oriental; 9, Eje Volcánico Transmexicano; 10, Cuenca del Balsas; 11, Sierra Madre del Sur; 12, Costa Pacífica Mexicana; 13, Golfo de México; 14, Chiapas.

extienden hacia el norte hasta los Estados Unidos de América; ellas fueron asignadas a la subregión Pacífica Norteamericana (Morrone et al., 1999). De acuerdo con varios análisis recientes (Morrone et al., 1999; Zink et al., 2000; ContrerasMedina y Eliosa-León, 2001; Morrone y Escalante, 2002; Zink, 2002; Rojas-Soto et al., 2003; Escalante et al., 2004; Katinas et al., 2004), es posible agrupar estas provincias en 2 componentes bióticos, tratados como los dominios Californiano y Neártico Continental (Morrone y Márquez, 2003). El dominio Neártico Californiano comprende las provincias de California y Baja California, y el Neártico Continental las provincias de Sonora, Altiplano Mexicano y Tamaulipas. La provincia de Sonora, sin embargo, habría jugado un papel importante en la evolución biótica de la provincia de Baja California (Rzedowski, 1973; Morafka et al., 1992; Grismer, 1994; Zink et al., 2000), por lo cual cabría proponer otro componente biótico que la incluyera en el dominio Californiano.

\section{Provincia de California}

Provincia Sandieguina: Smith (1941: 109).

Provincia de California: Goldman y Moore (1945: 350), Rzedowski (1978: 101), Casas-Andreu y Reyna-Trujillo (1990: mapa), Ferrusquía-Villafranca (1990: mapa), Ramírez-Pulido y Castro-Campillo (1990: mapa), Rzedowski y Reyna-Trujillo (1990: mapa), Arriaga et al. (1997: 59), Morrone et al. (1999: 510), EspinosaOrganista et al. (2000: 64), Morrone (2002c: 270), Morrone et al. (2002: 86), Morrone (2004a: 193, 2004b: 155).

Provincia del Bosque Montano: Cabrera y Willink (1973: 30).

Provincia de San Pedro Mártir: Álvarez-Castañeda et al. (1995: 80).

Ecorregión de los Bosques de Pino y Roble de la Sierra de Juárez: Dinerstein et al. (1995: 102).

Ecorregión de Salvia Costero Californiano: Dinerstein et al. (1995: 108).

Área Californiana: Katinas et al. (2004: 182).

Se ubica en la porción septentrional de la península de Baja California, extendiéndose hacia el norte, a lo largo de la Sierra Nevada, hasta el sudoeste de los Estados Unidos de América. En esta provincia el sistema montañoso de Baja California alcanza su desarrollo máximo, en las sierras de San Pedro Mártir y Juárez, con 2400 m de altitud. Predomina el chaparral perennifolio, con especies de Adenostoma, Rhus, Ceanothus y otros arbustos; también hay matorrales de Artemisia, y bosques de coníferas y Quercus.

La provincia de California se caracteriza por taxones de helechos (Ophioglossaceae: Ophioglossum californicum, Katinas et al., 2004); selaginelas (Selaginellaceae: Selaginella asprella, Wagner y Smith, 1993); angiospermas 
(Asteraceae: Adenothamnus y Erigeron sanctarum, Villaseñor, 1990; Katinas et al., 2004; Fagaceae: Quercus douglasii, Katinas et al., 2004; Lamiaceae: Trichostema parishii, Rzedowski, 1978; Papaveraceae: Romneya, Katinas et al., 2004; Polygonaceae: Hollisteria, Katinas et al., 2004); mariposas (Pieridae: Euphydryas edita quino, Katinas et al., 2004); peces (Cyprinidae: Gilia bicolor mojavensis, Katinas et al., 2004); anfibios (Bufonidae: Bufo punctatus, Duellman y Sweet, 1999; Hylidae: Hyla cadaverina y $H$. regilla, Duellman y Sweet, 1999; Pelobatidae: Spea hammondii, Duellman y Sweet, 1999); escamados (Colubridae: Masticophis flagellum ruddocki, Katinas et al., 2004; Iguanidae: Sceloporus occidentalis, Arriaga et al., 1997); aves (Fringillidae: Carpodactus purpureus, Arriaga et al., 1997; Muscicapidae: Chamaea fascista, Arriaga et al., 1997; Passeridae: Agelaius tricolor, Arriaga et al., 1997; Phasianidae: Callipepla p. picta, Arriaga et al., 1997; Picidae: Melanerpes lewis y Picoides nuttallii, Arriaga et al., 1997; Sturnidae: Toxostoma redivivum, Arriaga et al., 1997); y mamíferos (Heteromyidae: Dipodomys ingens, D. venustus y Perognathus inornatus, Katinas et al., 2004; Muridae: Neotoma fuscipes martirensis y Peromyscus californicus insignis, Arriaga et al., 1997).

\section{Provincia de Baja California}

Provincia de Baja California: Smith (1941: 109), Goldman y Moore (1945: 351), Rzedowski (1978: 105), FerrusquíaVillafranca (1990: mapa), Ramírez-Pulido y CastroCampillo (1990: mapa), Rzedowski y Reyna-Trujillo (1990: mapa), Arriaga et al. (1997: 60), Morrone et al. (1999: 510), Espinosa-Organista et al. (2000: 64), Morrone (2002c: 270), Morrone et al. (2002: 87), Morrone (2004a: 193, 2004b: 155).

Provincia del Cabo de Baja California: Smith (1941: 109).

Provincia de la Isla Guadalupe: Goldman y Moore (1945: 350), Rzedowski (1978: 101), Rzedowski y ReynaTrujillo (1990: mapa).

Provincia del Desierto Vizcaíno: Goldman y Moore (1945: 351), Álvarez-Castañeda et al. (1995: 82).

Provincia del Cabo: Casas-Andreu y Reyna-Trujillo (1990: mapa), Ramírez-Pulido y Castro-Campillo (1990: mapa), Arriaga et al. (1997: 60), Morrone et al. (1999: 510), Espinosa-Organista et al. (2000: 64).

Provincia Peninsular: Casas-Andreu y Reyna-Trujillo (1990: mapa).

Provincia de San Lucas: Ferrusquía-Villafranca (1990: mapa).

Provincia de los Llanos de Magdalena: Álvarez-Castañeda et al. (1995: 81).

Provincia de las Tierras Bajas de los Cabos: ÁlvarezCastañeda et al. (1995: 81).

Provincia de la Sierra de la Laguna: Álvarez-Castañeda et al. (1995: 81).

Provincia de Santo Domingo: Álvarez-Castañeda et al.
(1995: 82)

Provincia San Dieguina: Álvarez-Castañeda et al. (1995: 82).

Ecorregión de los Bosques de Pino y Roble de San Lucas: Dinerstein et al. (1995: 102).

Ecorregión del Matorral Xérico de Baja California: Dinerstein et al. (1995: 109).

Ecorregión del Mezquital de San Lucas: Dinerstein et al. (1995: 109).

Se ubica en la península de Baja California, al sur de la provincia anterior. Está recorrida por el sistema montañoso de Baja California, el cual continúa hacia el norte, para unirse con las montañas de Alta California, en particular con la Sierra Nevada. En esta provincia se incluye la isla Guadalupe, situada a $200 \mathrm{~km}$ de la costa, que fuera tratada como una provincia independiente por Rzedowski (1978). La vegetación consiste en bosques secos, bosques de pinoencino y matorrales. Entre los géneros de plantas más frecuentes se encuentran Agave, Burragea, Coulterella, Franseria, Pachycormus, Pelucha y Yucca.

La provincia de Baja California se caracteriza por taxones de licopodiofitas (Selaginellaceae: Selaginella eremophila, Wagner y Smith, 1993); angiospermas (Asteraceae: Alvordia, Amauria, Boeberastrum y Pelucha, Villaseñor, 1990; Burseraceae: Bursera hindsiana, Arriaga et al., 1997); escorpiones (Chactidae: Nullibrotheas spp., Lourenço y Sissom, 2000; Diplocentridae: Bioculus spp., Lourenço y Sissom, 2000; Iuridae: Anuroctonus phaiodactylus, Lourenço y Sissom, 2000; Vaejovidae: Paravaejovis spp., Syntropis spp. y Vejovoidus spp., Lourenço y Sissom, 2000); coleópteros (Elateridae: Deroconus sleeperi, Johnson, 1995; Scarabaeidae: Coenocycha sleeperi, Evans y d'Hotman, 1988); ortópteros (Pyrgomorphidae: Atyphacris californica, Kevan, 1977); saurios (Eublepharidae: Coleonyx switacki, Dial y Grismer, 1992); serpientes (Viperidae: Crotalus enyo, Campbell y Lamar, 1989); y aves (Accipitridae: Parabuteo unicinctus, Rojas-Soto et al., 2003; Laridae: Larus livens, Arriaga et al., 1997; Muscicapidae: Polioptila melanura, Rojas-Soto et al., 2003; Paridae: Parus gambeli, Arriaga et al., 1997; Phasianidae: Callipepla californica, Arriaga et al., 1997; Strigidae: Glaucidium hoskinsi, Arriaga et al., 1997).

El análisis de parsimonia de endemismos de RojasSoto et al. (2003), basado en especies de aves, ha señalado la existencia de algunas áreas dentro de la Península de Baja California (Figs. 32-33) que, una vez que se adicione información de otros taxones, como por ejemplo plantas (ver Garcillán et al., 2003), podrían permitir el reconocimiento de distritos.

\section{Provincia de Sonora}

Provincia de Sinaloa: Smith (1941: 109), Goldman y Moore (1945: 355), Ferrusquía-Villafranca (1990: mapa), Ramírez-Pulido y Castro-Campillo (1990: mapa), Álvarez-Castañeda et al. (1995: 79). 

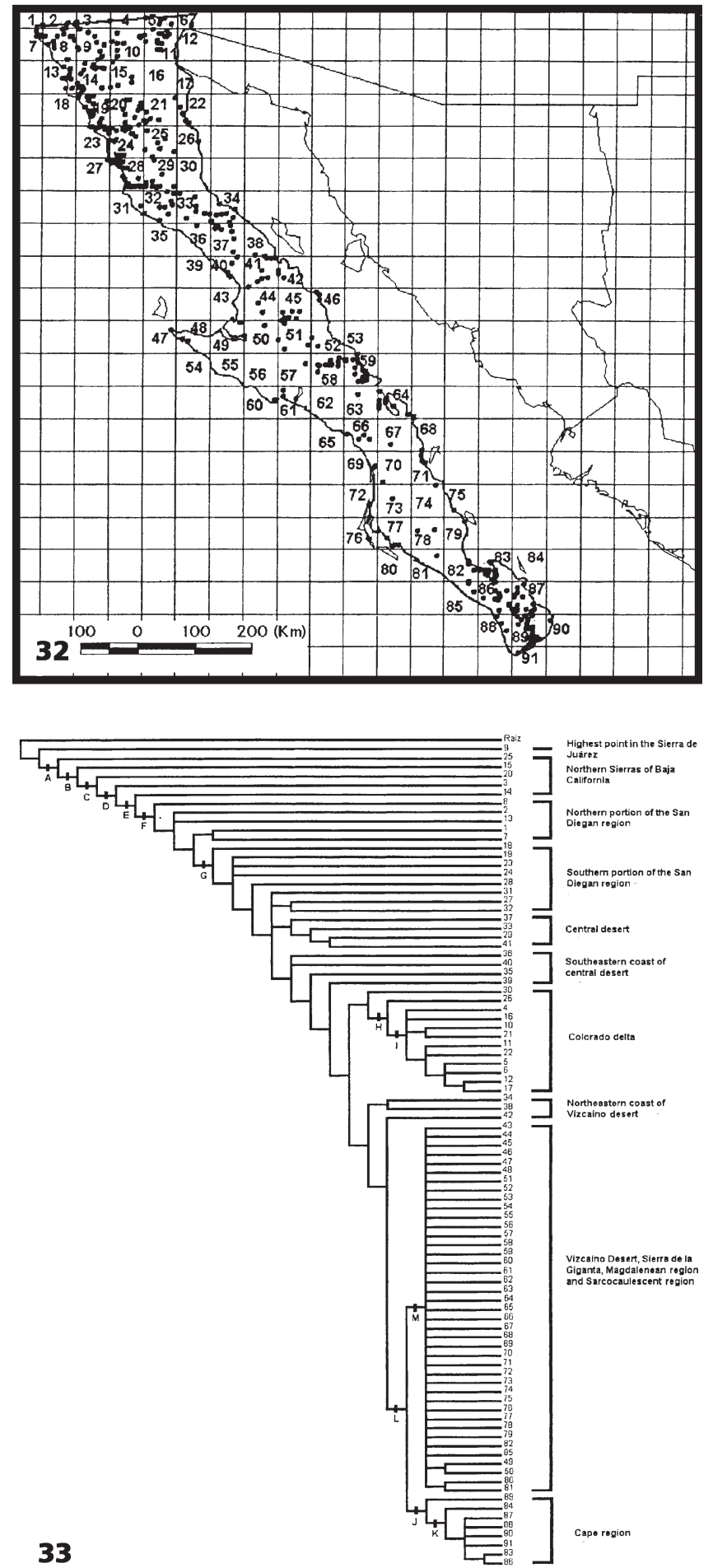

Figuras 32-33. Análisis de parsimonia de endemismos de la península de Baja California de Rojas-Soto et al. (2004). 32, Cuadrantes analizados; 33, cladograma obtenido.

Provincia Arizoniana: Smith (1941: 109).

Provincia de Sonora: Goldman y Moore (1945: 352), Ferrusquía-Villafranca (1990: mapa), Ramírez-Pulido y Castro-Campillo (1990: mapa), Álvarez-Castañeda et al. (1995: 81), Arriaga et al. (1997: 60), Morrone et al. (1999: 510), Espinosa-Organista et al. (2000: 64), Morrone (2002c: 270), Morrone et al. (2002: 88), Morrone (2004a: 193, 2004b: 155).

Provincia de la Planicie Costera del Noreste: Rzedowski (1978: 106), Rzedowski y Reyna-Trujillo (1990: mapa).

Provincia del Desierto Colorado-Sonorense: Casas-Andreu y Reyna-Trujillo (1990: mapa).

Provincia del Desierto del Altar: Álvarez-Castañeda et al. (1995: 80).

Provincia Guaymensis: Álvarez-Castañeda et al. (1995: 81). Provincia del Valle Inferior del Colorado: Álvarez-Castañeda et al. (1995: 82).

Ecorregión del Matorral Xérico de Sonora: Dinerstein et al. (1995: 110).

Ecorregión del Matorral de Cactos del Norte de Sonora: Dinerstein et al. (1995: 110).

Área Sonoriana: Katinas et al. (2004: 183).

Se ubica en la Planicie Costera Noroccidental de México, desde la porción nororiental de la península de Baja California hasta la cuenca del río Piaxtla en el sur, ocupando la mayor parte del estado de Sonora, la franja costera de Sinaloa, y porciones de los estados de Arizona y California, en los Estados Unidos de América. Es relativamente baja, no excediendo $1000 \mathrm{~m}$ de altitud, con llanuras interrumpidas por montañas de altura moderada y dunas. Predominan los matorrales xerófilos de Larrea divaricata y Franseria dumosa, alternando con bosques de cactos gigantes del género Cereus. Entre los géneros de plantas más frecuentes se encuentran Acacia, Agiabampoa, Canotia, Carnegiea, Cercidium, Forchammeria, Idria, Ipomoea, Lysiloma, Olneya, Pachycereus, Prosopis y Yucca.

La provincia de Sonora se caracteriza por taxones de helechos (Pteridaceae: Argyrochosma jonesii y Thelypteris puberula var. sonorensis, Morin, 1993); angiospermas (Asteraceae: Agiabampoa, Villaseñor, 1990; Burseraceae: Bursera laxiflora, Arriaga et al., 1997); coleópteros (Carabidae: Agonum parextimum, Liebherr, 1994b; Heteroceridae: Heterocerus unituberculosus, Miller, 1995; Scarabaeidae: Cotinis producta, Deloya y Ratcliffe, 1988); anfibios (Bufonidae: Bufo alvarius, Arriaga et al., 1997); serpientes (Viperidae: Crotalus cerastes, Campbell y Lamar, 1989); y aves (Fringillidae: Aimophila carpalis, Arriaga et al., 1997; Phasianidae: Callipepla gambelli, Arriaga et al., 1997; Sturnidae: Toxostoma bendirei, Arriaga et al., 1997).

\section{Provincia del Altiplano Mexicano}

Provincia Austro-Central: Smith (1941: 108).

Provincia Chihuahuense: Smith (1941: 109), FerrusquíaVillafranca (1990: mapa), Ramírez-Pulido y CastroCampillo (1990: mapa).

Provincia Apachiana: Smith (1941: 109).

Provincia de Chihuahua-Zacatecas: Goldman y Moore 
(1945: 354).

Provincia Xérica Mexicana, en parte: Cabrera y Willink (1973: 34).

Provincia del Desierto de Chihuahua: Casas-Andreu y Reyna-Trujillo (1990: mapa).

Provincia de Coahuila: Ferrusquía-Villafranca (1990: mapa), Ramírez-Pulido y Castro-Campillo (1990: mapa).

Provincia del Altiplano: Ferrusquía-Villafranca (1990: mapa), Rzedowski y Reyna-Trujillo (1990: mapa).

Provincia Zacatecana: Ramírez-Pulido y Castro-Campillo (1990: mapa).

Ecorregión del Matorral Xérico de Chihuahua: Dinerstein et al. (1995: 110).

Ecorregión del Matorral de Cactos del Centro de México: Dinerstein et al. (1995: 110).

Provincia del Altiplano Norte: Arriaga et al. (1997: 61), Morrone et al. (1999: 510), Espinosa-Organista et al. (2000: 64).

Provincia del Altiplano Sur: Arriaga et al. (1997: 62), Morrone et al. (1999: 510), Espinosa-Organista et al. (2000: 64).

Provincia del Altiplano Mexicano: Campbell (1999: 115), Morrone (2002c: 270), Morrone et al. (2002: 89), Morrone (2004a: 193, 2004b: 155).

Área Chihuahuense: Katinas et al. (2004: 183).

Área del Altiplano Mexicano: Katinas et al. (2004: 184). Corresponde al altiplano situado entre las Sierras Madre Occidental y Oriental, en los estados mexicanos de Zacatecas, San Luis Potosí, Guanajuato, Chihuahua, Jalisco, Michoacán, Tlaxcala, Puebla, Coahuila, Durango, Nuevo León y Sonora, y Nuevo México y el sur de Texas en los Estados Unidos de América. Su altitud varía entre 1000 y 2000 m. Abundan las cuencas endorreicas, algunas relativamente grandes, como las de los ríos Nazas, Aguanaval y Casas Grandes; y otras más reducidas, como las de los Bolsones de Mapimí y del Salado. La vegetación consiste en estepas de gramíneas de los géneros Bouteloua y Aristida, extendidas entre matorrales xéricos, y bosques en los llanos y valles intermontanos. Entre las especies de plantas más frecuentes se encuentran Andropogon citratus, Aristida glauca, Bouteloua aristidoides, B. eriopoda, B. hirsuta y Larrea divaricata var. tridentata.

La provincia del Altiplano Mexicano se caracteriza por taxones de licopodiofitas (Selaginellaceae: Selaginella viridissima y S. wrightii, Wagner y Smith, 1993); helechos (Pteridaceae: Argyrochosma limitanea var. mexicana y A. microphylla, Morin, 1993); angiospermas (Agavaceae: Yucca aloifolia, Y. decipes, $Y$. elephantipes, $Y$. potosina, $Y$. queretaroensis, $Y$. rigida y $Y$. zigadenus, Espinosa-Organista et al., 2000; Katinas et al., 2004; Asteraceae: Acourtia elizabethiae, Bartlettia, Dyscritothamnus, Geissolepis, Henricksonia, Hydrodyssodia, Leucactinia, Plateilema, Marshalljohnstonia y Stephanodoria, Villaseñor, 1990; Katinas et al., 2004; Berberidaceae: Berberis albicans,
Katinas et al., 2004; Burseraceae: Bursera medranoana y B. pinnata, Espinosa-Organista et al., 2000; Cactaceae: Lophophora diffusa y Mammillaria camptotricha, Katinas et al., 2004; Fabaceae: Acacia sororia, Leucaena stenocarpa y Pithecelobium recordii, Espinosa-Organista et al., 2000; Katinas et al., 2004; Juglandaceae: Juglans major, EspinosaOrganista et al., 2000; Lentibulariaceae: Pinguicula agnata, Katinas et al., 2004); coleópteros (Attelabidae: Pilolabus viridans, Espinosa-Organista et al., 2000; Carabidae: Agonum extimum y A. suturale, Liebherr, 1994b; Katinas et al., 2004; Dytiscidae: Deronectes roffi, Espinosa-Organista et al., 2000; Scarabaeidae: Cotinis rufipennis y Hologymnetis margaritas, Deloya y Ratcliffe, 1988); himenópteros (Halictidae: Paragapostemon, Katinas et al., 2004); anfibios (Ranidae: Rana dunni, R. forreri, R. magnaocularis, $R$. montezumae, $R$. neovolcanica, $R$. pustulosa, $R$. tlaloci, $R$. trilobata y $R$. zweifeli, Duellman y Sweet, 1999); y mamíferos (Heteromyidae: Perognathus f. flavus, P. f. medius y P. $f$. pallescens, Arriaga et al., 1997).

Arriaga et al. (1997) distinguieron una provincia del Altiplano Norte y otra del Altiplano Sur (Fig. 22). Pese a que ambas han sido tratadas como una provincia única por Morrone et al. (2002), información acerca de otros taxones quizá permitiría reconocer a estas entidades como distritos.

\section{Provincia de Tamaulipas}

Provincia de Tamaulipas: Smith (1941: 109), Goldman y Moore (1945: 354), Casas-Andreu y Reyna-Trujillo (1990: mapa), Ferrusquía-Villafranca (1990: mapa), Ramírez-Pulido y Castro-Campillo (1990: mapa), Morrone et al. (1999: 510), Espinosa-Organista et al. (2000: 64), Morrone (2002c: 270), Morrone et al. (2002: 90), Morrone (2004a: 193, 2004b: 155).

Provincia Tamaulipeca: Arriaga et al. (1997: 61).

Provincia de la Planicie Costera del Noroeste: Rzedowski (1978: 106), Rzedowski y Reyna-Trujillo (1990: mapa).

Ecorregión del Mezquital Oriental de México: Dinerstein et al. (1995: 110).

Área Tamaulipeca: Katinas et al. (2004: 183).

Se ubica en la porción septentrional de la Planicie Costera Nororiental de México, al norte de la cuenca del río Pánuco, en los estados mexicanos de Tamaulipas y Nuevo León, con pequeñas porciones de Coahuila, San Luis Potosí, el extremo norte de Veracruz y la porción adyacente del estado de Texas en los Estados Unidos de América. La Planicie Costera Nororiental de México ocupa tierras bajas al sur del río Bravo y limita al oeste con la Sierra Madre Oriental. La vegetación consiste en matorrales xerófilos y bosques espinosos, con abundantes agaves y cactos. Entre los géneros de plantas más frecuentes se encuentran Acacia, Aloysia, Celtis, Condalia, Prosopis y Ziziphus.

La provincia de Tamaulipas se caracteriza por taxones de helechos (Marsileaceae: Marsilea macropoda, Morin, 
1993); efedras (Ephedraceae: Ephedra pedunculata, Morin, 1993); angiospermas (Boraginaceae: Heliotropium torreyi, Katinas et al., 2004; Ebenaceae: Diospyros palmeri, Katinas et al., 2004; Euphorbiaceae: Croton torreyanus, Katinas et al., 2004; Fabaceae: Acacia rigidula y Mimosa malacophylla, Katinas et al., 2004; Lauraceae: Phoebe tampicensis, Katinas et al., 2004; Lentibulariaceae: Pinguicula gracilis, Katinas et al., 2004; Plantaginaceae: Leucophyllum frutescens, Katinas et al., 2004; Polygalaceae: Polygala glandulosa, Katinas et al., 2004; Rhamnaceae: Condalia hookeri, Katinas et al., 2004; Rutaceae: Amyris cordata, Katinas et al., 2004); opiliones (Nemastomatidae: Ortholasma sbordonii, Kury y Cokendolpher, 2000; Sclerosomatidae: Holcobunus mexicanus, Kury y Cokendolpher, 2000; Stygnommatidae: Stygnomma tuberculatum, Kury y Cokendolpher, 2000; Stynopsidae: Troglostygnopsis inops, Kury y Cokendolpher, 2000); coleópteros (Carabidae: Platynus bacatellus, Katinas et al., 2004); heterópteros (Reduviidae: Diaditus pictipes, Giacchi, 1982); peces(Cichlidae: Cichlasoma cyanoguttatum, Katinas et al., 2004; Poeciliidae: Gambusia marshi, Lydeard et al., 1995; saurios (Eublepharidae: Coleonyx brevis, Dial y Grismer, 1992); aves (Corvidae: Corvus imparatus, Arriaga et al., 1997; Troglodytidae: Thryothorus ludovicianus, Arriaga et al., 1997); y mamíferos (Sciuridae: Cynomys mexicanus, Katinas et al., 2004; Heteromyidae: Perognathus h. hispidus, Arriaga et al., 1997; Talpidae: Scalopus montanus, Katinas et al., 2004).

Zona de Transición Mexicana. Darlington (1957) sugirió la existencia de una zona de transición en América Central y México. En una serie de publicaciones referidas fundamentalmente a la entomofauna de zonas montañosas, Halffter (1962, 1964a, b, 1965, 1972, 1974, 1976, 1978, 1987, 2003) la definió como un área compleja y variada donde se superponen elementos bióticos neotropicales y neárticos. No solo resulta interesante la "mezcla" biótica de esta zona de transición, sino también la evolución in situ de numerosos taxones endémicos, lo cual la distingue de otras zonas de transición, como el Sahara entre las regiones Paleártica y Afrotropical.

De acuerdo con la concepción original de Halffter, la Zona de Transición Mexicana abarcaría el sudoeste de los Estados Unidos de América, México y América Central hasta las tierras bajas de Nicaragua. El istmo situado al sur del lago Nicaragua, en Costa Rica y Panamá, a pesar de su riqueza en especies endémicas, poseería afinidades mayores con la biota sudamericana, por lo que no pertenecería a la Zona de Transición Mexicana. Morrone (2004a, b) consideró apropiado restringir la Zona de Transición Mexicana a las provincias de la Sierra Madre Occidental, Sierra Madre Oriental, Eje Volcánico Transmexicano, Cuenca del Balsas y Sierra Madre del Sur. Equivale a la provincia Mesoamericana de Montaña (Cabrera y Willink, 1973), a la región Mesoamericana de Montaña (Rzedowski,
1978) y al componente Mexicano de Montaña (Morrone y Márquez, 2003). Los análisis panbiogeográficos de Ochoa et al. (2003), Escalante et al. (2004) y Morrone y Gutiérrez (2005) han corroborado la naturaleza transicional de estas provincias.

La Zona de Transición Mexicana en sentido restringido (Morrone, 2004a, b) comprende 5 provincias: Sierra Madre Occidental, Sierra Madre Oriental, Eje Volcánico Transmexicano, Cuenca del Balsas y Sierra Madre del Sur.

\section{Provincia de la Sierra Madre Occidental}

Provincia Durangueña: Smith (1941: 109).

Provincia de la Sierra Madre Occidental: Goldman y Moore (1945: 351), Rzedowski (1978: 102), Casas-Andreu y Reyna-Trujillo (1990: mapa), Ferrusquía-Villafranca (1990: mapa), Ramírez-Pulido y Castro-Campillo (1990: mapa), Rzedowski y Reyna-Trujillo (1990: mapa), Álvarez-Castañeda et al. (1995: 80), Arriaga et al. (1997: 64), Escalante et al. (1998: 285), Campbell (1999: 114), Morrone et al. (1999: 510), EspinosaOrganista et al. (2000: 64), Morrone (2001b: 47, 2002c: 270), Morrone et al. (2002: 91), Morrone (2004a: 194, 2004b: 157).

Ecorregión de los Bosques de Pino y Roble de la Sierra Madre Occidental: Dinerstein et al. (1995: 102).

Área de la Sierra Madre Occidental: Katinas et al. (2004: 183).

Se ubica en el oeste de México, en los estados de Chihuahua, Durango, Zacatecas, Sonora, Sinaloa, Nayarit y el norte de Jalisco, por encima de $1000 \mathrm{~m}$ de altitud. Ocupa el sistema montañoso de la Sierra Madre Occidental, el más largo y continuo de los sistemas orográficos mexicanos, que corre desde la costa del Océano Pacífico, al sur de la frontera mexicano-estadounidense, hasta la altura de Nayarit y Jalisco, donde converge con el Eje Volcánico Transmexicano. Posee $1400 \mathrm{~km}$ de largo y en algunos sitios supera los $200 \mathrm{~km}$ de ancho y $3000 \mathrm{~m}$ de altitud, siendo la altura promedio de sus partes más altas de 2000-2500 m. Predominan los bosques de pino y de pino-encino (Rzedowski, 1978; Dinerstein et al., 1995). Entre los géneros de plantas más frecuentes se encuentran Arnicastrum, Pinus, Pionocarpus, Pippenalia, Quercus, Stenocarpha y Trichocoryne.

La provincia de la Sierra Madre Occidental se caracteriza por taxones de licopodiofitas (Selaginellaceae: Selaginella mutica var. mutica, Wagner y Smith, 1993); helechos (Dryopteridaceae: Woodsia philipsii, Morin, 1993; Pteridaceae: Argyrochosma limitanea var. limitanea, Morin, 1993); gimnospermas (Pinaceae: Pinus engelmanii y P. strobiformis, Morin, 1993); angiospermas (Asteraceae: Alvordia congesta, Correlia, Damnxanthodium, Hofmeisteria sinaloensis, Perityle grandifolia, Pippenalia, Trichocoryne y Urbinella, Villaseñor, 1990; Katinas et al., 2004; Cactaceae: Ferocactus schwartzii, Mammillaria rubidea y Stenoccereus martinezii, Katinas et al., 2004; Crassulaceae: Echeveria 
kimnachii y Sedum copalense, Katinas et al., 2004; Ericaceae: Arbutusmadrensis, González-Elizondoy González-Elizondo, 1992; Euphorbiaceae: Ditaxis sinaloae, Katinas et al., 2004; Onagraceae: Lopezia ciliatula, L. conjugens, L. gentry, L. laciniata, L. lopezioides, L. semiandra, L. sinaloensis y $L$. suffrutescens, Katinas et al., 2004; Polygonaceae: Ruprechtia occidentalis, Katinas et al., 2004); escorpiones (Vaejovidae: Serradigitus spp., Lourenço y Sissom, 2000); coleópteros (Carabidae: Elliptoleus olisthopoides, Katinas et al., 2004; Cleridae: Enoclerus madrensis, Rifkind, 1994; Lampyridae: Photinus chihuahuensis y P. gorhami, Zaragoza Caballero, 1995; Scarabaeidae: Coscinocephalus cribrifrons, $C$. tepehuanus, Hologymnetis argenteola, Homoiosternus beckeriy Onthophagus coporoides, Lobo y Halffter, 1994; Morón, 1995; Morón y Ratcliffe, 1996; Delgado y BlackallerBages, 1997); neurópteros (Myrmeleontidae: Maracandula apicalis, Katinas et al., 2004); anfibios (Ambystomatidae: Ambystoma rosaceum, Arriaga et al., 1997); serpientes (Colubridae: Thamnophis nigronuchalis, Arriaga et al., 1997; Viperidae: Crotalus pricei y C. willardi, Campbell y Lamar, 1989); aves (Corvidae: Cyanocorax dickeyi, Arriaga et al., 1997; Psittacidae: Rhynchopsitta pachyrrhyncha, Arriaga et al., 1997; Trogonidae: Euptilotis neoxenus, Arriaga et al., 1997); y mamíferos (Muridae: Microtus mexicanus madrensis y Peromyscus aztecus spicilegus, Arriaga et al., 1997; Sullivan et al., 1997; Sciuridae: Glaucomys volans madrensis y Sciurus nayaritensis apache, Arriaga et al., 1997).

\section{Provincia de la Sierra Madre Oriental}

Provincia Austro-Oriental: Smith (1941: 108).

Provincia de Hidalgo: Smith (1941: 108).

Provincia de la Sierra Madre Oriental: Goldman y Moore (1945: 356), Rzedowski (1978: 103), Casas-Andreu y Reyna-Trujillo (1990: mapa), Ferrusquía-Villafranca (1990: mapa), Ramírez-Pulido y Castro-Campillo (1990: mapa), Rzedowski y Reyna-Trujillo (1990: mapa), Arriaga et al. (1997: 64), Escalante et al. (1998: 285), Campbell (1999: 114), Morrone et al. (1999: 510), Espinosa-Organista et al. (2000: 64), Morrone (2001b: 48, 2002c: 270), Morrone et al. (2002: 92), EspinosaOrganista et al. (2004: 487), Márquez y Morrone (2004: 375), Morrone (2004a: 194, 2004b: 157).

Ecorregión de los Bosques de Pino y Roble de la Sierra Madre Oriental: Dinerstein et al. (1995: 102).

Área de la Sierra Madre Oriental: Katinas et al. (2004: 184).

Se ubica en el este de México, en los estados de San Luis Potosí, Coahuila, Hidalgo, Nuevo León, Tamaulipas, Veracruz, Puebla y Querétaro, por encima de $1500 \mathrm{~m}$ de altitud. Corresponde al sistema montañoso de la Sierra Madre Oriental, que se extiende desde el centro de Nuevo León en el norte hasta Puebla y Veracruz en el sur, donde se une con el Eje Volcánico Transmexicano. La ladera occidental es más seca; la oriental es más húmeda, pues recibe los vientos alisios del Golfo de México. Esto, aunado a la existencia de valles alargados, facilita la existencia de elementos tropicales a elevaciones relativamente altas y elementos montañosos a altitudes menores. Predominan los bosques templados, principalmente de encino, aunque también hay bosques de pino y otras comunidades vegetales. Entre los géneros de plantas más frecuentes se destacan Carpinus, Cornus, Fagus, Greenmaniella, Hamamelis, Illicium, Loxothysanus, Mathiasella, Pinus, Platanus, Quercus y Schizandra.

La provincia de la Sierra Madre Oriental se caracteriza por taxones de gimnospermas (Pinaceae: Pinus culminicola, $P$. greggi y $P$. pinceana, Espinosa-Organista et al., 2004); angiospermas (Agavaceae: Agave tenuifolia, Zamudio-Ruiz y Sánchez-Martínez, 1995; Asteraceae: Greenmaniella y Viereckia, Villaseñor, 1990; Caprifoliaceae: Viburnum cuneifolium, Katinas et al., 2004; Celastraceae: Wimmeria concolor, Katinas et al., 2004; Fabaceae: Inga huastecana, Sousa, 1995; Fagaceae: Fagus grandifolia ssp. mexicana y Quercus rysophylla, Katinas et al., 2004; Juglandaceae: Juglans mollis, Rzedowski, 1978; Katinas et al., 2004; Oleaceae: Forestiera racemosa, Katinas et al., 2004; Onagraceae: Lopezia nuevoleonis, Katinas et al., 2004; Sabiaceae: Meliosma alba, Katinas et al., 2004); coleópteros (Carabidae: Calathus potosi, C. rotgeri y Platynus robustulus, Katinas et al., 2004; Passalidae: Odontotaenius zodiacus, Oileus nonstriatus, Petrejoides nebulosus, P. sylvaticus y Pseudacanthus aztecus, Castillo y Reyes-Castillo, 1984; Castillo et al., 1988; Reyes-Castillo, 2004; Scarabaeidae: Anopsiostes pauliani, Cotinis orientalis y Homoiosternus setosus, Deloya y Ratcliffe, 1988; Delgado y BlackallerBages, 1997; Delgado y Hernández, 1998; Staphylinidae: Styngetus deyrollei, Navarrete-Heredia, 1997); lepidópteros (Papilionidae: Parides alexiares, Priamides erostratus erostratinus y Pterourus palamedes leontis, LlorenteBousquets et al., 1997; Espinosa-Organista et al., 2004; Katinas et al., 2004); tisanópteros (Thripidae: Frankliniella oneillae y F. zacualtipana, Johansen, 1998); saurios (Anguidae: Abronia graminea y A. taeniata, Katinas et al., 2004); serpientes (Colubridae: Rhadinea gaigae, Arriaga et al., 1997); aves (Phasianidae: Dendrortix barbatus, Arriaga et al., 1997; Psittacidae: Rhynchopsitta terrisi, Arriaga et al., 1997; Strigidae: Glaucidium sanchezi, Arriaga et al., 1997); y mamíferos (Muridae: Peromyscus a. aztecas, Sullivan et al., 1997). Numerosos taxones endémicos de la Sierra Madre Oriental se detallan en las contribuciones de Balcázar Lara y Revuelta Morales (2004), Canseco-Márquez et al. (2004), Contreras-Medina (2004), Delgadillo-Moya (2004), Espinosa-Pérez et al. (2004) y Palacios-Vargas et al. (2004).

Existen varios análisis recientes que han reconocido unidades menores dentro de la Sierra Madre Oriental, basados en taxones de hongos (Cifuentes Blanco et al., 2004), anfibios y reptiles (Canseco-Márquez et al., 2004), aves (Navarro et al., 2004) y mamíferos (León-Paniagua et 
al., 2004). Espinosa-Organista et al. (2004) han reconocido cuatro distritos (Fig. 34), teniendo en cuenta taxones animales y vegetales. El distrito Parras-Saltillo se ubica en el extremo norte, abarcando parte de las Sierras SaltilloParras y Transversales, y el norte de la Gran Sierra Plegada. El distrito Potosí, al sur del anterior, abarca la Gran Sierra Plegada y marginalmente las Sierras y Llanuras Occidentales. Los otros dos distritos se encuentran en el sur de la Sierra Madre Oriental: el distrito de la Sierra Gorda se sitúa en el oeste del Carso Huasteco, estando delimitado por los ríos Moctezuma y Verde (afluentes altos del Pánuco); y el distrito de Zacualtipán abarca el este del Carso Huasteco.

\section{Provincia del Eje Volcánico Transmexicano}

Provincia Austro-Occidental: Smith (1941: 108).

Provincia Volcánica Transversal: Goldman y Moore (1945: 356), Ramírez-Pulido y Castro-Campillo (1990: mapa).

Provincia de las Serranías Meridionales, en parte: Rzedowski (1978: 103), Rzedowski y Reyna-Trujillo (1990: mapa).

Provincia del Valle de Tehuacán-Cuicatlán: Rzedowski (1978: 107), Rzedowski y Reyna-Trujillo (1990: mapa).

Provincia del Eje Neovolcánico: Casas-Andreu y ReynaTrujillo (1990: mapa), Escalante et al. (1998: 285), Morrone et al. (1999: 510).

Provincia Neovolcánica: Ferrusquía-Villafranca (1990: mapa).

Ecorregión de los Bosques de Roble del Centro de México: Dinerstein et al. (1995: 102).

Ecorregión de los Bosques de Pino y Roble Transvolcánicos de México: Dinerstein et al. (1995: 102).

Ecorregión del Matorral Xérico de Puebla: Dinerstein et al. (1995: 110).

Provincia del Eje Volcánico: Arriaga et al. (1997: 64), Morrone et al. (1999: 510), Espinosa-Organista et al. (2000: 64).

Provincia del Eje Volcánico Transmexicano: Morrone (2001b: 48, 2002c: 270), Morrone et al. (2002: 93), Morrone (2004a: 194, 2004b: 157).

Mesa Central: Pérez-Ponce de León (2003: 126), PérezPonce de León y Choudhoury (2005: 646).

Área del Eje Volcánico Transmexicano: Katinas et al. (2004: 183).

Se ubica en el centro de México, en los estados de Guanajuato, Distrito Federal, Estado de México, Jalisco, Michoacán, Puebla, Oaxaca, Tlaxcala y Veracruz. Corresponde básicamente al sistema montañoso del Eje Volcánico Transmexicano, situado aproximadamente a lo largo de los paralelos de $19^{\circ}$ y $20^{\circ}$ de latitud norte, que constituye el límite austral del Altiplano Mexicano y lo separa de la Cuenca del Balsas. El Eje Volcánico Transmexicano comenzó a desarrollarse durante el oligoceno, pero su actual configuración no finalizó hasta el holoceno. Posee 959 km

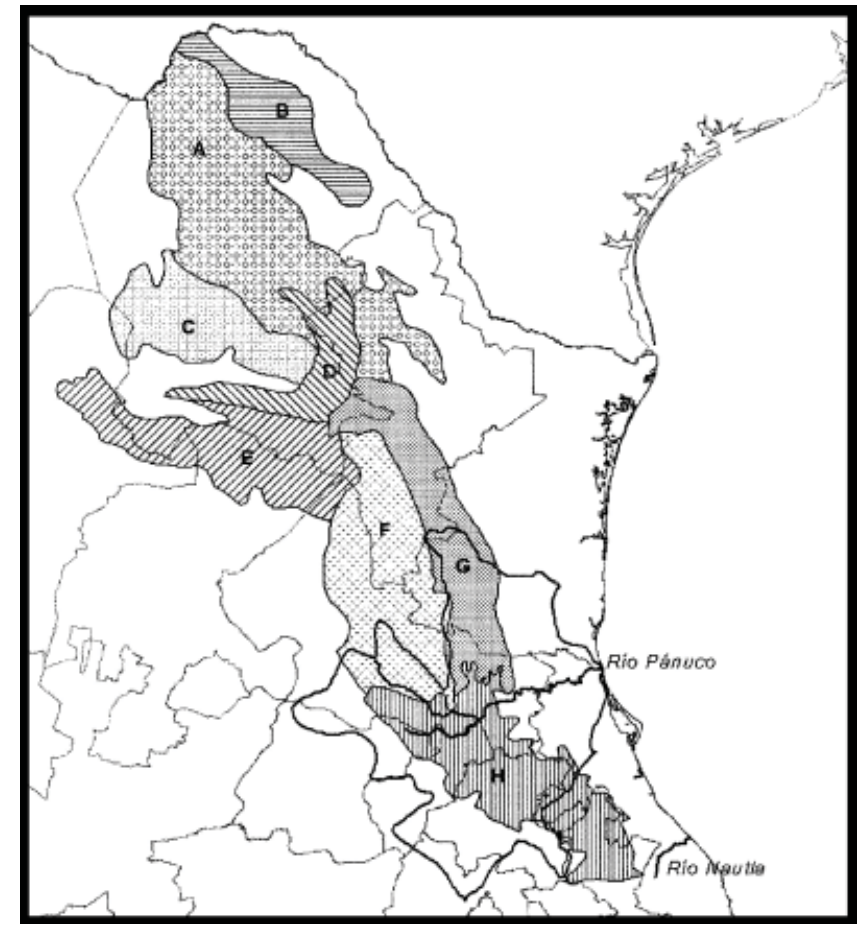

Figura 34. Mapa de la provincia fisiográfica de la Sierra Madre Oriental, sobre el cual Espinosa-Organista et al. (2004) reconocieron cuatro distritos biogeográficos. A, Sierras y Llanuras Coahuilenses; B, Serranía del Burro; C, Sierra de la Paila; D, Sierras SaltilloParra; E, Sierras Transversales; F, Sierras y Llanuras Occidentales; G, Gran Sierra Plegada; H, Carso Huasteco.

de longitud y $50-150 \mathrm{~km}$ de ancho, e incluye las elevaciones mayores del territorio mexicano. Su posición es privilegiada, ya que conecta entre sí las Sierras Madre Occidental, Oriental y del Sur, y ha constituido un evento vicariante importante para muchos taxones (Marshall y Liebherr, 2000; Mateos et al., 2002; Hulsey et al., 2004). Predominan los bosques de pino-encino; también existen "zacatonales" o pastizales alpinos cerca de la cima de los grandes volcanes. Entre los géneros de plantas más frecuentes se destacan Achillea, Alchemilla, Arenaria, Cerastium, Geranium, Hintonella, Lupinus, Microspermum, Omiltemia, Peyritschia, Pinus, Quercus, Ranunculus y Salvia.

La provincia del Eje Volcánico Transmexicano se caracteriza por taxones de angiospermas (Asteraceae: Cirsium nivale, Gnaphalium sarmentosum, G. vulcanicum, Montanoa frutescens, Senecio calcarius, S. gerberaefolius, S. procumbens y S. roseus, Funk, 1982; Katinas et al., 2004; Garryaceae: Garrya longifolia, Katinas et al., 2004; Meliaceae: Cedrela saxatilis, Katinas et al., 2004; Onagraceae: Lopezia longiflora, Katinas et al., 2004: Orchidaceae: Pleurothallis nigriflora, Katinas et al., 2004; Oxalidaceae: Oxalis cuernavacana y O. stolonifera, Katinas et al., 2004); gimnospermas (Pinaceae: Abies flinckii y Pinus rzedowski, Contreras-Medina, com. pers.); coleópteros 
(Carabidae: Calathus azteca, Elliptoleus corvus, E. luteipes y Platynus machetellus, Katinas et al., 2004; Passalidae: Odontotaenius cuspidatus y Petrejoides laticornis, Castillo et al., 1988; Reyes-Castillo, 2004; Scarabaeidae: Golofa globulicornis y Onthophagus hippopotamus, Lobo y Halffter, 1994; Morón, 1995); dípteros (Ceratopogonidae: Culicoides albomaculata, C. bakeri y C. dampfi, Arriaga et al., 1997; Mydidae: Mydas oaxacensis, Arriaga et al., 1997); himenópteros (Anthophoridae: Loxoptilus, Katinas et al., 2004; Formicidae: Polybia simillina, Arriaga et al., 1997); anfibios (Ambystomidae: Ambystoma rivularis, Katinas et al., 2004; Phletodontidae: Pseudoeurycea scandens, Arriaga et al., 1997; Ranidae: Rana montezumae, Arriaga et al., 1997); aves (Fringillidae: Geothlypis speciosa, Arriaga et al., 1997); y mamíferos (Didelphidae: Marmosa canescens oaxacae, Arriaga et al., 1997; Leporidae: Sylvilagus floridanus aztecas, Arriaga et al., 1997; Muridae: Neotomodon alstoni, Peromyscus aztecus hylocetes, P. leucotus y Reithrodontomys chrysopsis, Arriaga et al., 1997; Sullivan et al., 1997; Katinas et al., 2004; Sciuridae: Spermophilus m. mexicanus, Arriaga et al., 1997; Soricidae: Cryptotis goldmani alticola y Sorex vagrans orizabae, Arriaga et al., 1997).

\section{Provincia de la Cuenca del Balsas}

Provincia del Balsas Superior: Smith (1941: 108).

Provincia del Balsas Inferior: Smith (1941: 110).

Provincia de la Cuenca del Balsas: Rzedowski (1978: 108), Rzedowski y Reyna-Trujillo (1990: mapa), Arriaga et al. (1997: 62), Escalante et al. (1998: 285), Morrone et al. (1999: 510), Espinosa-Organista et al. (2000: 64), Morrone (2001b: 49, 2002c: 270), Morrone et al. (2002: 94), Morrone (2004a: 194, 2004b: 157).

Provincia del Balsas: Ramírez-Pulido y Castro-Campillo (1990: mapa).

Ecorregión de los Bosques Secos del Balsas: Dinerstein et al. (1995: 99).

Se ubica en el centro de México, en los estados de Guerrero, Jalisco, Michoacán, Morelos, Estado de México, Oaxaca y Puebla, por debajo de 2000 m de altitud, intercalada entre el Eje Volcánico Transmexicano y la Sierra Madre del Sur. La vegetación consiste en bosques tropicales secos y pastizales. Entre los géneros de plantas más frecuentes se encuentran Backebergia, Bursera, Castela, Haplocalymma y Pseudolopezia. Halffter (1964) considera que en la Cuenca del Balsas coexisten especies de insectos de filiación neotropical junto con otras del Altiplano Mexicano y del Eje Volcánico Transmexicano.

La provincia de la Cuenca del Balsas se caracteriza por taxones de angiospermas (Asteraceae: Boeberoides, Montanoa liebmannii, M. reveali y Stuessya, Funk, 1982; Villaseñor, 1990; Burseraceae: Bursera aloexylon, B. aptera, B. longipes, B. submoniliformis y B. trimera, Rzedowski, 1978; Kohlman y Sánchez, 1984; Arriaga et al., 1997; Fabaceae: Brongniartia montalvoana, Dorado y Arias, 1992); coleópteros (Scarabaeidae: Cotinis pueblensis, Deloya y Ratcliffe, 1988); aves (Certhiidae: Campylorhynchus jocosus, Arriaga et al., 1997; Fringillidae: Aimophila humeralis, Arriaga et al., 1997; Strigidae: Otus seductus, Arriaga et al., 1997); y mamíferos (Geomyidae: Orthogeomys grandis alleni, O. g. carbo, O. g. guerrerensis y O. g. soconuscensis, Arriaga et al., 1997).

\section{Provincia de la Sierra Madre del Sur}

Provincia de la Altiplanicie Oaxaqueña: Smith (1941: 107). Provincia Guerrerense: Smith (1941: 108).

Provincia de la Sierra Madre del Sur: Goldman y Moore (1945: 358), Casas-Andreu y Reyna-Trujillo (1990: mapa), Ramírez-Pulido y Castro-Campillo (1990: mapa), Arriaga et al. (1997: 65), Campbell (1999: 116), Morrone et al. (1999: 510), Espinosa-Organista et al. (2000: 64), Morrone (2001b: 49, 2002c: 270), Morrone et al. (2002: 95), Morrone (2004a: 194, 2004b: 157).

Provincia de las Serranías Meridionales, en parte: Rzedowski (1978: 103), Rzedowski y Reyna-Trujillo (1990: mapa).

Provincia de Oaxaca: Ferrusquía-Villafranca (1990: mapa), Arriaga et al. (1997: 65), Morrone et al. (1999: 510), Espinosa-Organista et al. (2000: 64).

Provincia Oaxaco-Tehuacanense: Ramírez-Pulido y CastroCampillo (1990: mapa).

Ecorregión de los Bosques de Pino y Roble de la Sierra Madre del Sur: Dinerstein et al. (1995: 103).

Ecorregión del Matorral de Cactos de Guerrero: Dinerstein et al. (1995: 111).

Provincia del Nudo del Zempoaltépetl: Escalante et al. (1998: 285).

Provincia de la Sierra de Mihuatlán: Escalante et al. (1998: 285).

Provincia de la Sierra Madre del Sur-Oaxaca: Escalante et al. (1998: 285).

Provincia de la Sierra Madre del Sur-Guerrero: Escalante et al. (1998: 285).

Área de la Sierra Madre del Sur: Katinas et al. (2004: 184).

Se ubica en el centro sur de México, desde el sur de

Michoacán hasta Guerrero, Oaxaca y parte de Puebla, por encima de $1000 \mathrm{~m}$ de altitud. Corresponde al sistema montañoso de la Sierra Madre del Sur, que corre en dirección noroeste-sureste paralelamente a la costa del Océano Pacífico, desde Jalisco hasta el Istmo de Tehuantepec. Su continuidad está interrumpida por valles, cuyos ríos se sitúan generalmente por encima de $1000 \mathrm{~m}$. Posee unos $1100 \mathrm{~km}$ de longitud y su ancho promedio es de $120 \mathrm{~km}$. Aunque la Sierra Madre del Sur posee un origen laramídico común con la Sierra Madre de Chiapas, hace unos 70 millones de años, ambas están separadas por la depresión del Istmo de Tehuantepec. Predominan los bosques de pino-encino; también hay matorrales de cactos. Entre los géneros de plantas más frecuentes figuran Achaenipodium, Chirantodendron, 
Hintonella, Microspermum, Omiltemia, Peyritschia, Pinus, Juniperus, Quercus y Salvia.

La provincia de la Sierra Madre del Sur se caracteriza por taxones de angiospermas (Agavaceae: Yucca mixtecana, Katinas et al., 2004; Asteraceae: Montanoa grandiflora, M. mollissima y M. tomentosa subsp. microcephala, Funk, 1982; Lauraceae: Mocinnodaphne cinnamonoidea, Katinas et al., 2004; Malvaceae: Hibiscus tenori, Katinas et al., 2004; Melastomataceae: Miconia teotepencis, Katinas et al., 2004; Onagraceae: Fuchsia ravenii y Lopezia smithii, Katinas et al., 2004; Ruscaceae: Maianthemum amoenum, M. macrophyllum y M. comaltepecense, Katinas et al., 2004); coleópteros (Carabidae: Calathus ovipennis, Elliptoleus crepericornis, E. whiteheadi y Platynus platynellus, Katinas et al., 2004; Passalidae: Petrejoides imbellis y P. jalapensis, Castillo y Reyes-Castillo, 1984; Scarabaeidae: Cotinis ibarrai y Onthophagus bassarisus, Deloya y Ratcliffe, 1988; Lobo y Halffter, 1994; Deloya, 1995; Staphylinidae: Gansia flavata, Ashe y Lingafelter, 1995); ortópteros (Pyrgomorphidae: Sphenarium p. purpurascens, Kevan, 1977); anfibios (Plethodontidae: Thorius grandis y T. infernalis, Katinas et al., 2004; Ranidae: Rana sierramadrensis, Arriaga et al., 1997); saurios (Anguidae: Abronia deppii, Katinas et al., 2004); serpientes (Viperidae: Porthidium barbouri, Campbell, 1988); aves (Trochilidae: Amazilia wagleri, Calothorax lucifer, Cynanthus sordidus y Eupherusa cyanophrys, Arriaga et al., 1997); y mamíferos (Muridae: Peromyscus aztecus evides, Sullivan et al., 1997).

Región Neotropical. Comprende los trópicos americanos, en el sur de México, América Central, las Antillas, el sur de la península de Florida y la mayor parte de América del Sur. De acuerdo con Sclater (1858) y Wallace (1876), esta región comprendía el área ubicada desde el norte de México hasta la Patagonia. Autores posteriores incluyeron a México y América Central dentro de la región Neártica (Schmidt, 1954), los trataron como un área de transición (Darlington, 1957) o incluso como una región independiente (Savage, 1966). En un sentido más restringido (Hershkovitz, 1969; Cabrera y Willink, 1973), la región Neotropical incluye la mayor parte de América del Sur, América Central, las Antillas, y el centro y sur de México. En América del Sur corresponde a la subregión o región Guyano Brasileña (Ringuelet, 1961), a la subregión Brasileña (Kuschel, 1969), al subreino Caribeño Amazónico (Rivas Martínez y Tovar, 1983) y al sistema Extra Andino (Morello, 1984); excluye los Andes, asignados a la región Andina y a la Zona de Transición Sudamericana (Morrone, 2004a, c). Existen evidencias de que antes del cuaternario, la biota neotropical sudamericana se expandió hacia el norte, a América Central y México (Halffter, 1964, 1987), y hacia el sur, a la región Andina y la Zona de Transición Sudamericana (Ringuelet, 1961; Morrone y Lopretto, 1994).

La región Neotropical está incluida en el reino
Holotropical, el cual comprende las áreas tropicales del mundo entre $\operatorname{los} 30^{\circ}$ de latitud norte y los $30^{\circ}$ de latitud sur, y que corresponde a la Gondwana oriental (Crisci et al., 1993). Las otras regiones del reino Holotropical son la Afrotropical o Etiópica (África central, la península Arábiga, Madagascar y las islas del Océano Pacífico occidental), Oriental (India, Malasia, Indonesia, las Filipinas y las islas del Pacífico) y Australiana Tropical (noroeste de Australia) (Rapoport, 1968; Morrone, 2001a, 2002a). La relación más estrecha con la región Afrotropical es evidenciada por varios trazos generalizados (Craw et al., 1999). Para analizar las relaciones entre las diferentes áreas que integran el reino Holotropical, Schuh y Stonedahl (1986) llevaron a cabo un análisis biogeográfico cladístico de varios taxones de la familia Miridae (Hemiptera); su cladograma general de áreas muestra 2 componentes bióticos mayores, que corresponden a Laurasia y Gondwana. Dentro de Gondwana hallaron una tricotomía entre el Indo-Pacífico (África tropical y la región Oriental), América tropical y las áreas templadas australes (Sudáfrica, América del Sur templada y Australia). En otro análisis biogeográfico cladístico (Amorim y Tozoni, 1994), basado en varios taxones de animales y plantas, se obtuvo un cladograma general de áreas sustentando la separación de Laurasia y Gondwana, con una separación posterior dentro de esta última de un componente circumtropical y otro circumantártico, equivalentes a los reinos Holotropical y Austral, respectivamente.

La región Neotropical comprende 4 subregiones: Caribeña, Amazónica, Chaqueña y Paranaense. Con base en un análisis de parsimonia de endemismos basado en taxones de anuros (Ron, 2000), un análisis biogeográfico cladístico basado en especies de primates e insectos (Amorim y Pires, 1996) y los análisis filogenéticos de algunos taxones de insectos (Morrone, 2002b; Nihei y Carvalho, 2004) es posible especular que la subregión Caribeña es el área hermana de las otras tres subregiones. La subregión Caribeña es la más septentrional de la región Neotropical, limitando al norte con la Zona de Transición Mexicana, que la separa de la región Neártica. Se extiende por el sur de México, Mesoamérica, las Antillas y el noroeste de América del Sur. La circunscripción aquí adoptada corresponde bastante fielmente con la región del Caribe de Samek (1988) y Borhidi (1996). Good (1974) y Gentry (1982), entre otros, extienden esta subregión a la península de Baja California o las áreas aquí asignadas a la Zona de Transición Mexicana. La historia geobiótica de la subregión Caribeña es muy compleja (Rosen, 1976, 1985; Savage, 1982; Samek, 1988; Crother y Guyer, 1996; Iturralde Vinent y MacPhee, 1999; López-Ramos, 2001), lo que se refleja en las relaciones múltiples con otras áreas neotropicales, con la región Neártica y con los trópicos del Viejo Mundo. Giunta et al. (1996) revisaron la historia tectónica de la placa Caribe y destacaron la presencia de porciones de corteza caribeña en las Antillas, Venezuela, Costa Rica y Guatemala, de edad jurásico-cretácica. 
La subregión Caribeña posee 24 provincias, las cuales se clasifican en 3 dominios: Mesoamericano, Antillano y Sudamericano Noroccidental (Morrone, 2004a, b). El dominio Mesoamericano abarca el sur de México y América Central, equivaliendo a las subregiones Centroamericana de Samek (1988) y Mesoamericana de Sánchez-Osés y Pérez-Hernández (1998, 2005). Con base en análisis panbiogeográficos, basados en Staphylinidae (Coleoptera) (Márquez y Morrone, 2003), Apidae (Hymenoptera) (Abrahamovich et al., 2004) y Buprestidae (Coleoptera) (Corona y Morrone, 2005), se planteó la existencia de componente bióticos menores dentro del dominio Mesoamericano separados por el Istmo de Tehuantepec y las tierras bajas de Nicaragua, los cuales serían nodos. El dominio Mesoamericano en México incluye las provincias de la Costa Pacífica Mexicana, Golfo de México y Chiapas. El dominio Antillano abarca las Antillas y la península de Yucatán. El dominio Antillano en México solo incluye la provincia de la Península de Yucatán. El dominio Sudamericano Noroccidental se restringe a América del Sur.

\section{Provincia de la Costa Pacífica Mexicana}

Provincia Tapachulteca: Smith (1941: 110).

Provincia Tehuanana: Smith (1941: 110).

Provincia de Nayarit-Guerrero: Goldman y Moore (1945: $355)$.

Provincia de Tehuantepec: Goldman y Moore (1945: 358), Barrera (1962: 101).

Provincia Escuintla-Usulután: Ryan (1963: 24).

Provincia de las Islas Revillagigedo: Goldman y Moore (1945: 352), Rzedowski (1978: 108), Rzedowski y Reyna-Trujillo (1990: mapa), Escalante et al. (1998: 285).

Provincia Chinandega: Ryan (1963: 27).

Provincia Xerófila Mexicana, en parte: Cabrera y Willink (1973: 34).

Centro Pacífico Americano: Müller (1973: 19).

Provincia de la Costa Pacífica: Rzedowski (1978: 107), Rzedowski y Reyna-Trujillo (1990: mapa), Arriaga et al. (1997: 62), Morrone et al. (1999: 510), EspinosaOrganista et al. (2000: 64), Morrone (2004a: 197).

Provincia Mexicana Occidental: Casas-Andreu y ReynaTrujillo (1990: mapa).

Provincia Pacífica: Ferrusquía-Villafranca (1990: mapa).

Provincia de Nayarit: Ferrusquía-Villafranca (1990: mapa).

Provincia Jaliscoana-Guerrerense: Ferrusquía-Villafranca (1990: mapa).

Provincia Guerrerense: Ramírez-Pulido y Castro-Campillo (1990: mapa).

Ecorregión de los Bosques Húmedos de Oaxaca: Dinerstein et al. (1995: 91).

Ecorregión de los Bosques Secos de Jalisco: Dinerstein et al. (1995: 99).

Ecorregión de los Bosques Secos del lado Pacífico de
América Central: Dinerstein et al. (1995: 99).

Ecorregión de los Bosques Secos de Sinaloa: Dinerstein et al. (1995: 99).

Ecorregión de las Sabanas de Tehuantepec: Dinerstein et al. (1995: 104).

Ecorregión de las Sabanas de Palmas de Jalisco: Dinerstein et al. (1995: 106).

Provincia de las Tierras Bajas del Istmo: Escalante et al. (1998: 285).

Provincia de la Costa Este Austral: Escalante et al. (1998: 285).

Provincia de las Islas Tres Marías: Escalante et al. (1998: 285).

Provincia de las Tierras Bajas del Pacífico: Campbell (1999: 117).

Provincia de la Costa Pacífica Mexicana: Morrone (2001b: 51, 2002c: 270), Morrone et al. (2002: 97, 2004b: 157).

Ocupa una franja angosta en la costa pacífica de México (estados de Sinaloa, Nayarit, Jalisco, Colima, Michoacán, Guerrero, Oaxaca y Chiapas), El Salvador, Honduras, Nicaragua, Costa Rica y Guatemala. También incluye el archipiélago de las Islas Revillagigedo (Socorro, San Benedicto y Clarión), situado en el Océano Pacífico. La vegetación consiste en bosques húmedos y secos, sabanas y palmares.

La provincia de la Costa Pacífica Mexicana se caracteriza por taxones de gimnospermas (Zamiaceae: Ceratozamia alvarezi, Contreras-Medina, com. pers.); angiospermas (Asteraceae: Eryngiophyllum, Matudina, Montanoa andersonii, M. laskowskii y M. standleyi, Funk, 1982, Villaseñor, 1990; Burseraceae: Bursera arborea, B. attenuata y B. excelsa, Rzedowski, 1978; Kohlman y Sánchez, 1984; Poaceae: Gouninia isabelensis, Ortiz-Díaz, 1993); coleópteros (Attelabidae: Euscelus rufiventris, Hamilton, 1997; Curculionidae: Tyloderma affine, Wibmer, 1989; Passalidae: Petrejoides olmecae, Castillo y Reyes-Castillo, 1984; Scarabaeidae: Onthophagus solisi y Viridimicus cyanochlorus, Jameson, 1990; Génier y Howden, 1999); dípteros (Ropalomeridae: Mexicoa mexicana, RamírezGarcía y Hernández-Ortiz, 1994; Simuliidae: Simulium pseudocallidum y S. veracruzanum, Coscarón et al., 1996); himenópteros (Apidae: Geotrigona acapulconis, Camargo y Moure, 1996); lepidópteros (Papilionidae: Battus eracon, Mimoides ilus occiduus y Pyrrhostica abderus baroni, Llorente-Bousquets et al., 1997; Pieridae: Dismorphia amphiona lupita, D. a. isolda, D. crisia alvarezi, Enantia lina sspp., Pieriballia viardi y Prestonia clarki, LlorenteBousquets et al., 1997); ortópteros (Pyrgomorphidae: Ichthiacris elongata, Kevan, 1977); anfibios (Hylidae: Hyla robertmertensi y H. sartori, Müller, 1973; Savage, 1982); serpientes (Viperidae: Bothrops langsbergi aphryomegas y Crotalus basiliscus, Müller, 1973; Campbell y Lamar, 1989); aves (Cracidae: Ortalis wagleri, Arriaga et al., 1997; Phasianidae: Callipepla douglasi, Arriaga et al., 1997; 
Psittacidae: Amazona finschi, Arriaga et al., 1997; Strigidae: Glaucidium hoskinsi, Arriaga et al., 1997); y mamíferos (Leporidae: Lepus flavigularis, Müller, 1973; Geomyidae: Orthogeomys grandis sspp., Arriaga et al., 1997; Sciuridae: Sciurus colliaei, Arriaga et al., 1997).

\section{Provincia del Golfo de México}

Provincia Veracruzana: Smith (1941: 110), Goldman y Moore (1945: 357), Barrera (1962: 101), Casas-Andreu y Reyna-Trujillo (1990: mapa).

Provincia de Tabasco-Palenque: Barrera (1962: 101).

Provincia de Lempira-Tegucigalpa: Ryan (1963: 25).

Provincia Xerófila Mexicana, en parte: Cabrera y Willink (1973: 34).

Centro de Bosque Lluvioso de América Central: Müller (1973: 10).

Provincia del Golfo de México: Rzedowski (1978: 109), Ferrusquía-Villafranca (1990: mapa), Rzedowski y Reyna-Trujillo (1990: mapa), Arriaga et al. (1997: 63), Morrone et al. (1999: 510), Espinosa-Organista et al. (2000: 64), Morrone (2001b: 49, 2002c: 270), Morrone et al. (2002: 96), Morrone (2004a: 197, 2004b: 157).

Provincia del Golfo: Ramírez-Pulido y Castro-Campillo (1990: mapa).

Ecorregión de los Bosques Húmedos de Tehuantepec: Dinerstein et al. (1995: 91).

Ecorregión de los Bosques Inundables de Belice: Dinerstein et al. (1995: 92).

Ecorregión de los Bosques Secos de Tamaulipas y Veracruz: Dinerstein et al. (1995: 99).

Ecorregión de los Bosques Secos de Veracruz: Dinerstein et al. (1995: 99).

Ecorregión de los Bosques de Roble de Veracruz: Dinerstein et al. (1995: 102).

Ecorregión de los Bosques de Pino de Belice: Dinerstein et al. (1995: 103).

Ecrregión de los Pastizales del Oriente de México: Dinerstein et al. (1995: 104).

Ecorregión de las Sabanas de Tabasco y Veracruz: Dinerstein et al. (1995: 104).

Ecorregión de las Sabanas de Palmas de Veracruz: Dinerstein et al. (1995: 106)

Provincia de la Sierra Norte de Chiapas: Escalante et al. (1998: 285).

Provincia de la Sierra de los Tuxtlas: Escalante et al. (1998: 285), Campbell (1999: 116).

Se ubica en la costa del Golfo de México, en el este de México (estados de Veracruz, Tabasco, Tamaulipas, San Luis Potosí, Hidalgo, Puebla, Oaxaca, Chiapas y Campeche), Belice y el norte de Guatemala. La vegetación consiste en bosques de encinos y de coníferas (donde domina Pinus caribaea), sabanas y palmares.

La provincia del Golfo de México se caracteriza por taxones de gimnospermas (Zamiaceae: Ceratozamia euryphyllidia, C. huastecorum, C. miqueliana y Zamia furfuracea, Contreras-Medina, com. pers.); angiospermas (Scrophulariaceae: Tetranema roseum, Méndez-Larios y Villaseñor, 1995); coleópteros (Attelabidae: Pilolabus purpureus y $P$. splendens, Hamilton, 1994; Curculionidae: Caecossonus sylvaticus, Howden, 1992; Heteroceridae: Heterocerus crossi, Miller, 1995; Pselaphidae: Eutrichites veracruzensis, Carlton, 1989; Scarabaeidae: Cotinis punctatostriata, Deloya y Ratcliffe, 1988); lepidópteros (Papilionidae:Troilidestolus, Llorente-Bousquets etal., 1997; Pieridae: Dismorphia eunoe popoluca, Llorente-Bousquets et al., 1997); ortópteros (Pyrgomorphidae: Sphenarium m. mexicanum, Kevan, 1977); peces (Poeciliidae: Gambusia eurystoma, Lydeard et al., 1995); anfibios (Hylidae: Hyla ebraccata y H. microcephala, Müller, 1973; saurios (Anguidae: Celestus eneagramus, Arriaga et al., 1997); serpientes (Elapidae: Micrurus elegans y M. limbatus, Campbell y Lamar, 1989); aves (Caprimulgidae: Caprimulgus maculicaudus, Arriaga et al., 1997; Emberizidae: Arremon arauntiirostris, Arriaga et al., 1997; Formicaridae: Taraba major, Arriaga et al., 1997; Icteridae: Psarocolinus wagleri, Arriaga et al., 1997; Momotidae: Electron carinatum, Arriaga et al., 1997; Tyrannidae: Deltarhynchus flammulatus y Ornithion semiflavum, Arriaga et al., 1997); y mamíferos (Dasyproctidae: Dasyprocta mexicana, Müller, 1973; Didelphidae: Caluromys derbianus aztecus, Arriaga et al., 1997; Muridae: Peromyscus leucopus incensus, Arriaga et al., 1997).

El análisis de parsimonia de endemismos de EspinosaPérez y Huidobro-Campos (2005), basado en especies de peces de agua dulce, ha señalado la existencia de algunas áreas (Fig. 35) que, una vez que se adicione información de otros taxones, podrían permitir el reconocimiento de distritos.

\section{Provincia de Chiapas}

Provincia de la Altiplanicie Chiapaneca: Smith (1941: 109). Provincia de los Altos de Chiapas: Goldman y Moore (1945: 359), Arriaga et al. (1997: 66), Espinosa-Organista et al. (2000: 64).

Provincia de Chiapas: Barrera (1962: 101), FerrusquíaVillafranca (1990: mapa), Ramírez-Pulido y CastroCampillo (1990: mapa), Morrone et al. (1999: 510), Morrone (2001b: 52, 2002c: 270), Morrone et al. (2002: 99), Morrone (2004a: 197, 2004b: 157).

Provincia de de las Tierras Altas de Chiapas-Guatemala: Ryan (1963: 23), Campbell (1999: 116).

Provincia Montana Nicaragüense: Ryan (1963: 28).

Centro del Bosque Montano de América Central: Müller (1973: 14).

Subcentro del Bosque Montano de Guatemala: Müller (1973: 14).

Provincia de las Serranías Transístmicas: Rzedowski (1978: 103), Rzedowski y Reyna-Trujillo (1990: mapa). 


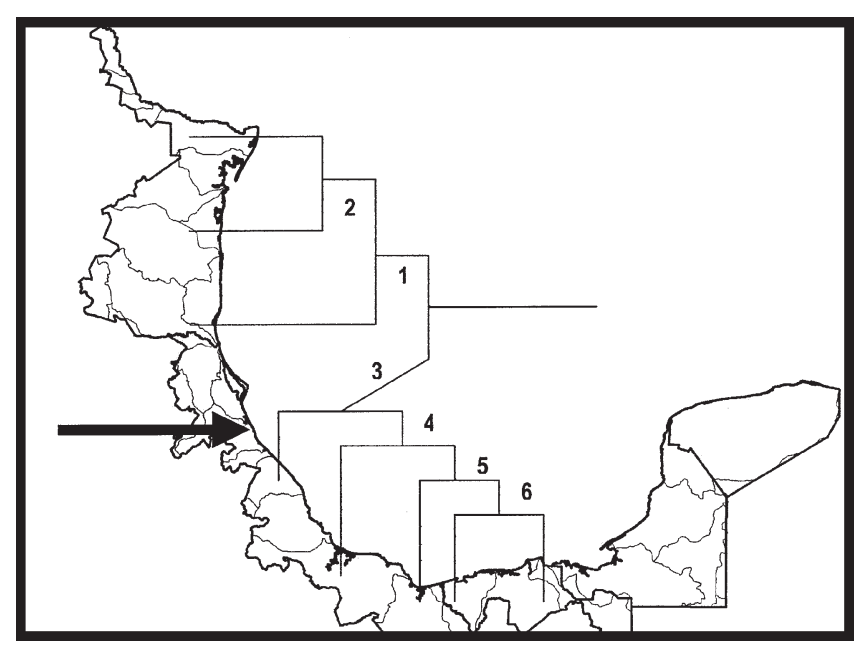

Figura 35. Cladograma del análisis de parsimonia de endemismos de peces dulceacuícolas del Golfo de México, obtenido por Espinosa-Pérez y Huidobro-Campos (2005).

Provincia de Soconusco: Rzedowski (1978: 109), Rzedowski y Reyna-Trujillo (1990: mapa), Arriaga et al. (1997: 66), Morrone et al. (1999: 510), Espinosa-Organista et al. (2000: 64).

Provincia de las Sierra Madre de Chiapas: Casas-Andreu y Reyna-Trujillo (1990: mapa).

Ecorregión de los Bosques Húmedos de la Sierra Madre: Dinerstein et al. (1995: 92).

Ecorregión de los Bosques Montanos de América Central: Dinerstein et al. (1995: 92.

Ecorregión de los Bosques de Pino y Roble de América Central: Dinerstein et al. (1995: 103).

Ecorregión de los Matorrales Xéricos del Valle de Motagua: Dinerstein et al. (1995: 111).

Se ubica en el sur de México, Guatemala, Honduras,

El Salvador y Nicaragua; básicamente corresponde a la Sierra Madre de Chiapas, desde 500 a 4000 m de altitud. La topografía presenta un patrón complejo, con volcanes de hasta $4000 \mathrm{~m}$ de altura y valles profundos, caracterizado por una gran variación climática. Incluye dos sistemas montañosos diferentes: el Macizo Central de Chiapas, que constituye la proyección septentrional del sistema montañoso Centroamericano y que alcanza su mayor altitud (2860 m) en la región de San Cristóbal; y la Sierra Madre de Chiapas, que se extiende a lo largo del litoral pacífico del estado de Chiapas, que va de 1000 a 3000 m. La vegetación consiste en bosques de pino-encino, sabanas y matorrales. En la provincia de Chiapas se encuentra la distribución más austral de varios grupos neárticos (Halffter, 1987; Conroy et al., 2001; Escalante et al., 2004).

La provincia de Chiapas se caracteriza por taxones de angiospermas (Asteraceae: Chionolaena sartorii, Montanoa echinacea, M. guatemalensis y M. pteropoda, Funk, 1982;
Freire, 1993; Cecropiaceae: Cecropia silvicola, Franco y Berg, 1997; Fabaceae: Leucaena greggii, Espinosa-Organista et al., 2000; Gunneraceae: Gunnera kilipiana, Rzedowski, 1978; Scrophulariaceae: Tetranema evolutum, MéndezLarios y Villaseñor, 1995); lombrices (Acanthodrilidae: Lavellodrilus, Fragoso, 1988); opiliones (Caddidae: Acropsopilio chomulae, Kury y Cokendolpher, 2000; Sclerosomatidae: Geaya lineada, Kury y Cokendolpher, 2000); coleópteros (Cerambycidae: Aneflus poriferus, Eburia schusteri, Megapsyrassa testacea, M. chiapaneca, Oxycoleus piceus, Pachymerola wappesi, Rhodoleptus nigripennis y Semanotus australis, Giesbert, 1993; Cleridae: Enoclerus gabriellae, Rifkind, 1994; Curculionidae: Hadromeropsis scintillans y Phymatophosus scapularis, Espinosa-Organista et al., 2000; Passalidae: Ogypes y Petrejoides guatemalae, Castillo y Reyes-Castillo, 1984; Schuster y Reyes-Castillo, 1990; Scarabaeidae: Apeltastes chiapasensis, Geotrupes pilanolensis, Golofa championi, Hologymnetis kinichahau, Trigonopletastes glabella y Viridimicus aurescens, Jameson, 1990; Howden, 1988, 1994a, b; Morón, 1995; Staphylinidae: Bledius strenuus, Gansia andersoni, G. fortemaculata, G. tibialis y Styngetus championi, Ashe y Lingafelter, 1995; Navarrete-Heredia, 1997; EspinosaOrganista et al., 2000); heterópteros (Lygaeidae: Toonglasa indomita, Slater y Brailovsky, 1994; Miridae: Atractotomus teopisca, Stonedahl y Schwartz, 1994); lepidópteros (Papilionidae: Baronia brevicornis rufodiscalis, Parides panares lycimenes y Priamides e. erostratus, LlorenteBousquets et al., 1997); Pieridae: Colias alexandra harfordii, C. philodice, Dismorphia eunoe chamula, D. e. eunoe, Perrhybris pamela chajuelnsis y Pseudopieris nehemia irma, Llorente-Bousquets et al., 1997); megalópteros (Corydalidae: Platyneuromus honduranus y $P$. reflexus, Contreras-Ramos, 2000); ortópteros (Pyrgomorphidae: Prosphena scudderi y Sphenarium mexicanum histrio, Kevan, 1977); anfibios (Ranidae: Rana maculata, Arriaga et al., 1997; Pletodontidae: Nototriton barbouri, N. nasales y N. veraepacis, Papenfuss y Wake, 1987); saurios (Iguanidae: Enyaliosaurus palearis y Sceloporus malachitichus, Savage, 1982; Anguidae: Abronia ochoterenai, Arriaga et al., 1997); aves (Furnariidae: Dendrocolaptes picumnus, Arriaga et al., 1997; Muscicapidae: Turdus plebejus, Arriaga et al., 1997; Picidae: Picoides pubescens, Espinosa-Organista et al., 2000; Strigidae: Otus barbatus, Arriaga et al., 1997); y mamíferos (Muridae: Peromyscus aztecus oaxacensis, Sullivan et al., 1997).

\section{Provincia de la Península de Yucatán}

Provincia de la Península de Yucatán: Smith (1941: 110), Goldman y Moore (1945: 360), Ryan (1963: 22), Rzedowski (1978: 109), Rzedowski y Reyna-Trujillo (1990: mapa), Morrone (2001b: 51, 2002c: 270), Morrone et al. (2002: 98), Morrone (2004a: 197, 2004b: 157). 
Provincia de El Petén: Smith (1941: 110), Barrera (1962: 101), Casas-Andreu y Reyna-Trujillo (1990: mapa), Arriaga et al. (1997: 63), Escalante et al. (1998: 285), Morrone et al. (1999: 510), Espinosa-Organista et al. (2000: 64).

Provincia de Yucatán: Barrera (1962: 79), Casas-Andreu y Reyna-Trujillo (1990: mapa), Ferrusquía-Villafranca (1990: mapa), Ramírez-Pulido y Castro-Campillo (1990: mapa), Arriaga et al. (1997: 63), Escalante et al. (1998: 285), Morrone et al. (1999: 510), Espinosa-Organista et al. (2000: 64).

Centro de Yucatán: Müller (1973: 16).

Provincia de Campeche-Petén: Ferrusquía-Villafranca (1990: mapa).

Ecorregión de los Bosques Húmedos de Yucatán: Dinerstein et al. (1995: 91).

Ecorregión de los Bosques Secos de Yucatán: Dinerstein et al. (1995: 99).

Ecorregión de los Humedales de Quintana Roo: Dinerstein et al. (1995: 106).

Provincia de Cozumel-Islas Mujeres: Escalante et al. (1998: 285).

Se ubica en la península homónima, en los estados mexicanos de Campeche, Yucatán y Quintana Roo, en áreas que no superan $200 \mathrm{~m}$ de altitud. La península de Yucatán es una de las pocas grandes penínsulas cuya base se encuentra más al sur que su ápice, lo cual aunado a la falta de relieves de magnitud, hace que se acentúe la influencia climática marina, la sitúa en la trayectoria de los vientos y ciclones caribeños, y la deja fuera de la franja principal continental de actividad tectónica y climática. Debido al efecto de peninsularidad, que determina gradientes para la flora y la fauna, los límites de esta provincia biogeográfica varían con los distintos taxones analizados (Barrera, 1962). La vegetación consiste en bosques húmedos y secos y pastizales inundables. La flora muestra numerosos elementos antillanos, aunque de acuerdo con Rzedowski (1978), esta influencia sería menor que la de la provincia del Golfo de México. Durán et al. (1998) consideraron la presencia de elementos florísticos antillanos, centroamericanos y del sureste de México. Ibarra Manríquez et al. (2002) hallaron relaciones entre la flora arbórea de la península de Yucatán con la de Chiapas, Oaxaca y Veracruz, mientras que las relaciones con la flora antillana resultaron débiles. Transgresiones marinas mantuvieron la península de Yucatán sumergida durante diferentes periodos (SuárezMorales, 2003; Suárez-Morales et al., 2004), por lo cual su biota sería básicamente de dispersión relativamente reciente, post-pliocénica.

La provincia de la Península de Yucatán se caracteriza por taxones de angiopermas (Fabaceae: Caesalpinia gaumeri, Pithecelobium lanceolatum y P. graciliflorum, Rzedowski, 1978; Arriaga et al., 1997; Espinosa-Organista et al., 2000; Poaceae: Gouninia latifolia var. guatemalensis y G. papillosa, Ortiz-Díaz, 1993); coleópteros (Carabidae: Amblygnathus subtinctus y Pasimachus purpuratus, Nichols, 1988; Espinosa-Organista et al., 2000; Chrysomelidae: Ophraella notullata, Espinosa-Organista et al., 2000; Curculionidae: Caecossonus continuus, Howden, 1992; Elateridae: Conoderus pilatei, Johnson, 1995; Staphylinidae: Bledius punctatissimus, Espinosa-Organista et al., 2000); lepidópteros (Papilionidae: Priamides phanases y P. rogeri, LlorenteBousquets et al., 1997; Espinosa-Organista et al., 2000); saurios (Iguanidae: Enyaliosaurus defensor y Sceloporus cozumelae, Savage, 1982; Arriaga et al., 1997); serpientes (Viperidae: Bothrops yucatannicus, Müller, 1973); aves (Caprimulgidae: Caprimulgus badius, Espinosa-Organista et al., 2000; Certhiidae: Campylorhynchus yucatanicus, Müller, 1973; Columbidae: Leptotila jamaicensis gaumeri, Arriaga et al., 1997; Phasianidae: Colinus nigrogularis y Meleagris ocellata, Arriaga et al., 1997; Picidae: Melanerpes rubricapillus, Espinosa-Organista et al., 2000; Psittacidae: Amazona xanthoclora, Arriaga et al., 1997; Tyrannidae: Myarchus yucatanensis, Müller, 1973); y mamíferos (Cebidae: Alouatta pigra, Emmons, 1990; Heteromyidae: Heteromys gaumeri, Barrera, 1962; Muridae: Otonyctomys hatti y Peromyscus yucatanicus, Barrera, 1962; Procyonidae: Nasua nasua yucatanica, Arriaga et al., 1997; Sciuridae: Sciurus yucatanensis, Barrera, 1962; Soricidae: Cryptotis mayensis, Barrera, 1962).

Dentro de la provincia de la Península de Yucatán autores previos han reconocido unidades menores, que podrían ser tratadas como distritos (Smith, 1941; Barrera, 1962; CasasAndreu y Reyna-Trujillo, 1990; Ferrusquía-Villafranca, 1990; Arriaga et al., 1997; Ibarra Manríquez et al., 2002). Un análisis de parsimonia de endemismos reciente (Espadas Manrique et al., 2003), basado en taxones vegetales, ha reconocido áreas de endemismo (Figs. 36-39) que podrían contribuir al reconocimiento de distritos.

\section{Conclusiones}

El origen y desarrollo de la biota mexicana ha llamado la atención de varios autores, quienes han reconocido que la biogeografía de México es sumamente compleja, donde varios eventos de dispersión y vicarianza han producido un "mosaico" biótico complejo (Rosen, 1976; Savage, 1982; Halffter, 1987; Brooks, 2005; entre otros). Al elemento que originalmente habitaba nuestro país, habría que superponer elementos bióticos neotropicales y neárticos. La mezcla de estos elementos durante la cenogénesis (sensu Reig, 1981) caracteriza en mayor o menor medida a todo México, aunque es en la Zona de Transición Mexicana en sentido estricto donde esta "mezcla" llega a tal complejidad que no es posible asignarla a la región Neártica o a la Neotropical. En principio podemos caracterizar 3 componentes básicos para la biota mexicana, cada uno con una combinación diferente de elementos bióticos. 


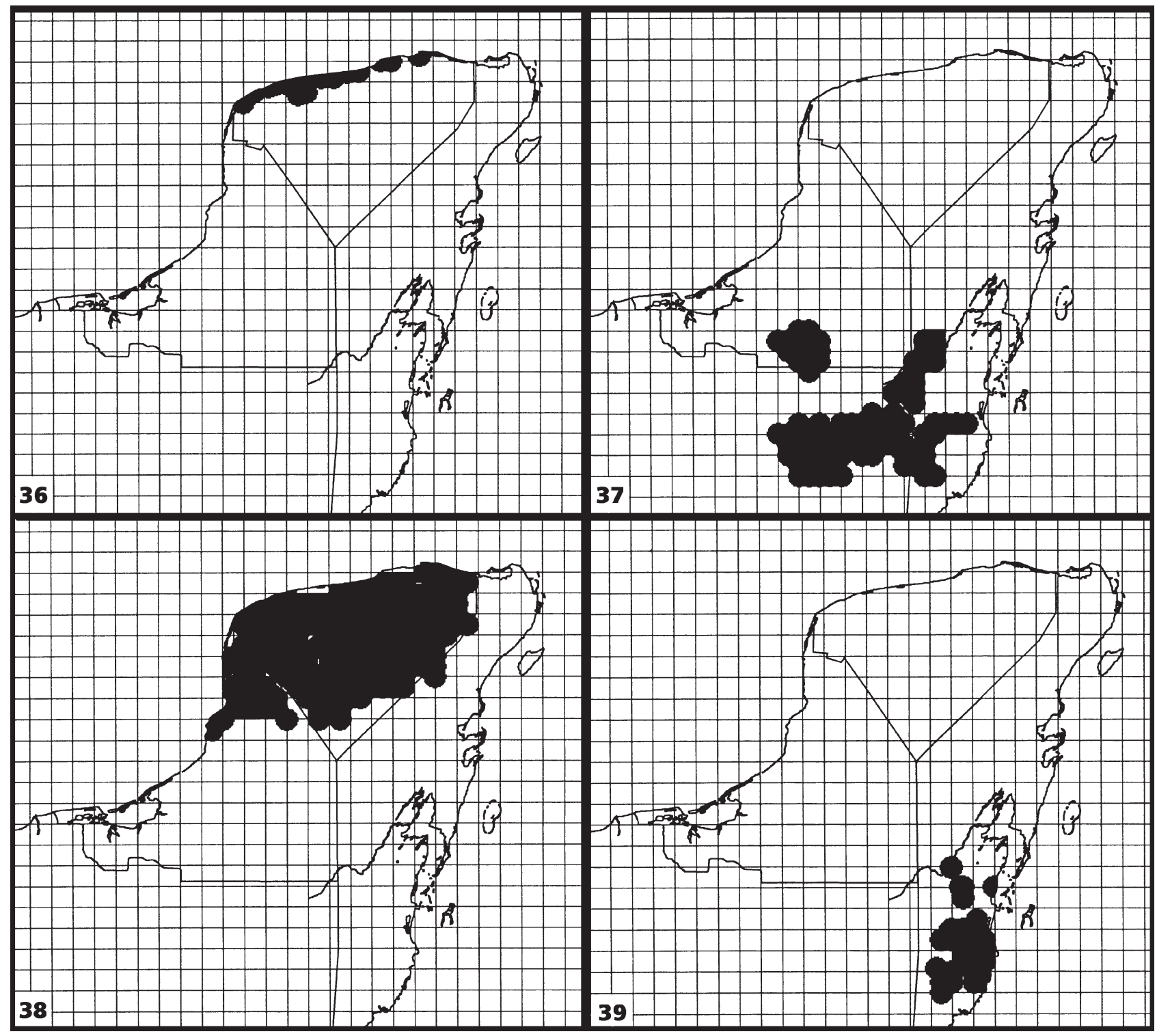

Figuras 36-39. Áreas de endemismo de la península de Yucatán, delimitadas por Espadas Manrique et al. (2003). 36, Zona seca de Yucatán; 37, El Petén; 38, Yucatán; 39, Belice.

El componente Neártico incluye las áreas áridas subtropicales del norte del país, en las provincias de California, Baja California, Sonora, Altiplano Mexicano y Tamaulipas. En este componente (región Neártica en sentido estricto) predomina el elemento original, denominado Septentrional Antiguo por Savage $(1966,1982)$ y Paleoamericano por Halffter (1987), junto con otro de dispersión más reciente, anterior al eoceno, denominado Neártico por Halffter (1987), el cual se habría diversificado en el área en el pliopleistoceno. Desde el punto de vista filogenético, los taxones emparentados con los que habitan este componente con frecuencia se hallarán en el resto de la región Neártica y el Viejo Mundo (taxones del elemento Paleoamericano), o sólo en la región Neártica (taxones del elemento Neártico). El límite austral de la influencia neártica se encuentra, según los taxones analizados, en el Eje Volcánico Transmexicano (Pérez-Ponce de León, 2003), en el Istmo de Tehuantepec (Halffter, 1987), o en la provincia de Chiapas (Escalante et al., 2004; Rosas-Valdés y Pérez-Ponce de León, 2005). Un tercer elemento, Neotropical Antiguo, está presente en el componente Neártico; éste se habría dispersado desde América del Sur entre el cretácico tardío y el paleoceno (Halffter, 1964a, b; Savage, 1982) y sus taxones están relacionados con formas de América del Sur y de los trópicos del Viejo Mundo. Los eventos vicariantes asociados con la evolución biótica del componente Neártico se relacionan con la formación de la Sierra Madre Occidental, que aisló el desierto de Chihuahua de los desiertos de Sonora y Mohave; 
y la expansión del Mar de Cortés, que aisló la Península de Baja California del continente (Morafka, 1977; Morafka et al., 1992; Grismer, 1994; Zink et al., 2000).

El componente Transicional incluye las áreas básicamente montañosas del centro del país, que se asignan a las provincias de la Sierra Madre Oriental, Sierra Madre Occidental, Eje Volcánico Transmexicano, Cuenca del Balsas y Sierra Madre del Sur. En este componente (Zona de Transición Mexicana en sentido estricto) coexisten los elementos Paleoamericano, Neártico, Mesoamericano Tropical y Mesoamericano de Montaña. Este último, de afinidad neotropical, equivale a los trazos generalizados Sudamericano-Caribeño de Rosen (1976) y Septentrional de Morrone y Márquez (2001); y se habría diversificado en el área en el oligoceno (Halffter, 1987). La provincia de la Cuenca del Balsas es la que exhibe una influencia mayor del elemento Mesoamericano Tropical. Los eventos vicariantes asociados con la evolución biótica del componente Transicional se relacionarían con el desarrollo de las Sierras Madre y el vulcanismo del Eje Volcánico Transmexicano (Liebherr, 1991, 1994a; Marshall y Liebherr, 2000; Escalante et al., 2004; Morrone y Gutiérrez, 2005).

El componente Neotropical incluye áreas tropicales húmedas y subhúmedas del sur de México, asignadas a las provincias de la Costa Pacífica Mexicana, del Golfo de México, de Chiapas y de la Península de Yucatán. En este componente (región Neotropical en sentido estricto) predomina el elemento Mesoamericano Tropical, equivalente a los trazos generalizados Sudamericano de Savage (1966, 1982) y Meridional de Morrone y Márquez (2001). En la provincia de la Península de Yucatán se encuentra también el elemento Antillano, y en la provincia de Chiapas hay relictos del elemento Neártico. Los taxones emparentados con los mesoamericanos tropicales se encontrarán en América del Sur y, más lejanamente, en los trópicos del resto del reino Holotropical (África, sudeste de Asia y parte de Australia). Los eventos vicariantes asociados con la evolución biótica del componente Neotropical se relacionan con el desarrollo de los istmos de Tehuantepec y Panamá y la inundación de las tierras bajas de Nicaragua y de la Península de Yucatán (Márquez y Morrone, 2001; Suárez-Morales, 2003; Abrahamovich et al., 2004; Suárez-Morales et al., 2004).

El reconocimiento de estos componentes bióticos principales constituye una primera etapa hacia una teoría biogeográfica sintética. Aún se requiere de más información para refinar este análisis, descubriendo otros componentes mediante análisis panbiogeográficos. Luego habría que contrastar las hipótesis de homología biogeográfica primaria previamente propuestas mediante análisis biogeográficos cladísticos, para corroborar los componentes identificados o identificar nuevos, y esclarecer el modo en que los diferentes elementos se integraron en el curso de la cenogénesis, con ayuda de análisis filogeográficos, relojes moleculares y, cuando existen, fósiles. Finalmente, será necesario proponer un escenario geobiótico que integre la información previa con datos geológicos y tectónicos, para explicar la integración biótica que ha conducido a la actual diversidad biótica de México. Espero que este ensayo sirva de estímulo a otros para contribuir al desarrollo de esta teoría.

\section{Agradecimientos}

A Tania Escalante Espinosa, Isolda Luna Vega, Jorge Meave del Castillo y Gerardo Pérez-Ponce de León por la lectura crítica del manuscrito. Se agradece el apoyo económico del Consejo Nacional de Ciencia y Tecnología (CONACYT), a través del subsidio 36488.

\section{Referencias}

Abrahamovich, A., N. B. Díaz y J. J. Morrone. 2004. Distributional patterns of the Neotropical and Andean species of the genus Bombus (Hymenoptera: Apidae). Acta Zoológica Mexicana (nueva serie) 20: 99-117.

Aguilar-Aguilar, R., R. Contreras-Medina y G. SalgadoMaldonado. 2003. Parsimony analysis of endemicity (PAE) of Mexican hydrological basins based on helminth parasites of freshwater fishes. Journal of Biogeography 30: 1861-1872.

Aguilar-Aguilar, R., R. Contreras-Medina, A. MartínezAquino, G. Salgado-Maldonado y A. GonzálezZamora. 2005. Aplicación del análisis de parsimonia de endemismos (PAE) en los sistemas hidrológicos de México: Un ejemplo con helmintos parásitos de peces dulceacuícolas. In Regionalización biogeográfica en Iberoamérica y tópicos afines: Primeras Jornadas Biogeográficas de la Red Iberoamericana de Biogeografía y Entomología Sistemática (RIBES XII.I-CYTED), J. Llorente-Bousquets y J. J. Morrone (eds.). Las Prensas de Ciencias, UNAM, México, D.F., p. 227-239.

Álvarez-Castañeda, S. T., C. A. Salinas-Zavala y F. de Lachica. 1995. Análisis biogeográfico del noroeste de México con énfasis en la variación climática y mastozoológica. Acta Zoológica Mexicana (nueva serie) 66: 59-86.

Amorim, D. de S. y M. R. S. Pires. 1996. Neotropical biogeography and a method for maximum biodiversity estimation. In Biodiversity in Brazil: a first approach, C. E. M. Bicudo y N. A. Menezes (eds.). CNPq, San Pablo, p. 183-219.

Amorim, D. S. y S. H. S. Tozoni. 1994. Phylogenetic and biogeographic analysis of the Anisopodoidea (Diptera, Bibionomorpha), with an area cladogram for intercontinental relationships. Revista Brasileira de Entomologia 38: 517-543.

Arriaga, L., C. Aguilar, D. Espinosa-Organista y R. Jiménez. 
1997. Regionalización ecológica y biogeográfica de México. Taller de la Comisión Nacional para el Conocimiento y Uso de la Biodiversidad (Conabio), México, D.F.

Ashe, J. S. y S. W. Lingafelter. 1995. Revision of Gansia Sharp of Mexico and Central America (Coleoptera: Staphylinidae: Aleocharinae). Journal of the New York Entomological Society 103: 251-280.

Axelrod, D. I. 1958. Evolution of the Madro-Tertiary geoflora. Botanical Review 24: 433-509.

Balcázar Lara, M. A. e I. Revuelta Morales. 2004. Palomillas bombicoides (Insecta: Lepidoptera). In Biodiversidad de la Sierra Madre Oriental, I. Luna, J. J. Morrone y D. Espinosa-Organista (eds.). Las Prensas de Ciencias, UNAM, México, D.F., p. 295-306.

Ball, G. E. 1992. The tribe Licinini (Coleoptera: Carabidae): A review of the genus-group and of the species of selected genera. Journal of the New York Entomological Society 100: 325-380.

Barrera, A. 1962. La península de Yucatán como provincia biótica. Revista de la Sociedad Mexicana de Historia Natural 23: 71-105.

Borhidi, A. 1996. Phytogeography and vegetation ecology of Cuba. Hungarian Academy of Sciences y Hungarian Nacional Research Fund, Budapest. 923 p.

Brooks, D. R. 2005. Historical biogeography in the age of complexity: Expansion and integration. Revista Mexicana de Biodiversidad 76(1): 79-94.

Cabrera, A. L. y A. Willink. 1973. Biogeografía de América Latina. Monografía 13, Serie de Biología, Organización de Estados Americanos, Washington, D.C. 117 p.

Camargo, J. M. F. y J. S. Moure. 1996. Meliponini neotropicais: O gênero Geotrigona Moure, 1943 (Apinae, Apidae, Hymenoptera), com especial referência à filogenia e biogeografia. Arquivos de Zoologia, Sâo Paulo 33: 95-161.

Campbell, J. A. 1988. The distribution, variations, natural history, and relationships of Porthidium barbouri (Viperidae). Acta Zoológica Mexicana (nueva serie) 26: $1-32$.

Campbell, J. A. 1999. Distribution patterns of amphibians in Middle America. In Patterns of distribution of amphibians: a global perspective, Duellman, W. E. (ed.). The Johns Hopkins University Press, Baltimore and London, pp. 111-210.

Campbell, J. A. y W. W. Lamar. 1989. The venomous reptiles of Latin America. Comstock, Cornell University Press, Ithaca and London. 425 p.

Canseco-Márquez, L., F. Mendoza-Quijano y M. G. Gutiérrez-Mayén. 2004. Análisis de la distribución de la herpetofauna. In Biodiversidad de la Sierra Madre Oriental, I. Luna, J. J. Morrone y D. Espinosa-Organista (eds.). Las Prensas de Ciencias, UNAM, México, D.F., p. 417-437.
Carlton, C. E. 1989. Revision of the genus Eutrichites LeConte (Coleoptera: Pselaphidae). Coleopterists Bulletin 43: 105-119.

Casas-Andreu, G. y T. Reyna-Trujillo. 1990. Herpetofauna (anfibios y reptiles). Mapa IV.8.6. In Atlas nacional de México, vol. III. Instituto de Geografía, UNAM, México, D.F.

Castillo, C. y P. Reyes-Castillo. 1984. Biosistemática del género Petrejoides Kuwert (Coleoptera, Lamellicornia, Passalidae). Acta Zoológica Mexicana (nueva serie) 4: $1-84$.

Castillo, C., L. E. Rivera-Cervantes y P. Reyes-Castillo. 1988. Estudio sobre los Passalidae (Coleoptera: Lamellicornia) de la Sierra de Manantlán, Jalisco. Acta Zoológica Mexicana (nueva serie) 30: 1-20.

Cifuentes Blanco, J., M. Villegas Ríos, R. García-Sandoval, G. Vidal-Gaona, S. Sierra Galván, R. Valenzuela-Garza, L.Pérez-Ramírez y E. Morales-Torres. 2004. Distribución de macromicetos: una aproximación al análisis de áreas de endemismos. In Biodiversidad de la Sierra Madre Oriental, I. Luna, J. J. Morrone y D. Espinosa-Organista (eds.). Las Prensas de Ciencias, UNAM, México, D.F., p. 355-374.

Conroy, V. C. J., Y. Hortelano, F. A. Cervantes y J. A. Cook. 2001. The phylogenetic position of southern relictual species of Microtus (Muridae: Rodentia) in North America. Mammalian Biology 66: 332-344.

Contreras-Medina, R. 2004. Gimnospermas. In Biodiversidad de la Sierra Madre Oriental, I. Luna, J. J. Morrone y D. Espinosa-Organista (eds.). Las Prensas de Ciencias, UNAM, México, D.F., p. 137-148.

Contreras-Medina, R. y H. Eliosa-León. 2001. Una visión panbiogeográfica preliminar de México. In Introducción a la biogeografía en Latinoamérica: conceptos, teorías, métodos y aplicaciones, J. Llorente-Bousquets y J. J. Morrone (eds.). Las Prensas de Ciencias, UNAM, México, D.F., Introducción a la biogeografía en Latinoamérica: Conceptos, teorías, métodos y aplicaciones,p. 197-211.

Contreras-Ramos, A. 2000. Megaloptera (Neuropterida). In Biodiversidad, taxonomía y biogeografía de artrópodos de México: hacia una síntesis de su conocimiento, vol. II, J. Llorente-Bousquets, E. González y N. Papavero (eds.). UNAM, México, D.F., p. 355-362.

Corona, A. M., R. Acosta y J. J. Morrone. 2005. Estudios biogeográficos en insectos de la Zona de Transición Mexicana. In Regionalización biogeográfica en Iberoamérica y tópicos afines: Primeras Jornadas Biogeográficas de la Red Iberoamericana de Biogeografía y Entomología Sistemática (RIBES XII.I-CYTED), J. Llorente-Bousquets, y J. J. Morrone (eds.). Las Prensas de Ciencias, UNAM, México, D.F., p. 241-255.

Corona, A. M. y J. J. Morrone. 2005. Track analysis of the species of Lampetis (Spinthoptera) Casey, 1909 (Coleoptera: Buprestidae) in North America, Central 
America, and the West Indies. Caribbean Journal of Science 41: 37-41.

Coscarón, S., S. Ibañez-Bernal y C. L. Coscarón-Arias. 1996. Revisión de Simulium (Psilopelmia) Enderlein en la región Neotropical y análisis cladístico de sus especies (Diptera: Simuliidae). Acta Zoológica Mexicana (nueva serie) 69: 37-104.

Craw, R. C., J. R. Grehan y M. J. Heads. 1999. Panbiogeography: Tracking the history of life. Oxford Biogeography Series 11, New York and Oxford. 229 p.

Crisci, J. V., M. S. de la Fuente, A. A. Lanteri, J. J. Morrone, E. Ortiz Jaureguizar, R. Pascual y J. L. Prado. 1993. Patagonia, Gondwana Occidental (GW) y Oriental (GE), un modelo de biogeografía histórica. Ameghiniana 30: 104.

Crother, B. I. y C. Guyer. 1996. Caribbean historical biogeography: was the dispersal debate eliminated by an extraterrestrial bolide? Herpetologica 52: 440-465.

Darlington, P. J. Jr. 1957. Zoogeography: The geographical distribution of animals. John Wiley, New York. 675 p.

Delgadillo-Moya, C. 2004. Musgos. In Biodiversidad de la Sierra Madre Oriental, I. Luna, J. J. Morrone y D. Espinosa-Organista (eds.). Las Prensas de Ciencias, UNAM, México, D.F., p. 127-135.

Delgado, L. y J. Blackaller-Bages. 1997. A new Mexican species of Homoiosternus (Coleoptera: Melolonthidae; Rutelinae). Journal of the New York Entomological Society 105: 170-179.

Delgado, L. y R. Hernández. 1998. Anopsiostes pauliani new species and a first record of the genus from Mexico (Coleoptera: Scarabaeidae: Ceratocanthinae). Journal of the New York Entomological Society 106: 105-108.

Deloya, C. 1995. A new species of Cotinis (Cotinis) Burmeister from Mexico (Coleoptera: Melolonthidae, Cetoninae). Coleopterists Bulletin 49: 149-152.

Deloya, C. y B. C. Ratcliffe. 1988. Las especies de Cotinis Burmeister en México (Coleoptera: Melolonthidae: Cetoniinae). Acta Zoológica Mexicana (nueva serie) 28:1-52.

Dial, B. E. y L. L. Grismer. 1992. A phylogenetic analysis of physiological-ecological character evolution in the lizard genus Coleonyx and its implications for historical biogeographic reconstruction. Systematic Biology 41: 178-195.

Dice, L. R. 1943. The biotic provinces of North America. University of Michigan Press, Chicago. 78 p.

Dinerstein, E. D. M. Olson, D. J. Graham, A. L. Webster, S. A. Primm, M. P. Bookbinder y G. Ledec. 1995. Una evaluación del estado de conservación de las ecoregiones terrestres de América Latina y el Caribe. World Bank, Washington, D.C. 129 p.

Dorado, O. y D. M. Arias. 1992. Brongniartia montalvoana (Fabaceae: Faboideae), una especie nueva de la cuenca del Balsas. Acta Botanica Mexicana 17: 13-17.
Duellman, W. E. y S. S. Sweet. 1999. Distribution patterns of amphibians in the Nearctic region of North America. In Patterns of distribution of amphibians: a global prespective, Duellman, W. E. (ed.). The Johns Hopkins University Press, Baltimore and London, p. 31-109.

Durán, R., J. C. Trejo-Torres y G. Ibarra Manríquez. 1998. Endemic phytotaxa of the peninsula of Yucatán. Harvard Papers in Botany 3: 263-314.

Emmons, L. H. 1990. Neotropical rainforest mammals: A field guide. The University of Chicago Press, Chicago and London. 396 p.

Escalante, P., A. G. Navarro y A. T. Peterson. 1998. Un análisis geográfico, ecológico e histórico de la diversidad de aves terrestres de México. In. Diversidad biológica de México: orígenes y distribución, T. P. Ramamoorthy, R. Bye, A. Lot y J. Fa (eds.). Instituto de Biología, UNAM, México, D.F., p. 279-304.

Escalante, T., G. Rodríguez y J. J. Morrone. 2004. The diversification of Nearctic mammals in the Mexican transition zone. Biological Journal of the Linnean Society 83: 327-339.

Espadas Manrique, C., R. Durán y J. Argáez. 2003. Phytogeographic analysis of taxa endemic to the Yucatán Peninsula using geographic information systems, the domain heuristic method and parsimony analysis of endemicity. Diversity and Distributions 9: 313-330.

Espinosa-Organista, D., C. Aguilar y T. Escalante. 2001. Endemismo, área de endemismo y regionalización biogeográfica. In Introducción a la biogeografía en Latinoamérica: conceptos, teorías, métodos y aplicaciones, J. Llorente-Bousquets y J. J. Morrone (eds.). Las Prensas de Ciencias, UNAM, México, D.F., p. 31-37.

Espinosa-Organista, D., C. Aguilar y S. Ocegueda. 2004. Identidad biogeográfica de la Sierra Madre Oriental y posibles subdivisiones bióticas. In Biodiversidad de la Sierra Madre Oriental, I. Luna, J. J. Morrone y D. Espinosa-Organista (eds.). Las Prensas de Ciencias, UNAM, México, D.F., p. 487-500.

Espinosa-Organista, D., J. J. Morrone, C. Aguilar y J. Llorente. 2000. Regionalización biógeográfica de México: Provincias bióticas. In Biodiversidad, taxonomía y biogeografía de artrópodos de México: hacia una síntesis de su conocimiento, vol. II, J. Llorente-Bousquets, E. González y N. Papavero (eds.). UNAM, México, D.F., p. 61-94.

Espinosa-Pérez, H. y L. Huidobro-Campos. 2005. Ictiogeografía de los peces dulceacuícolas de la vertiente del Golfo de México. In Regionalización biogeográfica en Iberoamérica y tópicos afines: Primeras Jornadas Biogeográficas de la Red Iberoamericana de Biogeografía y Entomología Sistemática (RIBES XII.I-CYTED), J. Llorente-Bousquets y J. J. Morrone (eds.). Las Prensas de Ciencias, UNAM, México, D.F., p. 295-318. 
Espinosa-Pérez, H. L. Huidobro-Campos y F. García de León. 2004. Ictiofauna. In Biodiversidad de la Sierra Madre Oriental, I. Luna, J. J. Morrone y D. EspinosaOrganista (eds.). Las Prensas de Ciencias, UNAM, México, D.F., p. 339-352.

Evans, A. V. y D. d’Hotman. 1988. Coenonycha Horn in Baja California, Mexico (Coleoptera: Melolonthidae: Melolonthinae). Coleopterists Bulletin 42: 205-210.

Ferrusquía-Villafranca, I. 1990. Regionalización biogeográfica. Mapa IV.8.10. In Atlas Nacional de México, vol. III, Instituto de Geografía, UNAM, México, D.F.

Flores-Villela, O. e I. Goyenechea. 2001. A comparison of hypotheses of historical biogeography for Mexico and Central America, or in search for the lost pattern. In Mesoamerican herpetology: systematics, zoogeography, and conservation, J. D. Johnson, R. G. Webb y O. FloresVillela (eds.). The University of Texas at El Paso, El Paso, p. 171-181.

Fragoso, C. 1988. Sistemática y ecología de un género nuevo de lombriz de tierra (Acanthodrilini, Oligochaeta) de la selva Lacandona, Chiapas, México. Acta Zoológica Mexicana (nueva serie) 25: 1-34.

Franco, P. y C. C. Berg. 1997. Distributional patterns of Cecropia (Cecropiaceae): A panbiogeographic analysis. Caldasia 19: 285-296.

Freire, S. E. 1993. A revision of Chionolaena (Compositae, Gnaphalieae). Annals of the Missouri Botanical Garden 80: 397-438.

Funk, V. A. 1982. The systematics of Montanoa (Asteraceae, Heliantheae). Memoirs of the New York Botanical Garden 36: 1-133.

Garcillán, P. P., E. Ezcurra y H. Riemann. 2003. Distribution and species richness of woody dryland legumes in Baja California, Mexico. Journal of Vegetation Science 14: 475-486.

Génier, F. y H. F. Howden. 1999. Two new Central American Onthophagus Latreille of the mirabilis species group (Coleoptera: Scarabaeidae, Scarabaeinae). Coleopterists Bulletin 53: 130-144.

Gentry, A. H. 1982. Neotropical floristic diversity: Phytogeographical connections between Central and South America, Pleistocene climatic fluctuations, or an accident of the Andean orogeny? Annals of the Missouri Botanical Garden 49: 557-593.

Giacchi, J. C. 1982. Revisión de los stenopodainos americanos. V. El género Diaditus Stal, 1859 (Heteroptera, Reduviidae). Physis (Buenos Aires) C, 41: 9-27.

Giesbert, E. F. 1993. New species of Cerambycidae (Coleoptera: Cerambycidae) from Guatemala and Chiapas, Mexico. Coleopterists Bulletin 47: 137-149.

Giunta, G. E. Navarro, L. Beccaluva, S. Bellia, P. CominChiaramonti, G. Dengo, W. Montero y S. Carnemolla.
1996. Geología de las márgenes de la placa del Caribe: Generalidades en Guatemala, Costa Rica, La Española y resultados preliminares del análisis de una transversal en la cordillera de la costa de Venezuela. Revista de Geología de América Central 19/20: 7-28.

Goldman, E. A. y R. T. Moore. 1945. The biotic provinces of Mexico. Journal of Mammalogy 26: 347-360.

González-Elizondo, M. S. y M. González-Elizondo. 1992. Una nueva especie de Arbutus (Ericaceae, Arbuteae) de la Sierra Madre Occidental, México. Acta Botanica Mexicana 17: 7-12.

Good, R. 1974. The geography of the flowering plants. Longman Group Limited, Londres. 557 p.

Grismer, L. L. 1994. The origin and evolution of the peninsular herpetofauna of Baja California, México. Herpetological Natural History 2: 51-106.

Halffter, G. 1962. Explicación preliminar de la distribución geográfica de los Scarabaeidae mexicanos. Acta Zoológica Mexicana (nueva serie) 5: 1-17.

Halffter, G. 1964a. La entomofauna americana, ideas acerca de su origen y distribución. Folia Entomologica Mexicana 6: 1-108.

Halffter, G. 1964b. Las regiones neártica y neotropical desde el punto de vista de su entomofauna. Anais do II Congresso Latinoamericano de Zoologia, San Pablo 1: 51-61.

Halffter, G. 1965. Algunas ideas acerca de la zoogeografía de América. Revista de la Sociedad Mexicana de Historia Natural 26: 1-16.

Halffter, G. 1972. Eléments anciens de l'entomofaune neotropicale: Ses implications biogéographiques. In Biogeographie et liasons intercontinentales au cours du Mésozoique, 17me. Congres International de Zoologie, Monte Carlo 1: 1-40.

Halffter, G. 1974. Eléments anciens de l'entomofaune neotropicale: Ses implications biogéographiques. Quaestiones Entomologicae 10: 223-262.

Halffter, G. 1976. Distribución de los insectos en la Zona de Transición Mexicana: Relaciones con la entomofauna de Norteamérica. Folia Entomologica Mexicana 35: 1-64.

Halffter, G. 1978. Un nuevo patrón de dispersión en la Zona de Transición Mexicana: El mesoamericano de montaña. Folia Entomologica Mexicana 39-40: 219-222.

Halffter, G. 1987. Biogeography of the montane entomofauna of Mexico and Central America. Annual Review of Entomology 32: 95-114.

Halffter, G. 2003. Biogeografía de la entomofauna de montaña de México y América Central. In Una perspectiva latinoamericana de la biogeografía, J. J. Morrone y J. Llorente-Bousquets (eds.). Las Prensas de Ciencias, UNAM, México, D.F., p. 87-97.

Halffter, G., M. E. Favila y L. Arellano. 1995. Spatial distribution of three groups of Coleoptera along an altitudinal transect in the Mexican Transition Zone and 
its biogeographical implications. Elytron 9: 151-185.

Hamilton, R. W. 1994. Revision of the New World genus Pilolabus Jekel (Coleoptera: Attelabidae). Transactions of the American Entomological Society 120: 369-411.

Hamilton, R. W. 1997. A new species of Euscelus Schoenherr from Mexico (Coleoptera: Attelabidae). Coleopterists Bulletin 51: 364-370.

Hernández-Baños, B. E., A. T. Peterson, A. G. NavarroSigüenza y B. P. Escalante-Pliego. 1995. Bird faunas of the humid montane forests of Mesoamerica: Biogeographic patterns and priorities for conservation. Bird Conservation International 5: 251-277.

Hershkovitz, P. 1969. The recent mammals of the Neotropical region. Quarterly Review of Biology 44: 1-70.

Hoffmann, C. C. 1922. Restos de una antigua fauna del norte entre los lepidópteros mexicanos. Revista Mexicana de Biología 3: 1-23.

Hoffmann, C. C. 1936. Relaciones zoogeográficas de los lepidópteros mexicanos. Anales del Instituto de Biología de la UNAM 7: 47-58.

Howden, A. T. 1992. Review of the New World eyeless weevils with uncinate tibiae (Coleoptera, Curculionidae: Molytinae, Cryptorhynchinae, Cossoninae). Memoirs of the Entomological Society of Canada 162: 1-76.

Howden, H. F. 1988. A new genus and four new species of New World Trichiinae (Coleoptera: Scarabaeidae). Coleopterists Bulletin 42: 241-250.

Howden, H. F. 1994a. A new Geotrupes Latreille (Coleoptera: Scarabaeidae) from the Sierra de las Minas range of Guatemala. Coleopterists Bulletin 48: 345-348.

Howden, H. F. 1994b. A new Apeltastes Howden and notes on Guatemalan Paragnorimus Becker (Scarabaeidae: Trichiinae). Coleopterists Bulletin 48: 349-353.

Hulsey, C. D., F. J. García de León, Y. Sánchez Johnson, D. A. Hendrickson y T. J. Near. 2004. Temporal diversification of Mesoamerican cichlid fishes across a major biogeographic boundary. Molecular Phylogenetics and Evolution 31: 754-764.

Humboldt, A. von. 1820. Ensayo sobre la geografía de las plantas. Versión española: 1997, Siglo Veintiuno, México, D.F. 134 p.

Ibarra Manríquez, G., J. L. Villaseñor, R. Durán y J. Meave. 2002. Biogeographical analysis of the tree flora of the Yucatán peninsula. Journal of Biogeography 29: 17-29.

Iturralde Vinent, M. A. y R. D. E. MacPhee. 1999. Paleogeography of the Caribbean region: Implications for Cenozoic biogeography. Bulletin of the American Museum of Natural History 238: 1-95.

Jameson, M. L. 1990. Revision, phylogeny and biogeography of the genera Parabyrsopolis Ohaus and Viridimicus, new genus (Coleoptera: Scarabeidae: Rutelinae). Coleopterists Bulletin 44: 377-422.

Johansen, R. M. 1998. The Mexican Frankliniella desertileonidum Watson species assemblage, in the "intonsa group" (Insecta, Thysanoptera: Thripidae). Acta Zoológica Mexicana (nueva serie) 75: 143-161.

Johnson, P. J. 1995. A new genus of Conoderini, with new generic classifications for Ctenicera sleeperi Becker and Ctenicera pilatei (Champion), and a new species from Jamaica (Coleoptera: Elateridae). Coleopterists Bulletin 49: 59-71.

Katinas, L., J. V. Crisci, W. L. Wagner y P. C. Hoch. 2004. Geographical diversification of tribes Epilobieae, Gongylocarpeae, and Onagreae (Onagraceae) in North America, based on parsimony analysis of endemicity and track compatibility analysis. Annals of the Missouri Botanical Garden 91: 159-185.

Kevan, D. K. M. 1977. The American Pyrgomorphidae (Orthoptera). Revista de la Sociedad Entomológica Argentina 36: 3-28.

Kohlmann, B. y G. Halffter, 1988. Cladistic and biogeographical analysis of Ateuchus (Coleoptera: Scarabaeidae) of Mexico and the United States. Folia Entomologica Mexicana 74: 109-130.

Kohlman, B. y S. Sánchez. 1984. Estudio areográfico del género Bursera Jacq. ex L. (Burseraceae) en México: una síntesis de métodos. In Métodos cuantitativos en la biogeografía, Publ. 12, Instituto de Ecología, A.C., México, D.F., p. 41-120.

Kury, A. B. y J. C. Cokendolpher. 2000. Opiliones. In Biodiversidad, taxonomía y biogeografía de artrópodos de México: hacia una síntesis de su conocimiento, vol. II, J. Llorente-Bousquets, E. González y N. Papavero (eds.). UNAM, México, D.F., p. 137-157.

Kuschel, G. 1969. Biogeography and ecology of South American Coleoptera. In Biogeography and ecology in South America, 2, E. J. Fittkau, J. Illies, H. Klinge, G. H. Schwabe y H. Sioli (eds.). Junk, La Haya, p. 709-722.

Lanteri, A. A. 1990. Systematic revision and cladistic analysis of Phacepholis Horn (Coleoptera: Curculionidae). Southwestern Entomologist 15(2): 179-204.

León-Paniagua, L., E. García-Trejo, J. Arroyo-Cabrales y S. Castañeda-Rico. 2004. Patrones biogeográficos de la mastofauna. In Biodiversidad de la Sierra Madre Oriental, I. Luna, J. J. Morrone y D. Espinosa-Organista (eds.). Las Prensas de Ciencias, UNAM, México, D.F., p. 469-486.

Liebherr, J. K. 1991. A general area cladogram for montane Mexico based on distributions in the Platynine genera Elliptoleus and Calathus (Coleoptera: Carabidae). Proceedings of the Entomological Society of Washington 93: 390-406.

Liebherr, J. K. 1994a. Biogeographic patterns of montane Mexican and Central American Carabidae (Coleoptera). Canadian Entomologist 126: 841-860.

Liebherr, J. K. 1994b. Identification of New World Agonum, review of the Mexican fauna, and description of Incagonum, new genus from South America 
(Coleoptera: Carabidae: Platynini). Journal of the New York Entomological Society 102: 1-55.

Llorente-Bousquets, J. 1996. Biogeografía de artrópodos de México: ¿Hacia un nuevo enfoque? In Biodiversidad, taxonomía y biogeografía de artrópodos de México, J. Llorente, A. N. García y E. González (eds.). UNAM, México, D.F., p. 41-56.

Llorente-Bousquets, J., L. Oñate, A. Luis e I. Vargas. 1997. Papilionidae y Pieridae de México: Distribución geográfica e ilustración. Conabio y UNAM, México, D.F. 229 p.

Lobo, J. M. y G. Halffter. 1994. Relaciones entre escarabajos (Coleoptera: Scarabaeidae) y nidos de tuza (Rodentia: Geomyidae): Implicaciones biológicas y biogeográficas. Acta Zoológica Mexicana (nueva serie) 62: 1-9.

Lobo, J. M. y G. Halffter. 2000. Biogeographical and ecological factors affecting the altitudinal variation of mountainous communities of coprophagous beetles (Coleoptera: Scarabaeoidea): A comparative study. Annals of the Entomological Society of America 93: 115-126.

López-Ramos, E. 2001. Evolución tectónica de América Central, del Sur y el Caribe, desde el jurásico hasta el reciente. In Introducción a la biogeografía en Latinoamérica: conceptos, teorías, métodos y aplicaciones, J. Llorente-Bousquets y J. J. Morrone (eds.). Las Prensas de Ciencias, UNAM, México, D.F., p. 15-30.

Lourenço, W. R. y W. D. Sissom. 2000. Scorpiones. In Biodiversidad, taxonomía y biogeografía de artrópodos de México: hacia una síntesis de su conocimiento, vol. II, J. Llorente, E. González y N. Papavero (eds.). UNAM, México, D.F., p. 115-135.

Luna Vega, I., O. Alcántara, D. Espinosa-Organista y J. J. Morrone. 1999. Historical relationships of the Mexican cloud forests: A preliminary vicariance model applying Parsimony Analysis of Endemicity to vascular plant taxa. Journal of Biogeography 26: 1299-1305.

Luna Vega, I., J. J. Morrone, O. Alcántara Ayala y D. Espinosa-Organista. 2001. Biogeographical affinities among Neotropical cloud forests. Plant Systematics and Evolution 228: 229-239.

Lydeard, C., M. C. Wooten y A. Meyer. 1995. Molecules, morphology, and area cladograms: A cladistic and biogeographic analysis of Gambusia (Teleostei: Poeciliidae). Systematic Biology 44: 221-236.

Márquez, J. y J. J. Morrone. 2003. Análisis panbiogeográfico de las especies de Heterolinus y Homalolinus (Coleoptera: Staphylinidae: Xantholinini). Acta Zoológica Mexicana (nueva serie) 90: 15-25.

Márquez, J. y J. J. Morrone. 2004. Relaciones biogeográficas basadas en la distribución de Coleoptera (Insecta). In Biodiversidad de la Sierra Madre Oriental, I. Luna, J. J. Morrone y D. Espinosa-Organista (eds.). Las Prensas de
Ciencias, UNAM, México, D.F., p. 375-392.

Marshall, C. J. y J. K. Liebherr. 2000. Cladistic biogeography of the Mexican transition zone. Journal of Biogeography 27: 203-216.

Martens, M. y H. Galeotti. 1842. Mémoire sur les fougères du Mexique et considerations sur la géographie de cetrée. Memoires de l'Academie de Sciences de Bruxelles 15: 1-99.

Mateos, M., O. I. Sanjur y R. C. Vrijenhoek. 2002. Historical biogeography of the livebearing fish genus Poeciliopsis (Poeciliidae: Cyprinodontiformes). Evolution 56: 972984.

Méndez-Larios, I. y J. L. Villaseñor. 1995. Revisión taxonómica del género Tetranema (Scrophulariaceae). Acta Botanica Mexicana 32: 53-68.

Miller, W. V. 1995. Two new species of Heterocerus Fabricius from Mexico (Coleoptera: Heteroceridae). Coleopterists Bulletin 49: 249-252.

Morafka, D. J. 1977. A biogeographical analysis of the Chihuahuan desert through its herpetofauna. Dr. W. Junk B. V. Publishers, La Haya. 313 p.

Morafka, D. J., G. A. Adest, L. M. Reyes, G. Aguirre y S. S. Lieberman. 1992. Differentiation of North American deserts: A phylogenetic evaluation of a vicariance model. Tulane Studies in Zoology and Botany, Supplementary Publication 1: 195-226.

Morello, J. 1984. Perfil ecológico de Sudamérica: características estructurales de Sudamérica y su relación con espacios semejantes del planeta. Ediciones Cultura Hispánica, Instituto de Cooperación Iberoamericana, Barcelona. 93 p.

Morin, N. R. 1993. Flora of North America. North of Mexico, vol. 2. Oxford University Press, Nueva York. 475 p.

Morón, M. A. 1991. Estudio biogeográfico-ecológico preliminar del género Plusiotis Burmeister (Coleoptera: Melolonthidae, Rutelinae). Giornale Italiano di Entomologia 5: 309-323.

Morón, M. A. 1992. Análisis biogeográfico preliminar del género Plusiotis Burmeister (Coleoptera: Melolonthidae, Rutelinae).InBiogeography of Mesoamerica, Proceedings of a Symposium, S. P. Darwin y A. L. Welden (eds.). Tulane University, New Orleans, p. 235-242.

Morón, M. A. 1995. Review of the Mexican species of Golofa Hope (Coleoptera: Melolonthidae, Dynastinae). Coleopterists Bulletin 49: 343-386.

Morón, M. A. y B. C. Ratcliffe. 1996. New tribal placement of the genus Coscinocephalus Prell, 1936, with description of the larva, pupa and adult of a new species from Mexico (Coleoptera: Scarabaeidae; Dynastinae). Journal of the New York Entomological Society 104: 48-61.

Morrone, J. J. 1999. Presentación preliminar de un nuevo esquema biogeográfico de América del Sur. Biogeographica 75: 1-16.

Morrone, J. J. 2001a. Biogeografía de América Latina y el 
Caribe. Manuales y Tesis SEA 3, Zaragoza (España). $148 \mathrm{p}$.

Morrone, J. J. 2001b. Toward a cladistic model for the Caribbean subregion: Delimitation of areas of endemism. Caldasia 23: 43-76.

Morrone, J. J. 2002a. Biogeographic regions under track and cladistic scrutiny. Journal of Biogeography 29: 149-152.

Morrone, J. J. 2002b. The Neotropical weevil genus Entimus (Coleoptera: Curculionidae: Entiminae): Cladistics, biogeography, and modes of speciation. Coleopterists Bulletin 56: 501-513.

Morrone, J. J. 2002c. Presentación sintética de un nuevo esquema biogeográfico de América Latina y el Caribe. In Hacia un proyecto CYTED para el inventario y estimación de la diversidad entomológica en Iberoamérica: PrIBES, volumen 2, C. Costa, S. A. Vanin, J. M. Lobo y A. Melic (eds.). Zaragoza (España), p. 267-275.

Morrone, J. J. 2004a. Homología biogeográfica: las coordenadas espaciales de la vida. Cuadernos del Instituto de Biología 37, Instituto de Biología, UNAM, México, D.F. 199 p.

Morrone, J. J. 2004b. Panbiogeografía, componentes bióticos y zonas de transición. Coleopterists Bulletin 48: 149162.

Morrone, J. J. 2004c. La Zona de Transición Sudamericana: Caracterización y relevancia evolutiva. Acta Entomológica Chilena 28: 41-50.

Morrone, J. J. y T. Escalante. 2002. Parsimony analysis of endemicity (PAE) of Mexican terrestrial mammals at different area units: when size matters. Journal of Biogeography 29: 1095-1104.

Morrone, J. J., D. Espinosa-Organista, C. Aguilar-Zúñiga y J. Llorente-Bousquets. 1999. Preliminary classification of the Mexican biogeographic provinces: A parsimony analysis of endemicity based on plant, insect, and bird taxa. Southwestern Naturalist 44: 508-515.

Morrone, J. J., D. Espinosa-Organista y J.Llorente-Bousquets. 2002. Mexican biogeographic provinces: preliminary scheme, general characterizations, and synonymies. Acta Zoológica Mexicana (nueva serie) 85: 83-108.

Morrone, J. J. y A. Gutiérrez. 2005. Do fleas (Insecta: Siphonaptera) parallel their mammal host diversification in the Mexican transition zone? Journal of Biogeography 32: 1315-1325.

Morrone, J. J. y E. C. Lopretto. 1994. Distributional patterns of freshwater Decapoda (Crustacea: Malacostraca) in southern South America: a panbiogeographic approach. Journal of Biogeography 21: 97-109.

Morrone, J. J. y J. Márquez. 2001. Halffter's Mexican Transition Zone, beetle generalised tracks, and geographical homology. Journal of Biogeography 28: 635-650.

Morrone, J. J. y J. Márquez. 2003. Aproximación a un Atlas Biogeográfico Mexicano: componentes bióticos principales y provincias biogeográficas. In Una perspectiva latinoamericana de la biogeografía, J. J. Morrone, y J. Llorente-Bousquets (eds.). Las Prensas de Ciencias, UNAM, México, D.F., p. 217-220.

Müller, P. 1973. The dispersal centres of terrestrial vertebrates in the Neotropical realm: a study in the evolution of the Neotropical biota and its native landscapes. Junk, La Haya. 244 p.

Navarrete-Heredia, J. L. 1997. Descripción de Styngetus adrianae sp. nov., incluyendo nuevos datos de Styngetus de México (Coleoptera: Staphylinidae). Folia Entomologica Mexicana 101: 59-71.

Navarro, A. G., H. A. Garza-Torres, S. López de Aquino, O. R. Rojas-Soto y L. A. Sánchez-González. 2004. Patrones biogeográficos de la avifauna. In Biodiversidad de la Sierra Madre Oriental, I. Luna, J. J. Morrone y D. Espinosa-Organista (eds.). Las Prensas de Ciencias, UNAM, México, D.F., p. 439-467.

Nichols, S. W. 1988. Kaleidoscopic biogeography of West Indian Scaritinae (Coleoptera: Carabidae). In Zoogeography of Caribbean insects, Cornell University Press, J. K. Liebherr (ed.). Ithaca and London, p. 71120.

Nihei, S. S. y C. J. B. de Carvalho. 2004. Taxonomy, cladistics and biogeography of Coenosopia Malloch (Diptera, Anthomyiidae) and its significance to the evolution of anthomyiids in the Neotropics. Systematic Entomology 29: 260-275.

Ochoa, L., B. Cruz, G. García, y A. Luis-Martínez. 2003. Contribución al atlas panbiogeográfico de México: los géneros Adelpha y Hamadryas (Nymphalidae), y Dismorphia, Enantia, Leinix y Pseudopieris (Pieridae) (Papilionoidea; Lepidoptera). Folia Entomologica Mexicana 42: 65-77.

Ortega, J. y H. T. Arita. 1998. Neotropical-Nearctic limits in Middle America as determined by distributions of bats. Journal of Mammalogy 79: 772-781.

Ortiz-Díaz, J. J. 1993. Estudio sistemático del género Gouninia (Gramineae, Chloridoideae, Eragrostideae). Acta Botánica Mexicana 23: 1-33.

Palacios-Vargas, J. G., D. A. Estrada y J. Paniagua. 2004. Collembola. In Biodiversidad de la Sierra Madre Oriental, I. Luna, J. J. Morrone y D. Espinosa-Organista (eds.). Las Prensas de Ciencias, UNAM, México, D.F., p. 271-281.

Palestrini, C. y M. Zunino. 1986. L'analisi dell'entomofauna nelle zone di transizioni: Prospective e problemi. Biogeographia 12: 11-25.

Papenfuss, T. J. y D. B. Wake. 1987. Two new species of plethodontid salamanders (genus Nototriton) from Mexico. Acta Zoológica Mexicana (nueva serie) 21: 116.

Pérez-Ponce de León, G. 2003. Biodiversity and biogeographic patterns in the Mesa Central of México: 
Insights from host-parasite systems. Journal of Parasitology (Supplement) 89: S126-S133.

Pérez-Ponce de León, G. y A. Choudhoury. 2005. Biogeography of helminth parasites of freshwater fishes in Mexico: The search for patterns and processes. Journal of Biogeography 32: 645-659.

Ramírez, J. 1899. La vegetación de México. Secretaría de Fomento, México, D. F. 271 p.

Ramírez-García, E. y V. Hernández-Ortiz. 1994. Revisión de la familia Ropalomeridae (Diptera) en México. Acta Zoológica Mexicana (nueva serie) 61: 57-85.

Ramírez-Pulido, J. y A. Castro-Campillo. 1990. Regionalización mastofaunística (mamíferos). Mapa IV .8.8.A. In Atlas Nacional de México, vol. III, Instituto de Geografía, UNAM, México, D.F.

Rapoport, E. H. 1968. Algunos problemas biogeográficos del nuevo mundo con especial referencia a la región Neotropical. In Biologie de l'Amerique Australe, 4, Delamare Debouteville y E. H. Rapoport (eds.). CNRS, Paris, p. 55-110.

Reig, O. A. 1981. Teoría del origen y desarrollo de la fauna de mamíferos de América del Sur. Museo Municipal de Ciencias Naturales Lorenzo Scaglia, Mar del Plata. 162 p.

Reyes-Castillo, P. 1970. Coleoptera, Passalidae: Morfología y división en grandes grupos; géneros americanos. Folia Entomologica Mexicana 20-22: 1-240.

Reyes-Castillo, P. 1978. Revisión monográfica del género Spurius Kaup. Studia Entomologica 20: 269-290.

Reyes-Castillo P. 2003. Las ideas biogeográficas de Gonzalo Halffter: importancia e impacto. In Una perspectiva latinoamericana de la biogeografía, J. J. Morrone y J. Llorente-Bousquets (eds.). Las Prensas de Ciencias, México, D.F., p. 99-108.

Reyes-Castillo, P. 2004. Passalidae (Insecta: Coleoptera). In Biodiversidad de la Sierra Madre Oriental, I. Luna, J. J. Morrone y D. Espinosa-Organista (eds.). Las Prensas de Ciencias, UNAM, México, D.F., p. 283-293.

Rifkind, J. 1994. New species of Mexican Enoclerus Gahan (Coleoptera: Cleridae). Coleopterists Bulletin 48: 283292.

Ringuelet, R. A. 1961. Rasgos fundamentales de la zoogeografía de la Argentina. Physis (Buenos Aires) 22: 151-170.

Rivas Martínez, S. y O. Tovar. 1983. Síntesis biogeográfica de los Andes. Collectanea Botanica (Barcelona) 14: 515 521.

Rojas-Soto, O. R., O. Alcántara-Ayala y A. G. Navarro. 2003. Regionalization of the avifauna of the Baja California peninsula, Mexico: A parsimony analysis of endemicity and distributional modeling approach. Journal of Biogeography 30: 449-461.

Ron, S. R. 2000. Biogeographic area relationships of lowland Neotropical rainforest based on raw distributions of vertebrate groups. Biological Journal of the Linnean
Society 71: 379-402.

Rosas-Valdés, R. y G. Pérez-Ponce de León. 2005. Biogeografía histórica de helmintos parásitos de ictalúridos en América del Norte: una hipótesis preliminar utilizando el método panbiogeográfico. In Regionalización biogeográfica en Iberoamérica y tópicos afines: Primeras Jornadas Biogeográficas de la Red Iberoamericana de Biogeografía y Entomología Sistemática (RIBES XII.I-CYTED), J. Llorente y J. J. Morrone (eds.). Las Prensas de Ciencias, UNAM, México, D.F., p. 217-226.

Rosen, D. E. 1976. A vicariance model of Caribbean biogeography. Systematic Zoology 24: 431-464.

Rosen, D. E. 1978. Vicariant patterns and historical explanation in biogeography. Systematic Zoology 27: 159-188.

Rosen, D. E. 1985. Geological hierarchies and biogeographic congruence in the Caribbean. Annals of the Missouri Botanical Garden 72: 636-659.

Ruggiero, A. y C. Ezcurra 2003. Regiones y transiciones biogeográficas: Complementariedad de los análisis en biogeografía histórica y ecológica. In Una perspectiva latinoamericana de la biogeografía, J. J. Morrone y J. Llorente (eds.). Las Prensas de Ciencias, UNAM, México, D.F., p. 141-154.

Ryan, R. M. 1963. The biotic provinces of Central America as included by mammalian distribution. Acta Zoológica Mexicana 6:1-55.

Rzedowski, J. 1973. Geographical relationships of the flora of Mexican dry regions. In Vegetation and vegetational history of northern Latin America, A. Graham (ed.). Elsevier, Amsterdam, p. 61-72.

Rzedowski, J. 1978. Vegetación de México. Limusa, México, D.F.

Rzedowski, J. y T. Reyna-Trujillo. 1990. Tópicos biogeográficos. Mapa IV.8.3. In Atlas Nacional de México, vol. III, Instituto de Geografía, UNAM, México, D.F.

Samek, V. 1988. Fitorregionalización del Caribe. Revista del Jardín Botánico Nacional (Cuba) 9: 25-38.

Sánchez-Osés, C. y R. Pérez-Hernández. 1998. Revisión histórica de las subdivisiones biogeográficas de la región Neotropical, con especial énfasis en Suramérica. Montalbán 31: 169-210.

Sánchez-Osés, C. y R. Pérez-Hernández. 2005. Historia y tabla de equivalencias de las propuestas de subdivisiones biogeográficasdelaregiónNeotropical.In Regionalización biogeográfica en Iberoamérica y tópicos afines: Primeras Jornadas Biogeográficas de la Red Iberoamericana de Biogeografía y Entomología Sistemática (RIBES XII.ICYTED), J. Llorente y J. J. Morrone (eds.). Las Prensas de Ciencias, UNAM, México, D.F., p. 145-169.

Sanmartín, I., H. Enghoff y F. Ronquist. 2001. Patterns of animal dispersal, vicariance and diversificaction in the 
Holarctic. Biological Journal of the Linnean Society 73: 345-390.

Savage, J. M. 1966. The origins and history of the Central America herpetofauna. Copeia 4: 719-766.

Savage, J. M. 1982. The enigma of the Central American herpetofauna: Dispersal or vicariance? Annals of the Missouri Botanical Garden 69: 464-547.

Schmidt, K. P. 1954. Faunal realm, regions and provincies. Quarterly Review of Biology 29: 322-331.

Schuh, R. T. y G. M. Stonedahl. 1986. Historical biogeography in the Indo-Pacific: A cladistic approach. Cladistics 2: 337-355.

Schuster, J. C. 1992. Biotic areas and the distribution of Passalid beetles (Coleoptera) in northern Central America: Post-pleistocene montane refuges. Tulane Studies in Zoology and Botany, supplement 1: 285-292.

Schuster, J. y P. Reyes-Castillo. 1990. Coleoptera, Passalidae: Ogypes Kaup, revisión de un género mesoamericano de montaña. Acta Zoológica Mexicana (nueva serie) 40: 149.

Sclater, P. L. 1858. On the general geographic distribution of the members of the class Aves. Journal of the Linnean Society of Zoology 2: 130-145.

Slater, A. A. y H. Brailovsky. 1994. A remarkable new bamboo Lygaeid from Mexico and a new species of Patritius from Venezuela (Hemiptera: Lygaeidae: Blissinae). Journal of the New York Entomological Society 102: 355-360.

Smith, H. M. 1941. Las provincias bióticas de México, según la distribución geográfica de las lagartijas del género Sceloporus. Anales de la Escuela Nacional de Ciencias Biológicas 2: 103-110.

Sousa, M. 1995. Especie nueva de Inga (Leguminosae: Mimosoideae) de la Sierra Madre Oriental, México. Acta Botánica Mexicana 31: 51-54.

Stonedahl, G. M. y M. D. Schwartz. 1994. Two new species of Atractotomus from southern Mexico (Heteroptera: Miridae: Phylinae). Journal of the New York Entomological Society 102: 374-390.

Stuart, L. C. 1964. Fauna of Middle America. In Handbook of Middle American Indians, vol. 1, R. C. West (ed.), p.
316-363.

Suárez-Morales, E. 2003. Historical biogeography and distribution of the freshwater calanoid copepods (Crustacea: Copepoda) of the Yucatan Peninsula, Mexico. Journal of Biogeography 30: 1851-1859.

Suárez-Morales, E., J. W. Reid, F. Fiers y T. M. Iliffe. 2004. Historical biogeography and distribution of the freshwater cyclopine copepods (Copepoda, Cyclopoida, Cyclopinae) of the Yucatan Peninsula, Mexico. Journal of Biogeography 31: 1051-1063.

Sullivan, J., J. A. Markert y C. W. Kilpatrick. 1997. Phylogeography and molecular systematics of the Peromyscus aztecus species group (Rodentia: Muridae) inferred using parsimony and likelihood. Systematic Biology 46: 426-440.

Villaseñor, J. L. 1990. The genera of Asteraceae endemic to Mexico and adjacent areas. Aliso 12: 685-692.

Wagner, W. H. y A. R. Smith. 1993. Pteridophytes. In Flora of North America. North of Mexico, vol 1, N. R. Morin (ed.). Oxford University Press, Oxford, p. 247-266.

Wibmer, G. J. 1989. Revision of the weevil genus Tyloderma Say (Col.: Curculionidae) in Mexico, Central America, South America, and the West Indies. Evolutionary Monographs 11: 3-118.

Wallace, A. R. 1876. The geographical distribution of animals. 2 vol. McMillan. Londres. 1110 p.

Zamudio-Ruiz, S. y E. Sánchez-Martínez. 1995. Una nueva especie de Agave del subgénero Littaea (Agavaceae) de la Sierra Madre Oriental, México. Acta Botanica Mexicana 32: 47-52.

Zaragoza Caballero, S. 1995. Descripción de ocho especies nuevas de Photinus (Coleoptera: Lampyridae, Photinini) de México. Acta Zoológica Mexicana (nueva serie) 66: $1-21$.

Zink, R. M. 2002. Methods in comparative phylogeography, and their application to studying evolution in the North American aridlands. Integrative and Comparative Biology 42: 953-959.

Zink, R. M., R. C. Blackwll-Rago y F. Ronquist. 2000. The shifting roles of dispersal and vicariance in biogeography. Proceedings of the Royal Society of London B 267: 497-503. 